\title{
Development of a soccer specific functional rehabilitation program using the Modified Delphi Technique
}

Sarah R. Leslie

West Virginia University

Follow this and additional works at: https://researchrepository.wvu.edu/etd

\section{Recommended Citation}

Leslie, Sarah R., "Development of a soccer specific functional rehabilitation program using the Modified Delphi Technique" (2009). Graduate Theses, Dissertations, and Problem Reports. 2766.

https://researchrepository.wvu.edu/etd/2766

This Thesis is protected by copyright and/or related rights. It has been brought to you by the The Research Repository @ WVU with permission from the rights-holder(s). You are free to use this Thesis in any way that is permitted by the copyright and related rights legislation that applies to your use. For other uses you must obtain permission from the rights-holder(s) directly, unless additional rights are indicated by a Creative Commons license in the record and/ or on the work itself. This Thesis has been accepted for inclusion in WVU Graduate Theses, Dissertations, and Problem Reports collection by an authorized administrator of The Research Repository @ WVU. For more information, please contact researchrepository@mail.wvu.edu. 
Development of a Soccer Specific Functional Rehabilitation Program Using the Modified Delphi Technique

\author{
Sarah R Leslie, ATC
}
Thesis submitted to the College of Physical Activity and Sports Science at West Virginia University in partial fulfillment of the requirements for the degree of

\author{
Master of Science \\ in \\ Athletic Training \\ Michelle A. Sandrey, Ph.D., ATC, Chair \\ J. Nathan Wilder, MS, ATC, CSCS \\ Sean Bulger, Ed.D \\ College of Physical Activity and Sport Sciences \\ Morgantown, West Virginia \\ 2009
}

Keywords: Lower Quarter, Core, Functional Rehabilitation, Soccer

Copyright 2009 Sarah R Leslie 


\begin{abstract}
Development of a Soccer Specific Functional Rehabilitation Program: Using the Modified Delphi Technique
\end{abstract}

Sarah R Leslie, ATC

Context: There are no concise and thorough core and lower quarter exercises for functional rehabilitation found in the literature or the clinical setting for soccer. An exercise program is needed to assist clinicians in developing sport specific functional rehabilitation programs. Objective: The purpose of this study was to develop a concise soccer specific functional rehabilitation program. Design: This was a prospective descriptive study following the Modified Delphi Technique to develop exercise components to include in a functional rehabilitation program based on opinion from a panel of experts. The dependent variable was the responses ranging from strongly agree to strongly disagree. Setting: This study took place at West Virginia University. Patients or Other Participants: Participants consisted of Certified Athletic Trainers ( $n=9$ round one, $n=6$ round two) and Physical Therapists ( $n=7$ round one, $n=5$ round two) with a minimum of five years clinical experience and criteria for selection of the researchers were based on publications and presentations on soccer. Eighteen clinical Certified Athletic Trainers, Physical Therapists and researchers participated in the first round. Eleven participants completed the second round. Interventions: Exercises to be included in a functional rehabilitation program was through a series of successive revisions with input being offered from colleagues. Three questionnaires were utilized in this study. The demographic questionnaire was e-mailed to the participants with the first round questionnaire. The panel was asked to fill out questions about credentials and experience and asked to respond to the exercise components on the Likert scale from strongly agree to strongly disagree. The participants submitted the questionnaire online. A link to the second questionnaire with means score, percentages and additional write in comments from round one was sent to the participants. Follow-up letters for the first and second rounds were e-mailed to the participants one week before the due dates as reminders to complete the questionnaire. The responses from the second questionnaire contributed to the development of the functional rehabilitation program. Main Outcomes Measures: With a consensus of the participants (75\% strongly agree and agree and a mean score of 4 ) the responses for each exercise section would be similar. The hypotheses included: dynamic flexibility, single leg balance, lunge sequencing, heel raise sequencing, squat sequencing, plyometrics, core stabilization and functional activity progression. Results: The initial questionnaire consisted of 168 exercise components. After the second round, 81 of the proposed exercise components reached consensus and therefore were used to develop the final program. The final program consisted of what should be included in a soccer specific functional rehabilitation program based on best clinical practice and evidence based guidelines. Conclusion: The responses from both rounds by the panel of experts led to the development of the soccer specific functional rehabilitation program. Although there was a dropout of seven participants, this program is still representative of Major League Soccer ATCs, PTs, and soccer researchers. Since the remaining exercise components are supported by evidence based research and best clinical practice, this program can serve as a guideline for a soccer specific functional rehabilitation program. Additional studies should be conducted for the development of a functional rehabilitation program. 


\section{ACKNOWLEDGEMENTS}

First and foremost this is for my parents. Without your love, patience, and support I would have never been able to have the experiences that made me the person I am today. Mom, thank you for giving me the motivation and strength to reach for the stars. Dad, thank you for never letting me give up and all the Rocky chants.

Rick and Kelly, thank you for your love, support and guidance. Also, thank you for your competitive nature and pushing me further than I thought possible.

Dr. Sandrey, thank you for allowing me to be part of the Graduate Athletic Training Program at WVU and gain clinical experience at WU.

Dr. Bulger, thank you for your willingness to participate this research. I appreciate all your time, guidance and expert opinions.

Nathan, thank you for sharing your professional and personal wisdom. I greatly appreciate the support, insight, and inspiration you have given. I could never thank you enough for the experience you have provided me with at Waynesburg University.

To my friends and classmates, thank you for being there making me laugh when needed the most and teaching me how to take things a little less serious. I wish you all the best life has to offer.

To Kevin Kotsko, Jason Mathews, and Anthony Pass, thank you for taking the time to help me develop this program. I would have been unable to do this without your expert opinion.

To Dr. Clement, thank your support and for being so willing to provide guidance throughout this process. 


\section{TABLE OF CONTENTS}

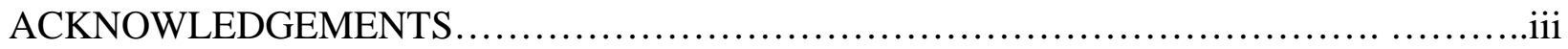

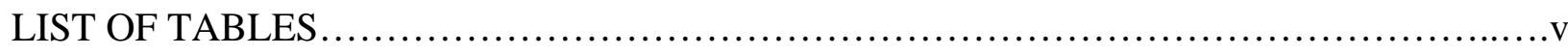

LIST OF FIGURE....................................................................

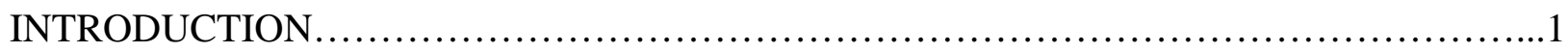

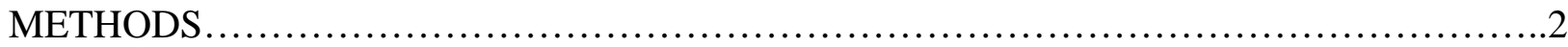

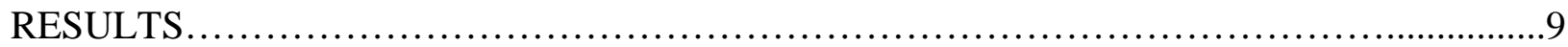

DISCUSSION ................................................................. 15

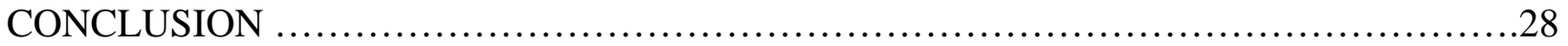

REFERENCES................................................................ 29

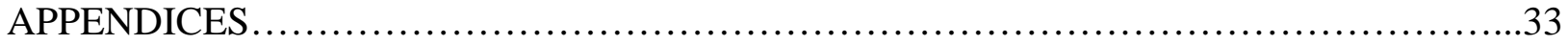

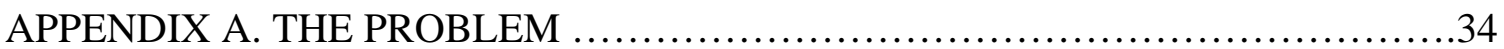

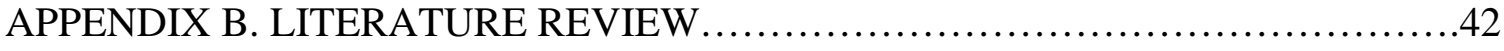

APPENDIX C. ADDITIONAL METHODS .....................................78

APPENDIX D. ADDITIONAL RESULTS ...................................123

APPENDIX E. RECOMMENDATIONS FOR FUTURE RESEARCH ...............141

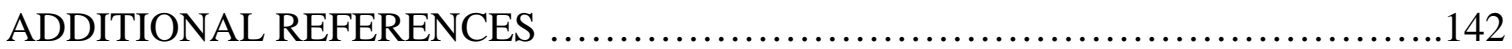




\section{LIST OF TABLES}

B1. Muscles Acting on the Hip \& Femur..........................................47

B2. Muscles of the "Core" ........................................................ 48

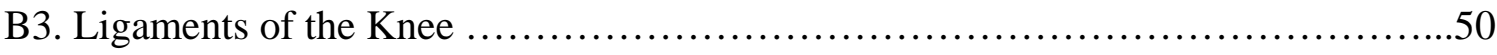

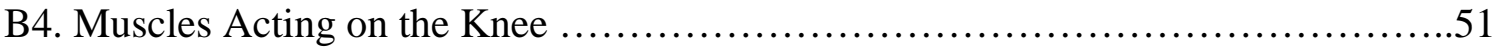

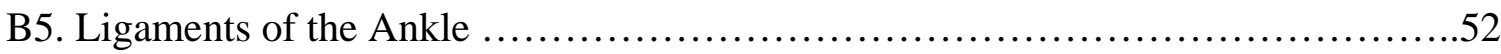

B6. Muscles Acting on the Ankle.................................................... 53

B7. Range of Motion of the Lower Extremity........................................55

B8. Summary of Joint Motions during the Stance Phase of Gait.......................58

B9. Summary of Joint Motions during the Swing Phase of Gait........................60

C1. Initial E-mail of Interest to Gauge Participation.................................78

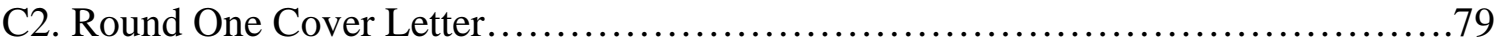

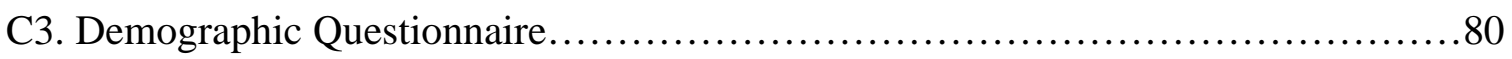

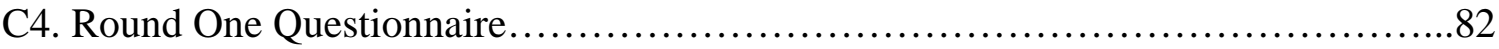

C5. Round One Follow-up Letter .................................................99

C6. Round Two Cover Letter.....................................................100

C7. Round Two Questionnaire................................................. 101

C8. Round Two Follow-up Letter..............................................121

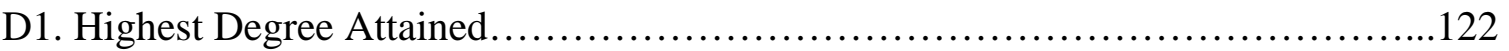

D2. Professional Credentials Held..............................................122

D3. Length of Time Participating in Primary Profession..............................122

D4. Length of Time Participating as an ATC or PT in Soccer.........................122 
D5. Practice Setting More Than 50\% of the Time

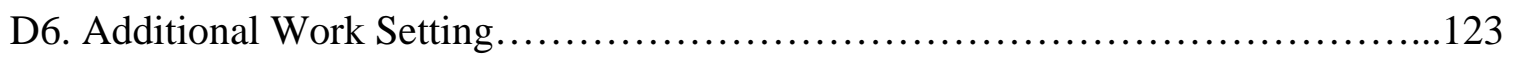

D7. Number of Presentations at Professional Meetings.............................123

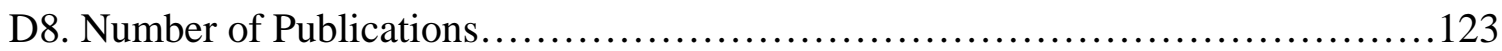

D9. Percentage Distribution and Mean Scores for First and Second Round - Dynamic

Flexibility.............................................................. 124

D10. Percentage Distribution and Mean Scores for First and Second Round - Single Leg

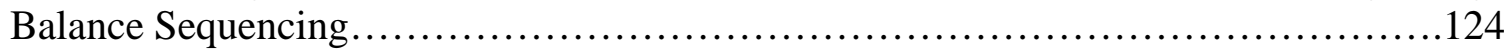

D11. Percentage Distribution and Mean Scores for First and Second Round - Squat

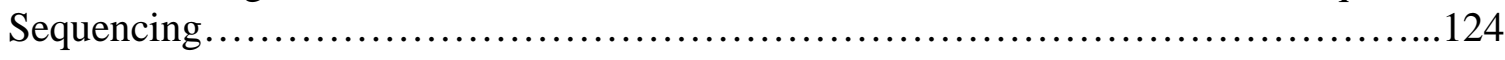

D12. Percentage Distribution and Mean Scores for First and Second Round - Heel Raise

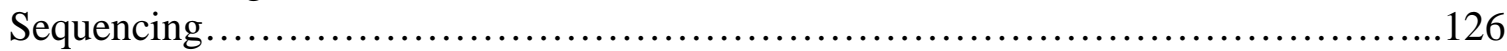

D13. Percentage Distribution and Mean Scores for First and Second Round - Lunge

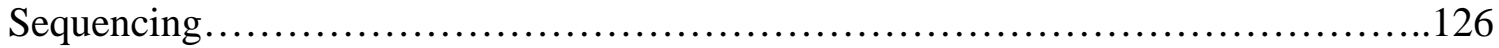

D14. Percentage Distribution and Mean Scores for First and Second Round - Core Stabilization.............................................................127

D15. Percentage Distribution and Mean Scores for First and Second Round -

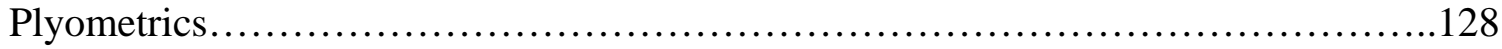

D16. Percentage Distribution and Mean Scores for First and Second Round - Functional Activity Progression......................................................129 


\section{LIST OF FIGURES}

D1. Participants.........................................................132

D3. Example Use of the Soccer Specific Functional Rehabilitation Program...........133

D4. Soccer Specific Functional Rehabilitation Program.............................137 


\section{INTRODUCTION}

Due to the nature of the sport, soccer athletes are at greater risk for injury to the lower extremity. The lower extremity, defined here, is the combination of joints, muscles, and ligaments within the lumbopelvic-hip complex distally to the ankle joint. The incidence of soccer-related injuries is estimated to be between 10 to 35 per 1000 playing hours in the adult male professional athlete. $^{1,2}$ The lower extremity is the most commonly injured, at a rate of $76-87 \%$ in professional soccer athletes based on the intense forces incurred during sport specific actions. ${ }^{1-5}$ Most common injuries include, but are not limited to hip and thigh strains, knee sprains, and lateral ankle sprains. An increased incidence of lower extremity injuries is related to intensity of training, running mechanics, player-to-player contact and poor conditioning., ${ }^{2,6-12 .}$

When injured soccer athletes begin a rehabilitation program to return to activity, most of the components included in this program apply to any rehabilitation. However, soccer is a unique sport and therefore sport specific exercises are necessary. Functional rehabilitation is an extension of the traditional elements of therapy. ${ }^{1}$ The purpose of functional rehabilitation is to return the athlete to highly complex movement patterns present within their specific sport. ${ }^{1,13}$ Functional rehabilitation consists of multifaceted techniques designed to replicate the nature of the game and prep the athlete to endure the stresses and forces they will endure following return to activity. ${ }^{1,13}$ Functional rehabilitation must include acceleration, deceleration, and proprioceptive activity in a multi-planar fashion. ${ }^{13}$ The functional rehabilitation program is designed to progress the athlete from simple activities, such as walking or jogging, to highly complex sport-specific activities that require refined levels of proprioceptive acuity. ${ }^{1,13,14}$ The exercises within such a program should emphasize dynamic flexibility, sensorimotor facilitation, strength, power, core stabilization, and 
functional activity progression (kicking, running, anaerobic and aerobic conditioning, as well as agility). ${ }^{1,13-19}$

Research on soccer epidemiology and etiology is plentiful, although very little has been found in the literature or in best clinical practice for soccer specific functional rehabilitation. When little or no information is available, clinicians and researchers that are considered experts should be used to develop programs, hence the use of the modified Delphi Technique is imperative. ${ }^{20-24}$ This in turn will incorporate evidence based guidelines and best clinical practice based on consensus of selection of components included in a functional rehabilitation program. Considering lack of evidence based research and the complexity of lower extremity injuries in regard to soccer, an evidence based and best clinical practice functional rehabilitation program should be developed. Therefore, the purpose of this study was to use a selected panel of Major League Soccer Certified Athletic Trainers and Physical Therapists and soccer researchers to gain expert opinion on what should be included in a soccer specific functional rehabilitation program. It was hypothesized that this panel of experts would have similar focus in regard to soccer and sport functional rehabilitation.

\section{METHODS}

The design of this study was a prospective descriptive study and was based on the modified Delphi technique. A soccer specific functional rehabilitation program was created by gathering information from researchers and clinicians who have experience with soccer and functional rehabilitation of soccer athletes. 


\section{Participants}

Thirty Certified Athletic Trainers and Physical Therapists affiliated with Major League Soccer (MLS) were the intended participant field of this study. Thirty researchers that were considered experts in soccer research were contacted to gauge their interest in participating in this study. Eighteen of the intended participants agreed to participate in this study: 11 ATCs/PTs and seven researchers. Two of the clinicians did not meet inclusion criteria leaving nine ATCs/PTs and seven researchers. The participants are further outlined in Figure D1. The experts were included based on their knowledge and expertise in functional rehabilitation of soccer players. The research participants were included based on studies published in the literature (five) or by the number of soccer presentations (five) given at professional meetings, such as, American College of Sports Medicine, National Athletic Trainers Association, or American Physical Therapy Association. Inclusion criteria for the MLS ATCs and PTs clinicians were five years of experience in their primary profession. Research participants were excluded with less than five presentations or publications. Clinicians were excluded if they had less than five years of clinical experience with soccer. The perspective participants were initially contacted by e-mail and informed of the purpose of the study and design. Those experts responding to the e-mail were the participants in the study. Only the responses from those participants completing both rounds was used determine to the functional rehabilitation program. The Office of Research Compliance at West Virginia University approved this study.

Instruments

A total of three questionnaires were utilized in this study. A demographic information questionnaire was included to gather information about each of the participants. The first questionnaire was provided to the participants, along with the demographic questionnaire, and 
involved possible components and exercises for a functional rehabilitation program for soccer players. This first round questionnaire also included photographs for select exercise components. The demographic questionnaire consisted of questions about type of professional certification and the type of work setting the participant spent $50 \%$ of the time.

The functional rehabilitation questionnaire was divided into eight sections. These sections are as follows: Dynamic Flexibility, Single Leg Balance Sequencing, Squat Sequencing, Heel Raise Sequencing, Lunge Sequencing, Core Stabilization, Plyometric Exercises, and Functional Activity Progression. The dynamic flexibility section included exercises components to be performed prior to the functional rehabilitation program for lower quarter joint range of motion. The single leg balance, squat, heel raise, and lunge sequencing sections included exercise components that are progressive in order of difficulty. Each of the specific components under the specified section are performed as a combination of sensorimotor facilitation, strength and core stabilization exercises. The core stabilization exercise components were not listed as progressive in order. These components were to be performed as a combination of sensorimotor facilitation, strength and core stabilization exercises. The plyometric exercise components were not listed as progressive in order, and performed as strength, power training and core stabilization. The functional activity progression exercise components were not considered to be progressive in order collectively, but rather individually. These exercise components included a kicking progression, anaerobic and aerobic progression, and agility progression. The participants were asked to rate 164 questions included in the seven sections of the questionnaire on a 5-point Likert scale. According to the Likert Scale, $1=$ strongly disagree, $2=$ disagree, $3=$ neutral, $4=$ agree, and $5=$ strongly agree . This scale is based on the importance of these components for a functional rehabilitation program for soccer athletes. 
The functional rehabilitation questionnaire consisted of a first round in which the participants were asked to provide feedback and additional comments as applicable. For the second round the same questionnaire, minus photographs, was submitted with mean and percentages of responses from the first round and additional write in comments. Again, the participants were asked to rate each component on the 5-point Likert scale and write in any responses that they deem necessary. Second round components were eliminated if they had not met consensus. The exercise components that reached consensus were then used to design the final functional rehabilitation program.

Content and face validity of the questionnaires was obtained through distribution and feedback from three Certified Athletic Trainers with experience in designing functional rehabilitation programs. Before the final questionnaire was determined, the Certified Athletic Trainers read the questionnaires and evaluated for readability and clarity. Delphi Technique

The Delphi technique is a systematic procedure of sequential rounds of questionnaires interspersed by controlled feedback that seek to gain the most reliable consensus of opinion of a group of experts. ${ }^{21-24}$ The use of the technique is well recognized in health care as a tool for solving problems. The method was developed as response to traditional committees employed to obtain a specific group's opinions or judgments for policy development. The Delphi Technique was first developed in the 1950s by the Rand Corporation to eliminate interpersonal interactions as the controlling variable in decision-making. ${ }^{20,21}$ Benefits of the Delphi Technique provide a more accurate assessment or judgments than those obtained either by individual or by interacting groups and avoid domination by powerful individuals to eliminate the biasing effects of personality traits and seniority found within committees. The technique is named after the Greek god Apollo 
Phythios, a master of Delphi and renowned for his ability to predict the future. Greek god Apollo Phythios, was a master of Delphi and renowned for his ability to predict the future.

Typically in the Delphi Technique a research question is developed and experts in the field are identified. Experts are chosen based on their knowledge, experience, and presentations/publications in the area of focus. The Delphi method can be used to develop consensus among a group of experts without engaging them in direct discussions. By maintaining anonymity and mailing questionnaires to be completed privately by selected participants, psychological influences are eliminated. ${ }^{22}$ Anonymity afforded by this method is thought to increase the likelihood that participants will express novel ideas, whereas the lack of direct interaction increases the accuracy of final judgments. ${ }^{20-24}$ With each successive round the responses are evaluated and experts are able to adjust their initial responses after reviewing the first round responses of the group, responses are again evaluated, and a final consensus is reached.

The first round consists of unstructured questions and seeks an open response. This allows the participants relatively free scope to elaborate on the topic under investigation. A qualitative analysis of the results is then undertaken and this provides the basis on which to construct the subsequent questionnaires. Second round questions are more specific seeking quantification of earlier findings. The round two questionnaires contain responses from the first round for all participants to see. After the second round is returned, those items that met consensus constitute the final product.

This study used a modified version of the Delphi technique to gather opinions of Certified Athletic Trainers, Physical Therapists, and research experts to obtain a better understanding of functional rehabilitation for the soccer athlete. The use of a questionnaire allowed for anonymity and eliminated outside influences such as peer pressure and group persuasion and bias. There are 
both advantages and limitations to the Modified Delphi technique. The advantages allow the researcher to collect the information using a panel of experts. Information collection follows a systematic fashion as it allows researchers to gain input, establish priorities, and build consensus through the use of expert opinion. The modified Delphi Technique allows researchers to quantify subjective or qualitative data for analysis. This technique allows for anonymity because of mailing questionnaires to be filled out privately by selected participants, psychological influences created by group discussion, such as persuasion, bias, geological barriers, and the bandwagon effect of group opinion are eliminated.

Limitations to the Modified Delphi technique include a poor effect in making routine decisions, the selection process of experts, time required for return of questionnaires, time delays between rounds, and drop-out rates with increasing rounds and analysis of open-ended questions. ${ }^{21-24}$ The panel of experts must have expertise in the area of study. There are dropout rates due to two rounds of questionnaires. A time gap between mailing the questionnaires and between the two rounds may be prolonged. Survey creating can be difficult and considered a limitation. In an attempt to offset these limitations it is imperative that participants directly involved in developing the tool agree to participate in both rounds. To decrease time delays, dropout rates and analysis of questions, the participants are given a set time to complete and return the questionnaires in each round and all responses are placed on a Likert scale. A follow-up letter can be sent one week before the due date of each round to encourage participation and allow for the time delay between each round to be only two weeks.

The greatest threat to external validity is that not enough participants will respond to make the results representative of the entire population. It has been suggested that a group of 12-30 experts for a homogenous population or 5-10 for a heterogeneous population is sufficient for 
accurate results. ${ }^{24}$ The limitation of the panel of experts can be removed since the selection of experts guarantees that the participants have expertise in the area of soccer athletes and functional rehabilitation. Internal threats to validity are receiving input from others on the first questionnaire, or the participants learn how to interpret the questions on the first questionnaire, which could affect their responses on the second questionnaire. External threats to validity include participants not being generalized toward a specific population. The way the participants are selected to take part in this study relates to a sample of convenience based on expert opinion. If the participants take the second questionnaire in a different setting than when they took the first one, it could change their responses or distract them from answering to the best of their ability. Procedures

The Office of Research Compliance approved this study. Once it was approved, an initial e-mail (Table C1) was sent to the participant field. This e-mail explained the research and the final intent of developing a functional rehabilitation program. Those in the selected field who agreed to participate were then sent, by e-mail, a cover letter (Table C2) was also included to explain the methodology of the study and to explain that there was complete confidentiality and anonymity. Along with the cover letter, the participants were spent a link to the online round one questionnaire and demographic questionnaire (Table C3, Table C4). A follow-up letter (Table C5) was then sent to the participants approximately one week before the due date as a reminder to submit the questionnaire. For the second round questionnaire percentages and mean scores from the first round were placed under the components for the participants to view. All additional comments provided during the first round were also included. This allowed participants to see the entire group's responses. One week following the completion of round one, the participants were then emailed the link to the second questionnaire with a cover letter (Table C6, Table C7). The 
participants were to rate the components based on their opinions as to what constitutes a soccer specific functional rehabilitation program. A follow-up e-mail (Table C8) was sent to all of the participants one week before the due date of the second questionnaire as a reminder. The responses from the second questionnaire that reached consensus as defined by $75 \%$ and a mean score of 4 were used to develop the program to be used for the soccer specific functional rehabilitation program.

Statistical Analysis

The statistical analysis of this study included frequencies of responses from the two questionnaires, as well as the demographic questionnaire. The rating and feedback that the participants selected for each exercise of the functional rehabilitation program plus additional write-in comments were compiled for both rounds. The consensus for this study is defined by a $75 \%$ group response of strongly agree or agree ( $5=$ strongly agree, $3=$ no opinion, $1=$ strongly disagree) and a mean score of 4 on the Likert scale for each component. All those components meeting consensus and a mean score of 4 from the second round was used to write the functional rehabilitation program for soccer players.

\section{RESULTS}

Demographic Information

A link to the demographic questionnaire was e-mailed to the respondents along with the Round One Questionnaire. Of the eighteen demographic information surveys and questionnaires that were sent, all eighteen were returned for a $100 \%$ return rate for the first round. These surveys provided information about the credentials of the panel. Two of the Certified Athletic Trainers had only 1-4 years of experience, and their information was not included in the analysis as they did not 
meet inclusion criteria. A total of 16 responses were used for the first round results. Nine of the sixteen panelists (64.3\%) were Certified Athletic Trainers (ATCs). Four (28.6\%) participants were Physical Therapists (PTs); two (14.3\%) have Performance Enhancement Specialist credentials; and six respondents (42.9\%) have Certified Strength and Conditioning Specialist credentials. Nine respondents (56.3\%) of the panel were certified athletic trainers, physical therapists or researchers, who have been practicing for over ten years. The panel of experts that participated in this study work in the academic setting $(n=5,31.3 \%$, ) athletic training room $(n=7,43.8 \%)$, and the sports medicine/outpatient clinic ( $\mathrm{n}=4,25.0 \%)$ for more than $50 \%$ of their job. The panel of experts also with varied level of education. The degrees ranged from a Bachelor of Science to Medical Doctor/ Doctor of Orthopedics. Eight of the participants (50\%) have attained a Masters degree, one (6.3\%) a Bachelors degree, six (37.5\%) a Ph.D/ Ed.D/ or other doctorate, and one (12.5\%) was a MD/DO. The research participants have a number of presentations and publications on soccer related rehabilitation. The number of publications was nine (56.3\%) for $5+$ presentations and ten (62.5\%) for 5+ studies in the literature. Refer to Table D1-D8 for additional results. The Soccer Specific Functional Rehabilitation Program

In order for each of the exercise components to remain in the rehabilitation program, a 75\% consensus of strongly agree and agree with a mean score of 4 was required. All of the exercise components from the first round remained on the second round questionnaire for the participants' review of scores. Refer to Table D9-D16 for complete results.

Dynamic Flexibility: In round one, only one of the ten components recorded a mean score of 4 and frequency of $75 \%$. The forward leg swing exercise was rated a 4.08 with $75 \%$ frequency. During round two, five of the 10 items reached consensus. The average scores ranged from 4.004.36 with 77\%- 90\% frequencies. Participants were also allowed to rate the additional comments 
from round one. None of the additional comments averaged a mean score of 4 . The exercise components which remained were walking lunge with torso rotation, walking side lunge, walking hurdler, forward leg swings, and lateral leg swings. Refer to Table D9 for additional information. Single Leg Balance: For round one, three of the 14 items recorded a mean score of 4 . Of these three items, scores ranged from $81 \%$ to $90 \%$ and mean scores ranged from 4.27 to 4.36 . During round two, three of the 14 items met the criteria for consensus. Of the three items that remained, consensus scores ranged from $77.5 \%$ to $87.5 \%$ and mean scores ranged from 4.00 to 4.25. Three of the four additional comments reached consensus, each of the comments made suggestions to the order of progression which however, is not the specific purpose of this study. The exercise components which remained were single leg balance with ball kick on unstable surface and single leg balance with header. The other item that reached consensus was progression with mastery of stable surface. Refer to Table D10 for additional results.

Squat Sequencing: For round one, nine of the 19 items recorded a mean score of 4 and $75 \%$ frequency. Of the nine items, frequency ranged from $77 \%$ to $100 \%$ and mean scores ranged from 4.00 to 4.50 . During round two, 10 of the 19 items met the criteria for consensus. Of the 10 items that remained, consensus scores ranged from $85.7 \%$ to $100 \%$ and mean scores ranged from 4.00 to 4.50. The four additional comments did not reach consensus. The exercises which remained were squat with soccer ball throw-in, squat with medicine ball throw-in, single leg squat with throw-in, single leg squat with medicine ball throw-in, squat on unstable surface with medicine ball throwin, squat to forward lunge, and squat to lateral lunge. The three additional items were progression with mastery of current exercise, progression with mastery of stable surface, and progression with mastery of unstable surface. Refer to Table D11 for additional results. 
Heel Raise Sequencing: For round one, two of the seven items recorded a mean score of 4 and frequency of $75 \%$. Of the two items, frequency ranged from $77 \%$ to $100 \%$ and mean scores ranged from 4.00 to 4.44. During round two, four of the seven items met the criteria for consensus. Of the four items that remained, frequency scores ranged from $87.5 \%$ to $100 \%$ and mean scores ranged from 4.00 to 4.33 . The two additional comments did not reach consensus. The exercise components that remained were heel raise with medicine ball throw-in and single leg heel raise with medicine ball throw in. The two additional items were progression with mastery of current exercise and progression with mastery of stable surface. Refer to Table D12 for additional results.

Lunge Sequencing: For round one, three of the 12 items met a mean score of 4 and frequency of $75 \%$. Of these four items, frequency ranged from $77 \%$ to $90 \%$ and mean scores ranged from 4.00 to 4.40. During round two, 10 of the 12 items met the criteria for consensus. Of the 10 items that remained, frequency ranged from $75 \%$ to $100 \%$ and mean scores ranged from 4.00 to 4.29 . The two additional comments did not reach consensus. The exercise components that remained were forward lunge with medicine ball throw-in, forward lunge onto unstable surface with medicine ball throw-in, lateral lunge with medicine ball throw-in, lateral lunge onto unstable surface with medicine ball throw-in, forward lunge onto Swissball, forward lunge onto Swissball with medicine ball toss, and lateral lunge on Swissball. The additional items were progression with mastery of current exercise, progression with mastery of stable surface and progression with mastery of unstable surface. Refer to Table D13 for additional results.

Core Stabilization: For round one, 13 of the 29 items recorded a mean score of 4 and frequency of $75 \%$. Of these 13 items, frequency ranged from $77 \%$ to $100 \%$ and mean scores ranged from 4.00 to 4.67. During round two, 13 of the 29 items met the criteria for consensus. Of the 13 items that remained, frequency ranged from $75 \%$ to $100 \%$ and mean scores ranged from 
4.00 to 4.29 . Each of the two additional responses reached consensus with average rating of 4.14 and 4.17 and $100 \%$ and $85.7 \%$ frequency respectively. The first comment was in regards to the theory of a neutral pelvis, while the second response was a recommendation for progression. The exercise components included were diagonal chops with medicine ball, side-plank, side-plank on Swissball, plank with forearms on Swissball, single leg plank with forearms on Swissball, single leg weighted ankle plank with forearms on Swissball, plank roll outs on Swissball, plank with feet on Swissball, plank with feet on Swissball with abdominal rolls, plank-pike-pushups on Swissball, Russian twist with medicine ball, crunch on Swissball with medicine ball toss, and Russian hamstrings. The additional items were progression with mastery of current exercise and progression with mastery of neutral spine. Refer to Table D14 for additional results.

Plyometric Exercises: For this portion of the program, nine of the 29 items recorded a mean score of 4 and frequency of $75 \%$. Of these nine items, frequency ranged from $80 \%$ to $100 \%$ and mean scores ranged from 4.10 to 4.75 . During round two, 10 of the 29 items met the criteria for consensus. Of the 10 items that remained, frequency ranged from $85.7 \%$ to $100 \%$ and mean scores ranged from 4.00 to 4.29. There were two additional comments, neither of which reached consensus. The exercise components included were depth box jumps with header, squat jump to header, lunge jump to header, pullover with sit up, lateral hops over cone, forward/backward hops over cone, single leg hops over cone, vertical jumps with header, scissor jumps, and resisted slide board and catch. Refer to Table D15 for additional results.

Functional Activity Progression: For round one, 32 of the 48 items recorded a mean score of 4 and frequency of $75 \%$. Of these 32 items, frequency ranged from $75 \%$ to $100 \%$ and mean scores ranged from 4.00 to 4.67 . During round two, 30 of the 48 items met the criteria for consensus. Of the 30 items that remained, frequency ranged from $85.7 \%$ to $100 \%$ and mean scores 
ranged from 4.00 to 4.50 . The exercise components included were dry kick with weight shift, dry kick with resistance, kick stationary ball for short distance, kick stationary ball for long distance, kick moving ball short distance, kick moving ball long distance, knee traps to kicks, dry kick with plant onto unstable surface, stationary ball kick with plant onto unstable surface and progression with mastery of current exercise. Fartleks, 50/50 interval training, treadmill for 15-30 minutes at 70\% maximum heart rate, figure eight runs, zigzag runs, two legged dot hop, ladder line run, ladder line sprint and backpedal, ladder line shuffles, Pro-Agility runs, carioca run, zigzag runs with dribbling, and up and back dot run with dribbling were also included. Refer to Table D16 for additional results.

Variance between Rounds

The results from both rounds on the soccer specific functional rehabilitation program questionnaires were comparable for the majority of the responses. The results were affected not only by the participants change in response but also due to participant attrition. For the first round a panel of eighteen returned the questionnaire, but of those 18, two were eliminated from the study leaving a group of 16 . Five participants dropped out of the study for the second round leaving only a final panel of eleven. Based on the Delphi Technique, an increase in means and percentages would be evident for the second round because the participants were shown the results from the first round when they received the second round questionnaire. Intent to build consensus was then created because the participants could change their responses based on the opinion of the other participants. For the majority of the components there was a slight increase in percentages as the number of participants changed from sixteen to eleven. 


\section{DISCUSSION}

The purpose of this study was to develop a soccer specific functional rehabilitation program using a select panel of Major League Soccer Certified Athletic Trainers and Physical Therapists along with researchers to generate consensus on the exercise components. The intent is to use these exercises in conjunction with traditional rehabilitation to ready the athlete for the demands of sport prior to return to soccer. This functional rehabilitation exercise program may be generalizable to all lower quarter injuries by focusing on the multi-planar movement of soccer and the prevention of re-injury. Ultimately, the goal was to use this information to determine components to be included within a soccer specific functional rehabilitation program. A panel of experts was selected to complete two rounds of questionnaires. They shared valuable knowledge that led to the development of this functional rehabilitation program. The panel selected included ATCs, PTs, and researchers who are considered to be experts in the rehabilitation of soccer athletes. This is consistent with the original hypothesized group. A review of the literature was performed first to gather the information that would be included in the proposed exercises. This evidence based information along with best clinical practice from clinical ATCs was compiled into a questionnaire for the panel of experts, which they provided feedback on. The modified Delphi Technique allowed the panel of experts to record their opinions on exercise components that were divided into eight sections of functional rehabilitation: Dynamic Flexibility, Single Leg Balance, Squat Sequencing, Heel Raise Sequencing, Lunge Sequencing, Core Stabilization, Plyometrics, and Functional Activity Progression. The exercises that reached consensus were used to create the program. Exercise components were outlined under their specific exercise group and listed on rehabilitation sheet with boxes for days, repetitions, sets, and weight for clinical use. Each individual exercise was identified with a number 1-5 to represent a suggested level of progression. 
This will provide a clinician with a simple visual of exercises that would be appropriate to group together.

It was hypothesized that responses from the participants for each exercise component would meet consensus (75\% and a mean score of 4.) Hypotheses were formulated based on reaching consensus of $75 \%$ and a mean score of four. Although all hypotheses were rejected, 75 exercise components and 12 progression items reached consensus and were used to design to soccer specific functional rehabilitation program from 164 purposed items in the original questionnaire. The exercises that reached consensus were than compared to the literature.

On a whole these results provide strong components to a soccer specific functional rehabilitation program. It contains multiple sources from both evidence based research and clinical practice. A large number of items were eliminated, however the items which remained were considered adequate for a thorough, yet concise functional rehabilitation program. This program is practical and pertinent to the sport of soccer. It can be used in the clinical setting for ATCs and PTs at any level. Professionals could follow the program or use what they deem important during the functional rehabilitation program design.

The Participant Population

The development of this soccer specific functional rehabilitation program is based on the opinion of eleven participants who were considered experts in the field. Eighteen participants were included in the first round and of the 16 eligible participants, 11 participated in the second round. Although eleven participants represent a small sample, the credential and professional achievements of these eleven professionals represent the upper tier of soccer rehabilitation expertise in the country. Nine of the sixteen panelists (64.3\%) hold the Certified Athletic Trainer (ATC) credential. Four (28.6\%) participants hold the Physical Therapist (PT) credential; two 
(14.3\%) hold the Performance Enhancement Specialist credential; and six respondents (42.9\%) hold the Certified Strength and Conditioning Specialist credential. Nine respondents (56.3\%) of the panel were certified athletic trainers, physical therapists or researchers, who have been practicing for over ten years.

Meeting Consensus

There were a total of 164 items included in the first round questionnaire. These components were brought together from best clinical practice and evidence based research. There were no components added to the second round, only additional comments from round one. There were 96 items that did not attain a mean score of 4 and $75 \%$ in round one, although these items were included in the second round to view. However, consensus on the second round determined the program. After the percentages were reported for round two, 77 exercise components did not meet consensus and mean score requirements and were eliminated from the rehabilitation program leaving 87 items that reached consensus. Change in response between rounds may have occurred when the participants were able to view the responses from round one. The 87 items reaching consensus included 75 exercises and 12 progression techniques. Nonetheless, these 75 items represent the exercise components to be included within a soccer specific functional rehabilitation program. The six progression technique components were not specifically included within the final program despite being used to determine the level of progression number. Thus, the remaining items were used to design the final rehabilitation program.

Practicality of this soccer specific functional rehabilitation program is the next limitation. The initial functional rehabilitation program started with 164 items. The final rehabilitation program contained a total of 75 items. Certified Athletic Trainers and Physical Therapists should be able to understand and direct an athlete to perform each of the components. Although most of 
the items were general descriptions of common exercises, variance between clinicians understanding of exercise may exist. Some items were used to describe unstable surface, where the specific unstable surface is left to the decision of the clinician. Select components of the initial program were provided with a photograph to describe the specific exercise to avoid any misinterpretation. Variance between choices of surfaces could be due to preference of clinician and also athlete's progression within the program from beginning to advanced exercises. Variance between Rounds

A change in results between round one and two was based on dropout rate and intent to build consensus. It was not expected that any of the participants would drop out following the first round. Participants initially agreed to complete both rounds of the questionnaire. In attempt to keep the full panel of experts, follow up e-mails were included. The variance between rounds of this study can be directly correlated to the rate of attrition. For a majority of the components, the dropout rate produced an increase in percentages between rounds. The second round questionnaire provided mean scores and frequency for the participants to view. Intent to build consensus was then created because the participants could change their responses based upon the opinions of the others within the panel of experts. The dynamic flexibility and lunge sequencing sections provided the most variance between rounds. The lunge sequencing section varied the most to ten out of twelve items remaining after the second round, as opposed to three selected items in the first round. The dynamic flexibility section was next with five out of 10 remaining following round two, which increased from one out of 10 in the first round.

The Soccer Specific Functional Rehabilitation Program

According to the literature, it is important for a functional rehabilitation program to consist of exercise components that contain principles of dynamic flexibility, strength, power, 
sensorimotor facilitation, agility, aerobic training, anaerobic training, and kicking progression. ${ }^{1,13-}$ ${ }^{19}$ The primary objective of functional rehabilitation is to return the athlete to pre-injury level of activity, ${ }^{13}$ therefore, the proposed exercise components were developed to incorporate soccer specific activity of kicking, headers, and throw-ins were applicable. Functional rehabilitation achieves this goal with focus on biomechanics by analyzing sport-specific movements and progressing from simple to complex motions. ${ }^{14}$ The sequencing exercise sections were originally designed for progression from simple to complex, or from stable to unstable surfaces to increase in level of difficulty. The completed soccer specific functional rehabilitation program reflected best clinical practice and evidence based research. Refer to Table D17 for the complete program. Dynamic flexibility: Stretching of muscles is widely incorporated into warm-up and cooldown exercises, training and rehabilitation to increase one’s flexibility. ${ }^{16,25-27}$ The literature supports dynamic stretching as being beneficial when compared with static stretching for professional soccer athletes. ${ }^{16}$ In sports with a high-intensity stretch-shortening cycle, such as soccer, a more complaint muscle-tendon unit is required for the storage and release of elastic energy. ${ }^{16} \mathrm{~A}$ muscle -tendon unit involved in such stretch-shortening cycles, requires a high storage capacity for potential energy and must, therefore, be sufficiently compliant. ${ }^{16}$ If an individual's muscle-tendon unit is less flexible in soccer specific activities, there exists a predisposing factor for exercise-related injuries. ${ }^{16,25}$ Although, dynamic flexibility should be used during a functional rehabilitation program, the final program was rather limited in this section. The exercises that reached consensus were specific to the sport of soccer and the main muscle groups used during activity, specifically the hamstrings and adductors. One participant did recommend the use of toepops to activate the gastronemius and the anterior tibialis. Another comment suggested that the walking piriformis stretch is too dangerous to be included as a dynamic flexibility exercise. 
Conflicts within the literature do exist, suggesting dynamic stretching to be disadvantageous compared to static stretching because of the activation of the stretch reflex causing the stretching muscle to contact, therefore no increase in range of motion. ${ }^{29}$ Even though the dynamic flexibility components outlined above mimic the motions of the sport, therefore preparing the athlete for activity, additional exercises would need to be included for a proper and thorough warm-up or flexibility training regimen. Additional exercise components should include the dynamic flexibility exercises outlined within the literature such as backwards reach run, drop lunge, trunk twist, trail leg walking, and heel-to-toe walk. ${ }^{16-18,30}$

Single leg balance, squat, heel raise, and lunge sequencing: Although individual exercise sections, each of these groups consisted of sensorimotor facilitation, strength, and core stabilization training. According to the literature, sensorimotor facilitation, strength, and core stabilization training are all necessary components to the design for a functional rehabilitation program. ${ }^{1,13-19}$ For this research, it was important to combine each of the training components within individual exercises, because restoring deficits in strength, flexibility, and power may not be sufficient to return an athlete to competition. ${ }^{1,12}$ The sport specificity of training is key, and must involve matching the neuromuscular and physiological demands to the sport. ${ }^{12}$ The goal of sensorimotor facilitation is to further increase joint stability. ${ }^{15,31}$ This program was developed to provide sensorimotor facilitation training for various sport specific skills, to provide the athlete with the most advantageous stability training. Functional rehabilitation is designed to restore functional stability, using dynamic mechanism, and sport specific skills. ${ }^{1,14}$ While the exercises are performed to train different musculoskeletal groups of the lower extremity, each are soccer specific and beneficial to the final program. The exercises within the final program consist of evidence based concepts of sensorimotor facilitation, strength training, and core stabilization while 
implementing soccer-specific skills. The combination of these specific exercises creates a thorough training program following evidence based guidelines for progression from unstable surface to stable surface training. This section is complete enough to provide the athlete and clinician with the necessary rehabilitation.

Research for sport-specific training specifies that programs should to be designed to enhance or reestablish the neural pathways necessary for optimal athletic performance. ${ }^{13}$ For example, the mechanics involved in running are different for kicking and sidestep cutting. Therefore, this should be taken into consideration when designing a program. Compared to running, sidestep cutting involves similar levels of knee flexion loading but also increased loading in varus-valgus and internal rotation of the knee. ${ }^{32}$ These external loads need to be stabilized or supported by the internal structures of the knee. The use of neuromuscular training thereby reduces ligament loading. ${ }^{32}$ Resistance training may not be appropriate for a soccer athlete because it enhances muscle stretch reflexes, which may reduce co-contraction, and produces no reductions in voluntary activation times and time to peak torque. ${ }^{32}$ However, stability and balance training is thought to suppress muscle stretch reflexes and, in turn, enhance co-contraction. Stability and balance training that stimulates the knee joint ligament and capsular receptors may reinforce cocontraction patterns to facilitate greater improvements in joint stabilization, therefore reducing the risk of injury. ${ }^{32}$

Functional rehabilitation programs must include functional positions as well as static and dynamic positions. ${ }^{1,12,13}$ These closed chain exercises place the extremity in a functional position, allowing the musculature optimal opportunity to be recruited in the manner in which it will be used during soccer. ${ }^{33}$ After perturbation training, the knee flexion angle increased and muscle cocontraction was generally lower in injured patients, making their movement patterns similar to 
those with no injury. ${ }^{33}$ Chronic ankle sprains can be prevented in soccer players by training that includes balance and postural control with visual and vestibular contributions, joint kinesthesia, position sense, and muscle reaction time. ${ }^{34}$ Although some clinicians may argue the functionality of the use of Olympic lifting and the use of machine training for strength, the literature suggests that elite soccer players should focus on maximal strength training, with emphasis on maximal mobilization of concentric movements, which may improve sprinting and jumping performance. ${ }^{26}$ It is specifically recommended to train maximal strength in half squats. ${ }^{26}$ This additional information should be not included within the final program due to the lack of multidirectional training, but should be implemented following return to play.

Core Stabilization: This section, as outlined in this study, consisted of sensorimotor facilitation, strength, and core stabilization training. The stress imposed and the force produced within the trunk are often associated with inertia from the lower extremities through the trunk during cutting and side-stepping within soccer, therefore special attention to strengthening and stabilizing the core is deemed necessary. ${ }^{35,36}$ A dynamic core stabilization training program is an important component of a functional rehabilitation program. ${ }^{35-39}$ Soccer involves multi-directional movement, therefore it is important to train the core musculature in a muliplanar fashion to ready the athlete for participation. ${ }^{40}$ While the core stabilization exercises that met consensus to be included within the final program do not directly use soccer movement patterns for training, the principle of each exercise component is specific enough to train the core and therefore applicable to a functional rehabilitation program. The literature recommends core stabilization training for the rehabilitation of injuries and the prevention of injuries. ${ }^{14,35-40}$ An efficient core allows the lengthtension relationship of functional agonists and antagonists to remain normal, which in turn allows the force couple relationship in the lumbopelvic-hip complex to remain normal. ${ }^{14}$ In an efficient 
state, each structural component of the core distributes weight, absorbs force, and transfers ground reaction forces. ${ }^{14}$ If the extremity muscles are strong and the core is weak, not enough force will be created to produce efficient movement; inefficient movements lead to injury. ${ }^{14}$

The core serves as the center of the functional kinetic chain, ${ }^{39}$ therefore proximal stability is requisite for distal mobility of the extremities and implies that successful extremity movement relies on trunk stability. ${ }^{41}$ The stress imposed and the force produced within the trunk are often associated with inertia from the lower extremities through the trunk during sport-specific movements, therefore special attention to strengthening and stabilizing the core is deemed necessary. The combination of multiple-injury prevention-training components into a comprehensive core stabilization program is shown to improve performance and movement biomechanics. ${ }^{42}$ The use of core stabilization for neuromuscular training program could potentially modify the soccer athlete's motion strategies, improve performance, and lower the athlete's risk for injury. ${ }^{43}$ Neural adaptations from core stabilization training include more efficient neural recruitment patterns, faster nervous system activation, improved synchronization of motor units and a lowering of neural inhibitory reflexes. Injury to the lower extremity sustained during sport specific movements are associated with insufficient strength and endurance of the core stabilizing muscles and inappropriate recruitment of the trunk and abdominal muscles. It is important that any core stabilizing muscle weakness is identified and corrected as this significantly increases an individual's muscle and joint injury risk. The evidence based exercises of planks, diagonal trunk rotations, and progression to ball exercises once the individual has demonstrated good postural control was similar to the results of this study. ${ }^{35,40-42,44}$ The panel of experts choose exercises in progression from stable surface to unstable surface and progression with a mastery of neutral spine during specific exercises. The chosen exercises vary from isometric exercises with side planks and 
progresses side planks with initiation of unstable surfaces to increase difficulty. While the core stabilization exercises may not be directly soccer-specific skills, the final program does correlate with the progression of training recommended within the literature.

Plyometrics: This section, as outlined in this study consisted of sensorimotor facilitation, strength, and core stabilization training. The advantage of functional rehabilitation for muscular strength and power is that the exercises are performed in a sport-specific movement patterns using loads similar to that in soccer. ${ }^{45}$ The literature was very limited in providing specifics for functional rehabilitation. Plyometric training produce reductions in voluntary activation times and times to peak torque, which may decrease muscle response times so players are more able to perform rapid and unexpected sports maneuvers. Training programs that emphasize these neuromuscular mechanisms may enhance protection of the anterior cruciate ligament and reduce the incidence of injury in soccer players. ${ }^{32}$ Each of the exercise components included within the final program are relevant to soccer and train the individual to prepare for the demands of the sport. Even though only nine items remained in this section, there are enough exercises to provide progression and challenge throughout the functional rehabilitation program.

Plyometric training has been shown to improve vertical jump height and agility time while having no negative effect in sprint performance of elite soccer players. ${ }^{46}$ Plyometrics should be performed in a vertical, lateral and horizontal pattern to prepare the soccer athlete for jumping and heading. The literature recommends squat jumps and line hops, double and single, which is consistent with this program. Additional exercises such as jump rope, skipping, bounding, split squat jumps, power skips, and broad jumps could be added, although may lack specificity to soccer. $^{18}$ 
Functional activity progression: Most activities in soccer are performed at a sub-maximal level of exertion, although alterations in pace, change of direction, and execution of specific game skills should be addressed. ${ }^{35}$ High intensity efforts constitute around professional soccer games where the percentage of the total distance covered spent in high intensity is almost one-quarter (22.6\%) and can, on occasions, exceed one-third. ${ }^{47,48}$ The goal of functional rehabilitation is to enhance integrated, multi-dimensional movement that requires acceleration, deceleration and dynamic stabilization. ${ }^{35}$ Within the functional activity progression section, there is a kicking progression, anaerobic and aerobic progression and agility progression. According to the research, each of the above components are important to the development of a functional rehabilitation program. ${ }^{12,15}$ The exercise components included in the final program for kicking progression were dry kick with weight shift, dry kick with resistance, kick stationary ball short distance, kick stationary ball long distance, kick moving ball short distance, kick moving ball long distance, knee traps to kick, dry kick with plant into unstable surface, and stationary ball kick with plant onto unstable surface. Kicking should be progressed with a mastery of the current exercise. Fartleks and 50/50 interval training should be used for anaerobic training, while the treadmill was the recommended equipment for aerobic training. It was recommended that progression of activity should occur when a 70\% maximum heart rate was maintained for 15-30 minutes of specified aerobic training.

Agility training consisted of figure eight runs, zigzag runs, T-run, two-legged dot hop, ladder line run, ladder line sprint and backpedal, ladder line shuffles, Pro-Agility run, carioca runs, zigzag runs with dribbling, and up and back dot runs with dribbling were all included in the completed program. Although there were was limited information within the literature defining specific exercises best to utilize, it is an objective of functional rehabilitation to restore sport- 
specific skills and movement patterns. The literature does suggest that agility and sport-specific activities are included within functional rehabilitation to refine the physiologic and psychological parameters necessary to return to pre-injury levels of functional performance. ${ }^{14}$ The functional activity progression provided numerous options for optimal soccer specific training to be included within the final program. Components such as figure eights, carioca, and backpedaling are consistent with the literature; components that should be added are the evidence based exercises of box running and vertical jumping ${ }^{47,48}$ More thorough training should be added to the anaerobic and aerobic training components. The treating clinician must prepare the individual athlete to return into a 90-minute game. During an average game, a field player runs over six miles at an intensity close to anaerobic threshold. ${ }^{19}$ The exercise components included within the final program may not be sufficient for optimal training and preparation for return to play. The literature presents different options for functional activity progression that is shown to be beneficial in soccer training. Interval training comprising four bouts of four minute work periods at intensity of 90-95\% maximum heart rate with rest periods of three minutes of jogging at 70\% of maximum heart rate has been shown to improve aerobic capacity of professional soccer players. ${ }^{46}$ Agility training has been shown to achieve maximum transfer to on field performance in soccer players, with no change in sprint time. ${ }^{47}$ Small-sided games to be more advantageous for training. Heart rate increases to the same level as that in short-duration intermittent running and bring more variety during training, mixing physical, technical, and tactical training. ${ }^{34}$ Clinical Implications

The final soccer specific functional rehabilitation program offers clinicians with suggested exercises of dynamic flexibility, sensorimotor facilitation, core stabilization, strength, power, and functional activity progression to include within their treatment. The final program was designed 
as a rehabilitation worksheet with eight outlined sections: dynamic flexibility, single leg balance, heel raise sequencing, squat sequencing, lunge sequencing, plyometrics, core stabilization, kicking progression, anaerobic and aerobic progression, and agility progression. A level of progression was identified for each individual exercise component within the eight sections. This level of progression can in turn be used by the clinician to determine which exercises to group together for a treatment session. The treating clinician can choose which exercises to use throughout the phases of the rehabilitation process and when to implement each dependent upon the athlete and the injury. For example, a clinician treating an attacking midfielder with a second degree hamstring strain can use the program to determine which exercises are suggested to incorporate by their level of progression. This clinician can begin to implement sport specific exercises with a level one or two progression early in the rehabilitation process. As the patient's healing and functionality progress, the clinician can then use level three, four and five exercises as a suggestion for possible progressions. Refer to Figure D2 for an example of the possible progression.

\section{Limitations}

There were specific limitations in this study due to the use of the modified Delphi Technique, which include drop-out rates, time delay of the participants submitting their responses, and a time delay between the two rounds of questionnaire so that the questionnaires could be modified. The questionnaires were sent to the participants electronically to prevent time delays in mailing. Participant attrition was a great limitation in the particular study as five participants dropped out between rounds.

In addition to these limitations, there were also threats to internal and external validity. It is possible that other environmental influences could have affected the responses of the participants, such as receiving input from others on the questionnaire. The participants may have 
also learned how to interpret the questions on the first questionnaire, which may have affected their responses on the second questionnaire. The reactive effect of experimental arrangements is another limitation. In this study, the participants most likely completed the second round questionnaire in a different setting than where they completed the first one. This may have produced a change in the way they responded to the questions. The initial e-mail to gauge interest was sent during the off-season. At this time frame most of the MLS clinicians were away from their home base and off contract for the season. Turnover in staff also commonly occurs during the offseason which may have limited the responses in participation. The first round questionnaire was sent to the participants during the MLS off-season and the second round questionnaire was sent at the beginning of the MLS pre-season training camp. During pre-season, most of the clinicians are traveling the United States and even outside of the country with their respective team for training. A busy schedule could have been a major distraction when trying to find time to complete the questionnaire.

The inclusion criteria to be considered an expert on soccer specific functional rehabilitation were based on an arbitrary number of publications and presentations for researchers and years of experience for clinicians. Those who have published five or more works in peer reviews journals, made five or more presentations at professional meetings, or those who have five of more years of clinical experience met the inclusion criteria.

Another limitation of this study is that photographs were not provided for every exercise nor were any further descriptions provided to the participants. The final limitation of this study comes from the change of the tool between round one and round two. The first round questionnaire provided the participants with photographs for specific exercises to prevent misinterpretation of the intended component. The photographs were removed from the second round questionnaire 
which may have led to confusion or misinterpretation of the exercise components, therefore, leading to a change in response.

\section{CONCLUSIONS}

The initial soccer specific functional rehabilitation program had 168 items. Ninety-six items failed to meet consensus in the first round and 81 items failed to meet consensus in the second round. The final soccer specific functional rehabilitation program contained 87 items. The responses given by the panel of expert for both rounds of the questionnaire allowed for the development of the final soccer specific functional rehabilitation program. This panel of experts proved to be valuable in determining what should be included in a soccer specific functional rehabilitation program. The information gained from this final program by the panel of experts may help health care professionals in various clinical settings that rehabilitate soccer injuries. Since there is limited information on functional rehabilitation exercises in the literature, this program could serve as a basis for developing an even more concise, yet complete, soccer specific functional rehabilitation program in the future. 


\section{REFERENCES}

1. Fuller C, Walker J. Quantifying the Functional Rehabilitation of Injured Football Players. Br J Sports Med. 2006; 40:151-157.

2. Agel J, Evans TA, Dick R, Putukian M, Marshall SW. Descriptive Epidemiology of collegiate men's soccer injuries: National Collegiate Athletic Association Injury Surveillance System, 1988-1989 through 2002-2003. J Athl Train. 2007;42(2):270-7.

3. Hawkins RD, Fuller CW. A Prospective Epidemiological Study of Injuries in Four English Professional Football Clubs. Br J Sports Med. 1999; 33:196-203.

4. Hawkins RD, Hulse MA, Wilkinson C, Hodson A, Gibson M. The Association Football Medical Research Programme: An Audit of Injuries in Professional Football. Br J Sports Med. 2001;35(1):43-7.

5. Junge A, Dvorak J, Graf-Baumann T, Peterson L. Football Injuries During FIFA Tournaments and the Olympic Game, 1998-2001. Development and Implementation of an Injury-Reporting System. Am J Sports Med. 2004; 32(1):80-89.

6. Morgan B, Oberlander M. An Examination of injuries in Major League Soccer: The Inagural Season. Am J Sports Med. 2001; 29(4):426-429.

7. Dvorak J, Junge A, Grimm K, Kirkendall D. Medical report from the 2006 FIFA World Cup Germany. Br J Sports Med. 2007;41(9):578-81; discussion 581. Epub 2007.

8. Dadebo B, White J, George KP. A survey of flexibility training protocols and hamstring strains in professional football clubs in England. Br J Sports Med. 2004;38(4):388-94.

9. Ekstrand J, Waldén M, Hägglund M. A congested football calendar and the wellbeing of players: correlation between match exposure of European footballers before the World Cup 2002 and their injuries and performances during that World Cup. Br J Sports Med. 2004;38(4):493-7.

10. Murphy DF, Connolly DAJ, Beynnon BD. Risk factors for lower extremity injury: a review of the literature. Br J Sports Med. 2003;37:13-29.

11. Rahnama N, Reilly $\mathrm{T}$, Lees A. Injury risk associated with playing actions during competitive soccer. Br J Sports Med. 2002;36(5):354-9.

12. Hägglund M, Waldén M, Ekstrand J. Previous injury as a risk factor for injury in elite football: a prospective study over two consecutive seasons. J Sports Med. 2006;40(9):76772.

13. Lephart SM, Henry TJ. Functional Rehabilitation for the Upper and Lower Extremity. Orthop Clin North Am. 1995 Jul;26(3):579-92. 
14. Clark M. Core Competency Underlies Functional Rehabilitation. Biomechanics. 2000 Feb

15. Lephart S, Pincivero D,Giraldo J, Fu F. The Role of Proprioception in the Management and Rehabilitation of Athletic Injuries. Am J Sport Med. 1997; 25(1).

16. Little T, Williams A. Effects of Differential Stretching Protocols During Warm-Ups on High-Speed Motor Capacities in Professional Soccer Players. J Strength Cond Res.2006; 20(1):203-207.

17. Mann D, Whedon C. Functional stretching: implementing a dynamic stretching program. ATT. 2001; 6(3):10-13.

18. Robinson B, Owens B. Five-week program to increase agility, speed, and power in the preparation phase of a yearly training plan. J Streng Cond Res. 2004; 26(4):30-35.

19. Hoff J , Wisløff U, Engen LC. Soccer specific aerobic endurance training. Br J Sports Med. 2002;36:218-21.

20. Hasson F, Keeney S, McKenna H. Research Guidelines for the Delphi Survey Technique. $J$ Adv Nursing. 2000; 32(4):1008-1015.

21. Goodman CM. The Delphi Technique: A Critique. J Adv Nursing. 1987; 12:729-734.

22. Powell C. The Delphi Technique: Myths and Realities. J Adv Nursing. 2003: 41(4):376382.

23. Couper MR. The Delphi Technique: Characteristics and Sequence Model. Adv Nursing Sci. 1984; 7:72-77.

24. Fisher RG. The Delphi Method: A description, review, and Criticism. J Academic Lib. 1978; 4:64-70.

25. Mahieu N, McNair P, De Muynck M, Stevens V, Blanckaert I, Smits N. Effect of Static and Ballistic Stretching on the Muscle-Tendon Tissue Properties. Med Sci Sports Exerc. 2007; 39(3):494-501.

26. Maerk S, Cramer J, Fincher L, Massey L, Dangelmaier S, Purkayastha S. J Ath Train. 2005; 40(2):94-103.

27. Nelson AG, Kokkonen J, Arnall D. Acute muscle stretching inhibits muscle strength endurance performance. J Strength Cond Res. 2005;19(2):338-43. 
28. Witvrouw E, Danneels L, Asselman P, D’Harve T, Cambler D. Muscle Flexibility as a Risk Factor for Developing Muscle Injuries in Male Professional Soccer Players: A Prospective Study. Am J Sports Med. 2003; 31:41.

29. Bergmark A. Stability of the Lumbar Spine: A study in Mechianical Engineering. Acta Orthop Scand Suppl. 1989; 230:1-54.

30. Devore P, Hagerman P. A pregame soccer warm-up. J Strength Cond Res. 2006; 28(1):1418.

31. Mattacola C, Lloyd J. Effects of a 6-Week Strength and Proprioception Training Program on Measures of Dynamic Balance: A Single-Case Design. J Ath Train.

32. Hanson A, Padua D, Blackburn T, Prentice W, Hirth C. Muscle activation during side-step cutting maneuvers in male and female soccer athletes. J Athl Train. 2008;42(2): 133-143.

33. Freidhoff G, Davies G, Malone T. Rehabilitation: chain links: rehabilitation program should balance open and closed chain activities. www.biomech.com 1998, March.

34. Ergen E. Ulkar B. Proprioception and ankle injuries in soccer. Clin Sports Med. 2008;27(1): 195-217.

35. Clark M. Essentials of Integrated Training Part 5: Core Stabilization Training. www.ptonthenet.com. 1998.

36. Panjabi MM. Clinical Spinal Instability and Low Back Pain. J Electromyog Kinesiol. 2003; 12:371-9.

37. Panjabi MM. The Stabilizing System of the Spine. Part I: Function, Dysfunction, Adaptation, and Enhancement. J Spinal Disord. 1992;5:383-389.

38. Panjabi MM, Tech D. White AA. Basic biomechanics of the spine. Neurosurgery.1980;7:76-93

39. Akuthota V, Nadler S. Core Strengthening. Arch Phys Med Rehabil. 2004; 85(3):86-92.

40. Kibler W, Sciascia A. The role of core stability in athletic function. Sports Med. 2006; 36(3):189-198.

41. Cross K, Worrel T. Effects of a static stretching program on the incidence of lower extremity musculotendinous strains. J Athl Train. 1999;34(1): 11-14.

42. Myer GD, Chu DA, Brent JL, Hewett TE. Trunk and hip control neuromuscular training for the prevention of knee joint injury. Clin Sports Med. 2008; 27(3):425-48. 
43. Chappell JD, Limpisvasti O. Effect of a neuromuscular training program on the kinetics and kinematics of jumping tasks. Am J Sports Med. 2008; 36(6):1081-1086.

44. Clark MA, Fater D, Reuteman P. Core (trunk) Stabilization and its Importance for Closed Kinetic Chain Rehabilitation. Orthop Phys Ther Clin North Am. 2000;9:119-135.

45. Schimitz M. Functional rehabilitation.

46. Thomas K, French D, Hayes PR. The effect of two plyometric training techniques on muscular power and agility in youth soccer players. J Strength Cond Res. 2009; 23(1):3325

47. Young W, Farrow D. A review of agility: practical applications for strength and conditioning. J Streng Cond Res. 2006; 28(5):24-29.

48. McMillan D, Moore J, Hatler D, Taylor D. Dynamic vs Static-Stretching Warm Up: The Effect on Power and Agility Performance. J Strength Cond Res. 2006; 20(3):492-499.

49. Dellal A, Chamari K, Pintus A, Girard O, Cotte T, Keller D. Heart rate responses during small-sided games and short intermittent running training in elite soccer players: a comparative study. J Streng Cond Res. 2008; 22(5):1449-1457. 
APPENDICES 


\section{APPENDIX A}

\section{THE PROBLEM}

\section{Research Question}

Injury is a major risk for any athlete, and for an athlete returning to competition after injury the risk is even greater. Soccer contributes to an increased incidence of lower extremity injuries. Most common injuries include, but are not limited to hip and thigh strains, knee sprains, and lateral ankle sprains. Approximately $70 \%$ of all game and practice injuries affected the lower extremities. ${ }^{1-6 .}$ Ankle ligament sprains, knee internal derangements, and leg contusions account for a substantial portion of game injuries. ${ }^{1-6}$ Upper leg muscle-tendon strains, ankle ligament sprains, knee internal derangements and pelvis and hip muscle strains represent most of the practice injuries. ${ }^{1-6}$ Player-to-player contact represents the highest risk factor for injury during games while the most common mechanism of injury during practice is non-contact. ${ }^{1,5,10-12 .}$

The treating clinician therefore has a responsibility to implement risk management strategies that: 1) will minimize the incidence and consequences of injury; and 2) ensure that injured athletes are effectively rehabilitated. ${ }^{1,13} \mathrm{~A}$ rehabilitation program can be divided into two stages consisting of traditional treatment rehabilitation and functional rehabilitation. ${ }^{1}$ The clinician begins care with traditional treatment immediately. Further along the process, functional rehabilitation, an extension of the traditional elements of therapy is added. The purpose of functional rehabilitation is to return the athlete to highly complex movement patterns present within their specific sport. ${ }^{1,13}$ While traditional rehabilitation focuses on flexibility, range of motion and strength, the functional rehabilitation program incorporates agility, proprioceptive training, and kinesthetic training. The primary goal of functional rehabilitation is to enable the athlete to participate at a pre-injury state of conditioning while reducing risk of secondary 
injury. ${ }^{1}$ The functional rehabilitation program is designed to progress the athlete from simple activities, such as walking or jogging, to highly complex sport-specific activities that require refined levels of proprioceptive acuity. The final phase of the functional rehabilitation program determines when the athlete is ready to resume participation of their sport. This is a very important and sometimes overlooked component of the functional rehabilitation program. The decision for returning an athlete to participation should be made using objective assessments of function that simulate sport activity whenever possible. ${ }^{1,13,24}$ With an injury, either acute or chronic, insufficient sport-specific conditioning is the main complication in the athlete's return to sport.

Clinical experience with soccer athletes supports the increased injury rate during preseason practice compared with in-season practice. During preseason practice, the athlete is at an increased risk of injury secondary to a lack of conditioning, increased intensity, scrimmaging, heat, and fatigue. ${ }^{2,6}$ While player-to-player contact and non-contact are the primary risks of injury throughout the season, insufficient conditioning remains the primary risk of complicated return to play and injury recurrence. ${ }^{2,5,11,12,14}$ Proper functional training needs to focus heavily on core and sensorimotor facilitation training for any lower extremity injury and is imperative to develop a well-conditioned athlete post-injury. ${ }^{2,11,12}$ The unsuccessful completion of the functional rehabilitation may be one contributing factor putting the athlete at risk for secondary ischemic injury. ${ }^{12}$ An athlete may also endure a secondary lower extremity injury proximal or distal from the injury in the kinetic chain.

Research on soccer epidemiology and etiology is plentiful, ${ }^{1-12}$ although very little research consists of soccer specific functional rehabilitation. There is limited evidence based research or best clinical practice guidelines on functional rehabilitation. When little or no information is available to serve as a guide, clinicians and researchers that are considered experts should be used 
to develop programs. This in turn will incorporate evidence based guidelines and best clinical practice based on consensus of selection of components included in a functional rehabilitation program. Considering lack of evidence based research and the complexity of lower extremity injuries in regard to soccer, a best clinical practice functional rehabilitation protocol needed to be developed. Therefore, the purpose of this study was to use a selected panel of Major League Soccer Certified Athletic Trainers and Physical Therapists and soccer researchers to gain expert opinion on what should be included in a soccer specific functional rehabilitation program. Therefore, my research questions were:

1. Which dynamic flexibility exercises should be included in the functional rehabilitation of a soccer athlete?

2. Which single leg balancing sequencing exercises should be included in the functional rehabilitation of a soccer athlete?

3. Which lunge sequencing exercises should be included in the functional rehabilitation of a soccer athlete?

4. Which squat sequencing exercises should be included in the functional rehabilitation of a soccer athlete?

5. Which heel raise sequencing exercises should be included in the functional rehabilitation of a soccer athlete?

6. Which core stabilization exercises should be included in the functional rehabilitation of a soccer athlete?

7. Which plyometric exercises should be included in the functional rehabilitation of a soccer athlete?

8. Which functional activity progression exercises should be included in the functional rehabilitation of a soccer athlete?

9. Will a panel of experts agree on exercise components of a soccer specific functional rehabilitation program? 


\section{Experimental Hypotheses}

1. There will be consensus of the participants (75\%) in the study and a mean score of 4 on dynamic flexibility exercise components.

2. There will be consensus of the participants (75\%) in the study and a mean score of 4 on single leg balance sequencing exercise components.

3. There will be consensus of the participants (75\%) in the study and a mean score of 4 on squat sequencing exercise components.

4. There will be consensus of the participants (75\%) in the study and a mean score of 4 on lunge sequencing exercise components.

5. There will be consensus of the participants (75\%) in the study and a mean score of 4 on heel raise sequencing exercise components.

6. There will be consensus of the participants (75\%) in the study and a mean score of 4 on core stabilization exercise components.

7. There will be consensus of the participants (75\%) in the study and a mean score of 4 on plyometric exercise components.

8. There will be consensus of the participants (75\%) in the study and a mean score of 4 on functional activity progression exercise components.

Assumptions

1. All participants will remain in the study to complete both rounds of questionnaires.

2. Each individual participant will answer all the questions to $100 \%$ of their clinical ability.

3. The questionnaire developed will be valid and reliable.

4. Surveys will be submitted in a timely manner.

5. All respondents will answer the questionnaire honestly.

Delimitations

1. A small panel of experts, based on their expertise, will be chosen to participate in this study.

2. This study will be only generalizable to the specific experts used. 
3. This study will be only generalizable to Major League Soccer.

4. The panel of experts will consist of Major League Soccer Certified Athletic Trainers and Physical Therapists with at least five years of experience.

5. The panel of experts will consist of soccer researchers with at least five professional publications and presentations

6. The results of the questionnaire will be based solely on the opinions of the chosen panel of experts.

Operational Definitions

1. Agility- The ability to change the body's position rapidly. Agility requires a combination of balance, coordination, speed, reflexes, and strength. ${ }^{14}$

2. Biomechanics- The effect of muscular forces, joint axes and resistance on the quality and quantity of human movement.

3. Certified Athletic Trainer (ATC)- An individual who graduated from a CAATE accredited program and becomes credentialed after passing an exam by the Board of Certification.

4. Consensus- This occurs when $70 \%$ of the participants agree on a certain question. Specific to this study consensus was determined by $75 \%$ and a mean score of 4 .

5. Core- The musculoskeletal core consists of the spine, hip and pelvis, proximal lower limb, and abdominal structures. The musculature includes the muscles of the trunk and pelvis that are responsible for the maintenance of stability of the spine and pelvis and help in the generation and the transfer of energy from large to small body parts during many sports activities. $^{35,36}$

6. Core Stabilization- The general term for how the global musculature keeps one's trunk and extremities stable. ${ }^{35.36}$

7. Dynamic Flexibility- Functional based exercises which are used with sport specific movements to prepare the body for movement, with a gradual increase in range of motion and speed of movement. ${ }^{25}$

8. Expert- Any ATC or PT with at least five years of clinical experience and any researchers with at least five professional publications and presentations.

9. Flexibility- The ability to move a joint through a full range of motion in an unrestricted and pain free manner. ${ }^{26}$

10. Functional Rehabilitation- A series of progressive sport specific exercise to prepare an individual for return to sport. ${ }^{1}$ 
11. Kinematics- Terms that permit the description of human movement: type of motion, location, magnitude and direction. ${ }^{11}$

12. Kinesthetic Awareness- Awareness of one's joint position to one another and to objects in the environment. ${ }^{31}$

13. Kinetics- The forces being analyzed; the cause of joint action. ${ }^{11}$

14. Likert Scale- Psychometric response, five-point scale often used in questionnaires ranging from 1-strongly disagree to 5 -strongly agree. ${ }^{20}$

15. Lower Extremity- The lower limb of the body. Specific to this study, focus will be on the lumbar-pelvic-hip complex.

16. Major League Soccer- Top-flight professional soccer league based in the United States and sanctioned by United States Soccer Federation. The league is comprised of 15 teams, 14 in the U.S and one in Canada.

17. Modified Delphi Technique- A form of the Delphi Technique that aims to gain expert opinion on a research question by surveying chosen participants in two rounds of mailed questionnaires in an effort to gain the most refined information on the particular topic. The primary objective is to obtain a consensus of opinion from the selected participants without having to meet in person. ${ }^{20}$

18. Panel of Experts- A small group of ATCs who have expertise in professional soccer and a small group of researchers with expertise in soccer.

19. Sensorimotor Facilitation- Sense of Joint position, kinesthesia, sensation of resistance gained from input and sensory nerve terminals in muscles and tendons. ${ }^{13}$

\section{Limitations}

The following limitations are specific to the use of the Modified Delphi Technique: ${ }^{20-24}$

1. The panel must have expertise in the functional rehabilitation of professional soccer athletes.

2. Drop out of participants may occur between the two rounds of questionnaires.

3. There will be a time delay between e-mailing the questionnaire to the participants and the submission of the completed questionnaires.

4. There will be a delay in time between the two rounds of questionnaires affecting questionnaire modification. 
The following limitations result from threats to internal and external validity:

5. History- Other environmental influences may affect the responses of the participants, such as receiving input from others on the first round of questions.

6. Testing- The participants may learn how to interpret the questions on the first questionnaire which could affect their responses on the second questionnaire.

7. Generalization- The responses of the experts can not be generalized to the entire population because of the small panel size.

8. Selections Bias- In this study, participants will be selected by using a sample of convenience.

9. Reactive Effects of Experimental Arrangements- The participants may choose to take the second round questionnaire in a different setting than the setting used during the first round. This could change their responses or cause a distraction altering the quality of their responses.

Significance of the Study

Evidence based guidelines and best clinical practice will help to develop a functional rehabilitation program for soccer. By using a panel of experts who treat and rehabilitate professional soccer athletes on a regular basis and the use of expert researchers on the topics of functional rehabilitation and soccer, such a program can be developed. Once developed the program will function as a base for clinicians to incorporate sport specific activity into their rehabilitation plan. This program will reiterate the importance of progressing from traditional treatment and rehabilitation into functional exercise. There will be an emphasis on dynamic postural control, sensorimotor facilitation and muscular endurance exercises. Soccer athletes will benefit primarily because it will return the post-injured athlete to a pre-injury level of sport function. Ultimately the program will serve as the most direct route to return to competition with the use of a variety of exercise to keep the athlete engaged and maintain a healthy frame of mind throughout the healing process. The final soccer specific functional rehabilitation program offers clinicians with suggested exercises to include within their treatment. The final program was 
designed as a rehabilitation worksheet with an identified level of progression for each individual exercise component. Based on the final program incorporated, the ATC and PT will be able to successfully progress a soccer athlete through proper succession of rehabilitation exercises.

Furthermore, this guide will enable the athlete with the necessary conditioning and endurance to successfully return to play. 


\section{APPENDIX B \\ LITERATURE REVIEW}

Introduction

Soccer is the most popular sport worldwide, with an estimated 200 million active players. It is the fastest-growing sport in the US with almost 20 million players and an annual increase in participation of greater than $20 \%{ }^{2}$ Soccer athletes are at great risk to injury of the lower extremity ${ }^{1-12}$ The lower extremity, as it pertains to this research study, is defined as the combination of joints, muscles, and ligaments within the lumbopelvic-hip complex distal to the ankle joint. The incidence of soccer-related injuries is estimated to be 10 to 35 per 1000 playing hours in the adult male professional athlete. ${ }^{1-7}$ The lower extremity is the most commonly injured, at a rate of $76-87 \%$ in professional soccer athletes secondary to the intense forces incurred during sport specific actions ${ }^{1-12}$. Most common sites of injury include the thigh, ankle, knee, and groin. ${ }^{1-12}$ Ankle ligament sprains contribute to a substantial portion of game injuries, while upper leg muscle-tendon strains represent most of the injuries incurred during training. ${ }^{5}$ An increased incidence of lower extremity injuries is related to intensity of training, running mechanics, playerto-player contact and poor conditioning. ${ }^{1-8}$

Functional rehabilitation is defined as multifaceted rehabilitation designed to replicate the nature of the game. ${ }^{1,13,43}$ Functional rehabilitation includes acceleration, deceleration, and sensiormotor facilitation activity in a multi-planar fashion. ${ }^{1,13,19}$ Muscular strength, endurance and power are also important facets, as the treating clinician must prepare the athlete to return into a 90-minute game. During an average game, a field player runs over six miles at an intensity close to anaerobic threshold. ${ }^{19}$ In the literature review the anatomy of the lower extremity, biomechanics, 
epidemiology, etiology, components of a functional rehabilitation program, and the Modified Delphi Technique will be discussed.

\section{Anatomy}

Lumbopelvic-hip complex: The lumbopelvic-hip complex, which can also be referred to as the 'core', represents the combination of bony anatomy and soft tissue of the lumbar spine, pelvis, and hip joint. ${ }^{39}$ All movement within the body generates from one’s center of gravity which is located within the core. ${ }^{14,39}$ The core consists of twenty nine muscles that provides major support to the loaded spine..$^{20,32-35,44}$ Efficient strength, endurance and firing of these trunk muscles, along with ligamentous support, is essential for maintaining stability and dynamic control of the kinetic chain. $^{45,46}$

The bony anatomy of the lumbar-pelvic-hip complex consists of the lumbar spine, pelvis, and hip joint. The lumbar spine consists of five large vertebrae located between the thorax and sacrum. ${ }^{46-49}$ The vertebrae of the lumbar spine are gradually larger than the proximal spine, in order to increase ability of weight-bearing, and then become smaller distally to the apex of the coccyx. ${ }^{47}$ Body weight is transmitted distally from L5 through the base of the sacrum. ${ }^{47}$ The pelvis is formed by the articulation of three bones including right and left innominates, coccyx and the sacrum. ${ }^{46-49}$ The primary functions of the pelvic girdle are to bear the weight of the upper body when sitting and standing, to transfer that weight from the axial to the lower appendicular skeleton for standing and walking, and to provide attachment for the powerful muscles of locomotion and posture. ${ }^{47-49}$ The sacrum is formed by the fusion of five sacral vertebrae located between the innominate hipbones. ${ }^{47}$ The lumbar-pelvic-hip complex is provided with additional strength and stability through the sacrum. ${ }^{47}$ The coccyx is a small bone formed through the fusion of four vertebrae. ${ }^{47}$ Unlike the vertebrae of the spine, the coccyx does not serve to bear weight. ${ }^{47}$ The right 
and left innominate hipbones are comprised of the fusion of the ilium, ischium, and pubis. ${ }^{47-49}$ The ilium, forming the superior portion of the hipbone, is the largest of the innominates and serves to bear weight and for attachment of the core musculature. The ischium, forming the posteroinferior part of the hipbone, bears weight in the sitting position. The pubis, forming the anteromedial part of the hipbone, serves as an attachment for the muscles of the medial thigh and divides and transfers weight to the limbs. ${ }^{47-49}$

The core consists of the sacroiliac, pubic symphysis, lumbosacral, and the hip joint. ${ }^{47-49}$ The sacroiliac joints connect the axial skeleton and the appendicular skeleton. Limited mobility is allowed within the joint due to the anterior synovial joint and a posterior syndesmosis. ${ }^{47-49}$ The pubic symphysis is a secondary cartilaginous joint consisting of a fibrocartilaginous interpubic disc and ligaments. ${ }^{49}$ The sacroccygeal joint is also a secondary cartilaginous joint that connects the sacrum and coccyx through fibrocartilage and ligaments. The ball and socket joint of the hip is comprised of the articulation between the femur and the acetabulum of the pelvis. The hip joint provides stability over a wide range of motions. The dense ligaments of the complex stabilize these joints. The sacrotuberous and sacrospinous ligaments pass from the ischial tuberosity and ischial spine of the ischium bone to the side of the sacrum and coccyx. ${ }^{47}$ These ligaments convert the sciatic notches into the greater and lesser foramina. ${ }^{48}$ The greater sciatic foramen is known as the doorway of the true pelvis, while the lesser foramen serves as the entrance to the perineum. The iliofemoral, pubofemoral, and ischiofemoral ligaments provide stability to the hip joint. ${ }^{49}$ The iliofemoral ligament is located anteriorly and superiorly and is suggested to be the strongest ligament of the body. The ligament prevents hyperextension of the hip joint. The pubofemoral ligament is located anteriorly and inferiorly. This ligament prevents hyperabduction of the hip joint. The ischiofemoral ligament is located posteriorly and is suggested to be the weakest of the 
three ligaments. The ligament of the head of the femur provides little support, but does serve to connect a small artery to the femoral head. Additional support is provided to the hip joint by the acetabular labrum and the transverse acetabular ligament. ${ }^{48}$ These structures deepen the acetabular articular area. ${ }^{47}$

There are numerous muscles acting on the lumbar-pelvic-hip complex ${ }^{20,32,33-35,45,47-49}$ Anteriorly are the iliacus and psoas major muscles, which are hip flexors. The satorious muscle is also anterior, along with the quadriceps muscle group of the rectus femoris, vastus medialis, vastus lateralis, and vastus intermedias muscles. ${ }^{47}$ The lateral and posterior hip is comprised of the tensor fascia latae, gluteus maximus, gluteus medius, and gluteus minimus. Lateral rotation of the hip is the action of the gemellus superior and inferior, obturator externus and internus, piriformis, and the quadratus femoris. ${ }^{47}$ Medial rotation of the hip occurs from the adductor longus and brevis, adductor magnus, gracilis and the pectineus muscles. Posteriorly, is the hamstring muscle group including biceps femoris, semitendinous, and semimembranosus muscle. ${ }^{49}$ All muscles acting on the hip are further described in Table B1, including the origin, insertion, nerve innervations and muscle action.

There is no universally accepted definition of "core" muscles, although few have created defined categories. Bergmark ${ }^{50}$ and Kornin ${ }^{51}$ have categorized the core musculature into two distinct groupings. One group is considered the global system, which consists of the external core muscles. These muscles are the larger, superficial torque-producing muscles of the pelvis. The defined global muscles are the rectus abdominis, external and internal oblique, and the illiocostalis ${ }^{50.51}$. The second group is considered as the local system, which consists of the internal core muscles. These muscles are shorter in length and closer to the central axis to control intersegmental motion of the pelvis. The defined local muscles are the multifidi, psoas major, 
transverse abdominis, quadratus lumborum, diaphragm, the posterior fibers of the internal oblique, and the lumbar portions of the illiocostalis and longissimus. ${ }^{50.51}$ The muscles of the core are further defined in Table B2, which includes origin, insertion, nerve innervations and muscle action.

Peripheral nerves innervating the pelvis and femur muscles originate along the lumbar plexus and sacral plexus. ${ }^{47-49}$ The nerves of the lumbar plexus are the iliohypogastric, ilioinguinal, genitofemoral, lateral femoral cutaneus, femoral saphenous and obturator nerve. The sacral plexus originates from the ventral rami of nerves L4, L5, S1, S2, S3, and S4. ${ }^{47-49}$ The following nerves are part of the sacral plexus including superior and inferior gluteal nerve, perforating cutaneous nerve, posterior cutaneous nerve, tibial nerve, common peroneal nerve, sciatic nerve, pudendal nerve, and the coccygessal nerve. ${ }^{47-49}$ Refer to Table B1 and B2 for specific neural innervation.

The arterial supply to the pelvis region and lower limb begins at the right and left common iliac arteries. ${ }^{47-49}$ These common iliac arteries divide into the internal and external iliac arteries. The internal iliac artery has seven branches. ${ }^{47-49}$ The most important of these would be the superior and inferior gluteal arteries and the obturator artery. The external iliac artery has four branches. The femoral artery, which is further divided into the deep and circumflex femoral arteries supply the hamstring muscles and femur, respectively. ${ }^{47-49}$ The remaining branches of the external iliac artery supply distal structures, which will be covered later in the review.

The venous drainage of the lower limb and pelvic regions comes from a combination of deep and superficial veins. ${ }^{47-49}$ The drainage begins at the toes and moves proximal, following the flow of blood to the inferior vena cava. There are nine deep and three superficial veins in the lower extremity. The femoral vein, and internal and external iliac veins are of importance in this section. The femoral vein is a continuation of the popliteal vein and receives drainage from the deep thigh muscles and the femur. ${ }^{47-49}$ The femoral and great saphenous veins converge into the external iliac 
vein. The internal iliac vein follows the course of the internal iliac artery. Among other structures, drainage for the gluteal muscles and the medial muscles of the thigh is provided. ${ }^{47-49}$

Table B1. Muscles Acting on the Hip and Femur ${ }^{47-49}$

\begin{tabular}{|c|c|c|c|c|}
\hline Muscle & Origin & Insertion & Nerve & Action \\
\hline Iliacus & Iliac fossa & $\begin{array}{l}\text { Lesser trochanter } \\
\text { of femur }\end{array}$ & Femoral & $\begin{array}{l}\text { Hip flexion; medial } \\
\text { rotation of femur }\end{array}$ \\
\hline Psoas Major & $\begin{array}{l}\text { Vertebral bodies } \\
\text { T12-L5 }\end{array}$ & $\begin{array}{l}\text { Lesser trochanter } \\
\text { of femur }\end{array}$ & Lumbar plexus & $\begin{array}{l}\text { Hip flexion; medial } \\
\text { rotation of femur }\end{array}$ \\
\hline $\begin{array}{l}\text { Tensor Fasciae } \\
\text { Latae }\end{array}$ & Iliac crest & $\begin{array}{l}\text { Lateral condyle of } \\
\text { tibia }\end{array}$ & Superior gluteal & $\begin{array}{l}\text { Hip flexion; abduction; } \\
\text { medial rotation of femur }\end{array}$ \\
\hline Gluteus Maximus & Ilium and sacrum & $\begin{array}{l}\text { Gluteal tuberosity } \\
\text { of femur, fascia } \\
\text { lata }\end{array}$ & Inferior gluteal & $\begin{array}{l}\text { Hip extension; } \\
\text { abduction; lateral } \\
\text { rotation of femur }\end{array}$ \\
\hline $\begin{array}{l}\text { Gluteus } \\
\text { Medius/Minimus }\end{array}$ & Ilium & $\begin{array}{l}\text { Greater trochanter } \\
\text { of femur }\end{array}$ & Superior gluteal & $\begin{array}{l}\text { Abduction; medial } \\
\text { rotation of femur }\end{array}$ \\
\hline Gemellus & Body of ishium & $\begin{array}{l}\text { Obturator internus } \\
\text { tendon }\end{array}$ & Sacral plexus & Lateral rotation of femur \\
\hline $\begin{array}{l}\text { Obturator } \\
\text { externus }\end{array}$ & $\begin{array}{l}\text { Anterior margin of } \\
\text { obturator foramen }\end{array}$ & $\begin{array}{l}\text { Greater trochanter } \\
\text { of femur }\end{array}$ & Obturator & Lateral rotation of femur \\
\hline $\begin{array}{l}\text { Obturator } \\
\text { Internus }\end{array}$ & $\begin{array}{l}\text { Posterior margin of } \\
\text { obturator foramen }\end{array}$ & $\begin{array}{l}\text { Greater trochanter } \\
\text { of femur }\end{array}$ & Sacral Plexus & $\begin{array}{l}\text { Abduction; lateral } \\
\text { rotation of femur }\end{array}$ \\
\hline Piriformis & $\begin{array}{l}\text { Anterior lateral } \\
\text { aspect of sacroiliac } \\
\text { region }\end{array}$ & $\begin{array}{l}\text { Greater trochanter } \\
\text { of femur }\end{array}$ & $\begin{array}{l}\text { Ventral rami of S1- } \\
\text { S2 }\end{array}$ & $\begin{array}{l}\text { Abduction; lateral } \\
\text { rotation of femur }\end{array}$ \\
\hline $\begin{array}{l}\text { Quadratus } \\
\text { Femoris }\end{array}$ & Ishial tuberosity & $\begin{array}{l}\text { Intertrochanteric } \\
\text { ridge of femur }\end{array}$ & Sacral plexus & $\begin{array}{l}\text { Adduction; lateral } \\
\text { rotation of femur }\end{array}$ \\
\hline $\begin{array}{l}\text { Adductor } \\
\text { Longus/Brevis }\end{array}$ & Pubis & $\begin{array}{l}\text { Posterior shaft of } \\
\text { femur }\end{array}$ & Obturator & $\begin{array}{l}\text { Adduction; lateral } \\
\text { rotation of femur; hip } \\
\text { flexion }\end{array}$ \\
\hline $\begin{array}{l}\text { Adductor } \\
\text { Magnus }\end{array}$ & Ishium & $\begin{array}{l}\text { Posterior shaft of } \\
\text { femur }\end{array}$ & Obturator; Tibial & $\begin{array}{l}\text { Adduction; lateral } \\
\text { rotation of femur; hip } \\
\text { flexion; hip extension }\end{array}$ \\
\hline Gracilis & Pubis & $\begin{array}{l}\text { Medial aspect of } \\
\text { proximal tibia }\end{array}$ & Obturator & $\begin{array}{l}\text { Adduction; knee flexion; } \\
\text { medial rotation of tibia }\end{array}$ \\
\hline Pectineus & Pubis & $\begin{array}{l}\text { Posterior aspect of } \\
\text { proximal femur }\end{array}$ & Fermoral & $\begin{array}{l}\text { Adduction; lateral } \\
\text { rotation of femur }\end{array}$ \\
\hline
\end{tabular}


Table B2. Muscles of the "Core” 34,35

\begin{tabular}{|c|c|c|c|c|}
\hline Muscle & Origin & Insertion & Innervation & Action \\
\hline $\begin{array}{l}\text { Rectus } \\
\text { Abdominis }\end{array}$ & $\begin{array}{l}\text { Pubic symphisis and } \\
\text { pubic crest }\end{array}$ & $\begin{array}{l}\text { Xiphoid process } \\
\text { and 5th-7th } \\
\text { costal cartilages }\end{array}$ & $\begin{array}{l}\text { Thoracoabdominal } \\
\text { nerves }\end{array}$ & $\begin{array}{l}\text { Flexes trunk and } \\
\text { compresses abdominal } \\
\text { viscera; stabilizes and } \\
\text { controls tilt of pelvis }\end{array}$ \\
\hline $\begin{array}{l}\text { Transverse } \\
\text { abdominal }\end{array}$ & $\begin{array}{l}\text { Internal surfaces of } \\
\text { 7th-12th costal } \\
\text { cartilages, } \\
\text { thoracolumbar fascia, } \\
\text { iliac crest, and lateral } \\
\text { third of inguinal } \\
\text { ligament }\end{array}$ & $\begin{array}{l}\text { Linea alba with } \\
\text { aponeurosis of } \\
\text { internal oblique, } \\
\text { pubic crest, and } \\
\text { pecten pubis via } \\
\text { conjoint tendon }\end{array}$ & $\begin{array}{l}\text { Thoracoabdominal } \\
\text { nerves and first } \\
\text { lumbar nerves }\end{array}$ & $\begin{array}{l}\text { Compresses and } \\
\text { supports abdominal } \\
\text { viscera }\end{array}$ \\
\hline Internal oblique & $\begin{array}{l}\text { Thoracolumbar } \\
\text { fascia, anterior two- } \\
\text { thirds of iliac crest, } \\
\text { and lateral half of } \\
\text { inguinal ligament }\end{array}$ & $\begin{array}{l}\text { Inferior borders } \\
\text { of 10th-12th } \\
\text { ribs, linea alba, } \\
\text { and pecten pubis } \\
\text { via conjoint } \\
\text { tendon }\end{array}$ & $\begin{array}{l}\text { Thoracoabdominal } \\
\text { nerves and first } \\
\text { lumbar nerves }\end{array}$ & $\begin{array}{l}\text { Compress and support } \\
\text { abdominal viscera, flex } \\
\text { and rotate trunk }\end{array}$ \\
\hline External oblique & $\begin{array}{l}\text { External surfaces of } \\
\text { 5th-12th ribs }\end{array}$ & $\begin{array}{l}\text { Linea alba, } \\
\text { pubic tubercle, } \\
\text { and anterior half } \\
\text { of iliac crest }\end{array}$ & $\begin{array}{l}\text { Thoracoabdominal } \\
\text { nerves and subcostal } \\
\text { nerve }\end{array}$ & \\
\hline $\begin{array}{l}\text { Erector spinae: } \\
\text { Iliocostalis, } \\
\text { Longissimus, } \\
\text { Spinalis }\end{array}$ & $\begin{array}{l}\text { Arises by a broad } \\
\text { tendon from posterior } \\
\text { part of iliac crest, } \\
\text { posterior surface of } \\
\text { sacrum, sacroliliac } \\
\text { ligaments, sacral and } \\
\text { inferior lumbar } \\
\text { spinous processes, } \\
\text { and supraspinous } \\
\text { ligament }\end{array}$ & $\begin{array}{l}\text { Iliocostalis: } \\
\text { lumborum, } \\
\text { thoracis, cervicis } \\
\text { Longissimus: } \\
\text { thoracis, } \\
\text { cervicis, capitis } \\
\text { Spinalis: } \\
\text { thoracis, } \\
\text { cervicis, capitis. }\end{array}$ & $\begin{array}{l}\text { Posterior rami of } \\
\text { spinal nerves }\end{array}$ & $\begin{array}{l}\text { Bilaterally: extend } \\
\text { vertebral column and } \\
\text { head; as back is flexed, } \\
\text { control movement by } \\
\text { gradually lengthening } \\
\text { fibers Unilaterally: } \\
\text { laterally flex vertebral } \\
\text { column }\end{array}$ \\
\hline Multifidus & $\begin{array}{l}\text { Multifidus: posterior } \\
\text { sacrum, posterior } \\
\text { superior iliac spine of } \\
\text { ilium, aponeurosis of } \\
\text { erector spinae, } \\
\text { sacroiliac ligaments, } \\
\text { mammillary } \\
\text { processes of lumbar } \\
\text { vertebrae, transverse } \\
\text { processes of T1-T3, } \\
\text { articular processes of } \\
\text { C4-C7 }\end{array}$ & $\begin{array}{l}\text { Spinous } \\
\text { processes of } \\
\text { more superior } \\
\text { vertebrae }\end{array}$ & $\begin{array}{l}\text { Posterior rami of } \\
\text { spinal nerves }\end{array}$ & Extension \\
\hline Psoas Major & $\begin{array}{l}\text { Vertebral bodies } \\
\text { T12-L5 }\end{array}$ & $\begin{array}{l}\text { Lesser } \\
\text { trochanter of } \\
\text { femur }\end{array}$ & Lumbar plexus & $\begin{array}{l}\text { Hip flexion; medial } \\
\text { rotation of femur }\end{array}$ \\
\hline
\end{tabular}




\begin{tabular}{|c|c|c|c|c|}
\hline $\begin{array}{l}\text { Quadratus } \\
\text { lumborum }\end{array}$ & $\begin{array}{l}\text { Medial half of } \\
\text { inferior border of } \\
\text { 12th ribs and tips of } \\
\text { lumbar trensverse } \\
\text { processes }\end{array}$ & $\begin{array}{l}\text { Iliolumbar } \\
\text { ligament and } \\
\text { internal lip of } \\
\text { iliac crest }\end{array}$ & $\begin{array}{l}\text { Anterior branches of } \\
\text { T12 and L4 }\end{array}$ & $\begin{array}{l}\text { Extends and laterally } \\
\text { flexes vertebral column }\end{array}$ \\
\hline
\end{tabular}

Knee joint: The knee joint is comprised of the tibiofemoral joints and the patellafemoral joints. The femur, the longest and heaviest bone of the body, transmits body weight from the hip to the tibia in standing position. ${ }^{47}$ The tibia, along with the fibula, completes the leg. The articulation of the tibia with the femur forms the tibiofemoral joint. Weight transmission also occurs through the tibia, while the fibula remains a non-weight bearing bone. ${ }^{49}$ The patella sits in a groove formed by the femur for the patellafemoral joint. The complete knee joint is a synovial hinge joint allowing for knee flexion and extension. Overall, the knee joint is relatively weak because of the incongruence of the articular surfaces. ${ }^{47-49}$ Stability of the knee joint relies on the strength and actions of the surrounding muscles, tendons and ligamentous support. The joint capsule of the knee is typical in consisting of an external fibrous layer and an internal synovial membrane. ${ }^{48}$ The quadriceps tendon, patella, and patellar ligament replace the fibrous layer anteriorly. Five ligaments strengthen the joint capsule consisting of the patellar ligament, fibular collateral ligament, tibial collateral ligament, oblique popliteal ligament, and arcuate popliteal ligament. The intra-articular ligaments of the knee are the cruciate ligaments and menisci. ${ }^{47-49}$ The cruciate ligaments are the anterior cruciate ligament and the posterior cruciate ligament. The anterior cruciate ligament limits posterior rolling of the femoral condyle on the tibial plateau during flexion. ${ }^{47-49}$ The posterior cruciate ligament limits anterior rolling of the femur on the tibial plateau during extension. The menisci of the knee are fibrocartilage on the articular surface of the tibia, which serve to deepen the surface and provide shock absorption. ${ }^{47-49}$ The ligaments of the knee joint are further outlined in Table B3 including distal and posterior attachment. 
Table B3. Ligaments of the Knee. ${ }^{47-49}$

\begin{tabular}{lll}
\hline Ligament & Distal Attachment & Proximal Attachment \\
\hline Patellar & Quadriceps tendon & Tibial tuberosity \\
Fibular Collateral & Lateral epicondyle of femur & Lateral surface of fibular head \\
Tibial Collateral & Medial epicondyle of femur & Medial surface of tibia \\
Oblique Popliteal & Semimembranosus tendon & Intracondylar fossa \\
Arcuate Popliteal & Posterior aspect of fibular head Posterior surface of knee joint \\
Anterior Cruciate & $\begin{array}{l}\text { Anterior intercondylar area of } \\
\text { tibia }\end{array}$ & Posterior part of medial side of lateral femoral condyle \\
Posterior Cruciate & $\begin{array}{l}\text { Posteror intercondylar area of } \\
\text { tibia }\end{array}$ & Anterior part of the lateral surface of medial femoral condyle \\
\hline
\end{tabular}

The muscles that act on the knee can be separated into anterior, lateral and posterior. The anterior compartment of the thigh consists of the sartorius muscle and quadriceps muscle group. The muscles of the quadriceps are the rectus femoris, vastus lateralis, vastus medialis, and vastus intermedius muscles. ${ }^{47-49}$ The muscles of the quadriceps femoris converge into the single quadriceps tendon. The tendon continues distally over the patella where it becomes the patellar ligament, which inserts on the tibial tuberosity. The posterior thigh contains the hamstring muscle group. The hamstrings are made up of the biceps femoris, semimembrinosus and semitendinosus. The popliteus muscle is also posterior. ${ }^{48}$ The fascia latae is a fibrous sheath that encircles the thigh and combines with the gluteus maximus to form the iliotibial band. The iliotibial band begins at the iliac crest and extends to the lateral condyle of the tibia. Distally, the iliotibial band spans out and inserts on the lateral border of the patella, the lateral retinaculum, and Gerdy's tubercle of the tibia. The pes anserine insertion is located medial and slightly distal to the tibial tuberosity. ${ }^{47-49}$ The pes anserine is the common aponeurosis of the semitendinosus, sartorius, and gracilis muscles. ${ }^{47-49}$ The muscles acting on the knee are found in Table B3, including origin, insertion, innervation and action. 
The nerve supply to the muscles acting on the knee starts as roots from the lumbar and sacral plexus. ${ }^{47-49}$ The femoral nerve originates from the posterior divisions of nerve roots L2, L3, and L4. The sacral plexus branches from the lumbar and the sciatic nerve, which divides into the tibial and common peroneal nerve. ${ }^{47-49}$ The tibial nerve is an anterior division of L4, L5, S1-S3. The common peroneal nerve comes from posterior divisions of L4, L5, S1, and S2. ${ }^{47-49}$ Refer to Table B4 for specific neural innervations.

The arterial supply to the muscles acting on the knee originates from several branches of the external iliac artery. ${ }^{47-49}$ The deep femoral artery supplies the hamstring muscles, while the circumflex femoral artery supplies both the hamstring muscles and the femur itself. The femoral artery provides circulation to the quadriceps femoris muscles and the sartorius. The popliteal artery supplies the popliteus muscle. ${ }^{47-49}$

The venous drainage of the muscles acting on the knee is similar to the arterial supply. ${ }^{47-49}$ The venous drainage of knee and thigh region comes from a combination of deep and superficial veins. The drainage begins at the toes and continues proximal, following the flow of blood to the inferior vena cava. Of the nine deep and three superficial veins in the lower extremity, the popliteal vein, femoral vein, and the great and small saphenous veins are of importance in this area. ${ }^{47-49}$ Table B4. Muscles Acting on the Knee. ${ }^{47-49}$

\begin{tabular}{|c|c|c|c|c|}
\hline Muscle & Origin & Insertion & Nerve & Action \\
\hline Rectus femoris & $\begin{array}{l}\text { Anterior inferior iliac } \\
\text { spine }\end{array}$ & Tibial tuberosity & Femoral & Knee extension; hip flexion \\
\hline Vastus lateralis & $\begin{array}{l}\text { Posteriolateral shaft } \\
\text { of femur }\end{array}$ & Tibial tuberosity & Femoral & Knee extension \\
\hline Vastus medialis & Linea aspera of femur & Tibial Tuberosity & Femoral & Knee extension \\
\hline Vastus Intermedius & $\begin{array}{l}\text { Anterior shaft of } \\
\text { femur }\end{array}$ & Tibial Tuberosity & Femoral & Knee extension \\
\hline Satorius & $\begin{array}{l}\text { Anterior superior } \\
\text { spine of ilium }\end{array}$ & $\begin{array}{l}\text { Medial aspect of } \\
\text { Tibial tuberosity }\end{array}$ & Femoral & $\begin{array}{l}\text { Hip flexion; medial rotation } \\
\text { of femur; lateral rotation of } \\
\text { tibia }\end{array}$ \\
\hline
\end{tabular}




\begin{tabular}{|c|c|c|c|c|}
\hline Biceps femoris & $\begin{array}{l}\text { Long head: ishial } \\
\text { tuberosity Short head: } \\
\text { posterior midshaft of } \\
\text { femur }\end{array}$ & Head of fibula & \multicolumn{2}{|c|}{$\begin{array}{l}\text { Long Head: Tibial Short Knee flexion; hip extension; } \\
\text { head: common peroneal lateral rotation of tibia }\end{array}$} \\
\hline Semimembranosus & Ishial tuberosity & $\begin{array}{l}\text { Medial condyle of } \\
\text { tibia; collateral } \\
\text { ligament of knee }\end{array}$ & Tibial & $\begin{array}{l}\text { Knee flexion; hip extension; } \\
\text { medial rotation of tibia }\end{array}$ \\
\hline Semitendinosus & Ishial tuberosity & Tibial Tuberosity & Tibial & $\begin{array}{l}\text { Knee flexion; hip extension; } \\
\text { medial rotation of tibia }\end{array}$ \\
\hline Popliteus & $\begin{array}{l}\text { Lateral condyle of } \\
\text { femur }\end{array}$ & $\begin{array}{l}\text { Posterior proximal } \\
\text { tibia }\end{array}$ & Tibial & $\begin{array}{l}\text { Knee flexion; medial rotation } \\
\text { of tibia }\end{array}$ \\
\hline
\end{tabular}

Ankle joint: The ankle joint is comprised of two important structures, the subtalar joint and the talocrural joint. ${ }^{30,47}$ The subtalar joint is a synovial plane joint consisting of the inferior talus and the superior calcaneus. The medial, lateral, posterior and interosseus talocalcaneal ligaments support a weak joint capsule. ${ }^{49}$ The talocrural joint of the ankle is described as the true ankle mortise. This joint is developed by the articulations of the distal and medial aspects of the tibia and fibula and the dome of the talus. ${ }^{47-49}$

The ligaments of the ankle can be divided into three groups including the medial, lateral, and syndesmotic. ${ }^{30,37-39}$ The calcaneofibular ligament and the anterior and posterior talofibular ligaments reinforce the lateral aspect of the ankle joint. Medially, the joint capsule is provided with much stronger support than laterally, with the deltoid ligament. The deltoid ligament complex contains the tibionavicular, tibiocalcaneal, and the anterior and posterior tibiotalar parts of the ligament. ${ }^{30,47-49}$ The ligaments of the ankle joint are outlined below in Table B5 including distal and proximal attachment and function.

Table B5. Ligaments of the Ankle Joint. ${ }^{47-49}$

\begin{tabular}{llll}
\hline Ligament & Distal Attachment & Proximal Attachment & Function \\
\hline $\begin{array}{l}\text { Anterior } \\
\text { Talofibular }\end{array}$ & Neck of talus & Lateral malleolus & $\begin{array}{l}\text { Primary restrain againt plantarflexion; internal } \\
\text { rotation of foot, inverion }\end{array}$ \\
Calcaneofibular & $\begin{array}{l}\text { Lateral surface of } \\
\text { calcaneus }\end{array}$ & Tip of lateral malleolus & Prevents inversion
\end{tabular}




$\begin{array}{llll}\begin{array}{l}\text { Posterior } \\ \text { Talofibular }\end{array} & \begin{array}{l}\text { Lateral tubercle of } \\ \text { talus }\end{array} & \text { Lateral malleolar fossa } & \text { Prevents inversion } \\ \begin{array}{l}\text { Lateral } \\ \text { Talocalcaneal }\end{array} & \begin{array}{l}\text { Posterolateral } \\ \text { calcaneus }\end{array} & \text { Posterolateral talus } & \text { Prevents excessive inversion and supination } \\ \text { Cervical } & \begin{array}{l}\text { Cervical tubercle of } \\ \text { calcaneus }\end{array} & \text { Neck of talus } & \text { Assists in prevention of inversion } \\ \begin{array}{l}\text { Anterior } \\ \text { Tibiotalar }\end{array} & \begin{array}{l}\text { Superior posterior } \\ \text { portion of navicular }\end{array} & \text { Inferior medial malleolus } & \text { Precention of eversion } \\ \text { Tibionavicular } & \begin{array}{l}\text { Sustenaculum tali of } \\ \text { calcaneus and } \\ \text { navicular bone }\end{array} & \text { Inferior medial malleolus } & \text { Prevention of eversion } \\ \text { Tibiocalcaneal } & \begin{array}{l}\text { Sustenaculum tali of } \\ \text { calcaneus }\end{array} & \text { Interior medial malleolus } & \text { Prevention of eversion } \\ \text { Posterior } & \begin{array}{l}\text { Medial tubercle of } \\ \text { talus, sustentaculum } \\ \text { tali of calcaneus }\end{array} & \text { Inferior medial malleolus } & \text { Preveion of inversion } \\ & & & \end{array}$

Motion at the subtalar joint is internal and external rotation of the leg, pronation and supination of the foot, and eversion and inversion of the foot. ${ }^{49}$ Several muscles in the anterior, posterior, and medial compartments control inversion and eversion of the ankle. Plantarflexion and dorsiflexion of the ankle joint occur at the talocrural joint. The muscles within the anterior compartment of the leg produce dorsiflexion. The muscles within the posterior compartment of the leg produce plantarflexion. ${ }^{47-49}$ The muscles acting on the ankle joint are outlined in Table B6, with origin and insertion, nerve innervations and muscle actions.

Table B6. Muscles Acting on the Ankle Joint. ${ }^{47-49}$

\begin{tabular}{lllll}
\hline Muscle & Origin & Insertion & Nerve & Action \\
\hline $\begin{array}{l}\text { Extensor } \\
\text { Digitorum } \\
\text { Longus }\end{array}$ & $\begin{array}{l}\text { Lateral condyle of tibia; } \\
\text { shaft of fibula; interosseus } \\
\text { membrane }\end{array}$ & $\begin{array}{l}\text { Middle, distal } \\
\text { phalanges II-V }\end{array}$ & Deep peroneal & $\begin{array}{l}\text { Extends toes II-V; } \\
\text { dorsiflexes, everts foot }\end{array}$ \\
$\begin{array}{l}\text { Extensor } \\
\text { Hallicus Longus }\end{array}$ & $\begin{array}{l}\text { Medial aspect of fibula; } \\
\text { interosseus membrane }\end{array}$ & Distal phalanx I & Deep peroneal & Extends Hallux; dorsiflexes, \\
Peroneus Tertius & Distal shaft of fibula & Metatarsal V & Deep peroneal & Dorsiflexes, everts foot \\
Tibialis Anterior & $\begin{array}{l}\text { Lateral tibia; interosseus } \\
\text { membrane }\end{array}$ & $\begin{array}{l}\text { Medial cuneiform; } \\
\text { metatarsal I }\end{array}$ & Deep peroneal & Dorsiflexes, inverts foot \\
Gastrocnemius & $\begin{array}{l}\text { Medial, lateral epicondyles Calcaneus } \\
\text { of femur }\end{array}$ & Tibial & Knee flexion, plantarflexion \\
& & & foot
\end{tabular}




\begin{tabular}{|c|c|c|c|c|}
\hline Soleus & $\begin{array}{l}\text { Proximal one-third of tibia } \\
\text { and fibula }\end{array}$ & Calcaneus & Tibial & Plantarflexion foot \\
\hline Plantaris & Distal femur & Calcaneus & Tibial & $\begin{array}{l}\text { Knee flexion; plantarflexion } \\
\text { foot }\end{array}$ \\
\hline $\begin{array}{l}\text { Flexor Digitorum } \\
\text { Longus }\end{array}$ & Midshaft of tibia & $\begin{array}{l}\text { Distal phalanges } \\
\text { II-IV }\end{array}$ & Tibial & $\begin{array}{l}\text { Flex toes II-IV; plantarflex, } \\
\text { inversion foot }\end{array}$ \\
\hline $\begin{array}{l}\text { Flexor Hallicus } \\
\text { Longus }\end{array}$ & Shaft of fibula & Distal phalanx I & Tibial & $\begin{array}{l}\text { Flexion of Hallux; plantar } \\
\text { flexion, foot eversion }\end{array}$ \\
\hline Tibialis Posterior & $\begin{array}{l}\text { Proximal half of tibia; } \\
\text { Fibula; interosseus } \\
\text { membrane }\end{array}$ & $\begin{array}{l}\text { Navicular, } \\
\text { cuneiforms, } \\
\text { metatarsals II-IV }\end{array}$ & Tibial & Plantarflexion, foot inversion \\
\hline Peroneus Brevis & Shaft of fibula & $\begin{array}{l}\text { Base of metatarsal } \\
\mathrm{V}\end{array}$ & Superficial peroneal & Plantarflexion, foot eversion \\
\hline Peroneus Longus & $\begin{array}{l}\text { Proximal half of tibia; } \\
\text { lateral condyle of tibia }\end{array}$ & $\begin{array}{l}\text { Medial cuneiform; } \\
\text { metatarsal I }\end{array}$ & Superficial peroneal & Plantarflexion, foot eversion \\
\hline
\end{tabular}

Several nerves provide innervations to the muscles acting on the ankle joint. The superficial and deep peroneal nerve as well as the tibial nerve supplies the muscles of inversion and eversion. ${ }^{47-49}$ The tibial nerve supplies the muscles of the posterior compartment of the leg, which is a posterior division of the sacral plexus. The arterial supply to the subtalar joint comes from the posterior tibial and fibular arteries. ${ }^{47-49}$ The posterior tibial and fibular veins supply the venous drainage. Arterial supply to the posterior compartment comes from the posterior tibial and fibular arteries. The venous drainage is supplied by the posterior tibial and fibular veins, as well as the small saphenous vein. ${ }^{47-49}$

Biomechanics

Activities such as kicking, running, and cutting are typical in the game of soccer. The kinematics and kinetics for the specific motions are described below. Kinematics is a term that describes human movement of the kinetic chain, type of motion, location, magnitude and direction. $^{52}$ The joints of the lower extremity, from distal to proximal, develop a kinetic chain. The kinetic chain is of great importance because motion and forces at one joint will cause motion and 
force at an adjacent joint..$^{54,55,56}$ Therefore, when a soccer player is kicking the ball motion will occur at all joints of the lower extremity. ${ }^{57}$ This is similar to misalignment of one joint can cause compensation resulting in injury at an adjacent joint. Kinetics are the forces being analyzed, the forces that cause joint action. The lower extremity encounters many forces as it serves to bear and transfer body weight while standing and during the gait cycle. The gait cycle, which will be discussed in detail below, consists of two major phases, the stance and swing phases. ${ }^{36.44}$ The forces placed upon the lower extremity during standing and gait has been well outlined throughout the literature, although kinetics during sport-specific motions is much less discussed.

Kinematics: Kinematics can further be defined as joint range of motion. The hip, being a ball and socket joint, has a great range of motion. ${ }^{11,12,35}$ Motion at the hip can occur in flexion, extension, internal and external rotation, adduction, and abduction. The quantitative range of motion for the joints of the lower extremity are described in Table B7.

Table B7. Range of Motion for the Lower Extremity. ${ }^{35}$

\begin{tabular}{ll}
\hline Motion & ROM \\
\hline Hip Flexion & $110-120$ degrees \\
Hip Extension & $10-15$ degrees \\
Hip Adduction & 30 degrees \\
Hip Abduction & $30-50$ degrees \\
Hip Internal Rotation & $40-60$ degrees \\
Hip External Rotation & 30 -40 degrees \\
Knee Flexion & 135 degrees \\
Knee Extension & 0 - negative 15 degrees \\
Dorsiflexion & 20 degrees \\
Plantarflexion & 50 degrees \\
Inversion & $45-60$ degrees \\
Eversion & $15-30$ degrees \\
\hline
\end{tabular}

Kinetics: The hip is a major weight-bearing joint that is subjected to extremely high loads during sports. ${ }^{54}$ During standing, the weight supported at each hip is one-half the weight of the body proximal to the hip. ${ }^{54-57}$ The total load on each hip in standing is greater than the weight secondary to the tension provided through the strong hip muscles adding further compression. ${ }^{54}$ 
During gait, compression on the hip is the same as body weight during the swing phase, but increases to six times body weight during the stance phase of gait. ${ }^{54-57}$ The knee undergoes similar forces, especially during gait. ${ }^{55}$ The tibiofemoral joint incurs compressive and shear forces. ${ }^{55}$ Weight-bearing and tension development in muscles crossing at the knee contribute to these forces. As knee flexion occurs and the angle of the joint increased to 90 degrees, the shear component of joint force produced by weight-bearing increases. ${ }^{55-58}$ The ligaments and muscular support must resist shear forces. These compressive forces at the knee can reach three times body weight during the stance phase of gait, increasing in force with activity. ${ }^{56}$ The menisci of the knee absorb approximately $45 \%$ of the total load placed upon the knee. ${ }^{49,55}$ Compressive force of the patellofemoral joint is approximately half of body-weight during gait. ${ }^{56,57}$ The joints of the leg are subject to tension, compression, bending and torsion forces. During running, the foot and ankle undergo forces up to three times body-weight. ${ }^{57}$ Approximately half of the body-weight is distributed through the subtalar joint during weight bearing activity. ${ }^{55-59}$

Gait-cycle: The gait cycle begins when one foot contacts the ground and ends when that foot contacts the ground again. ${ }^{54}$ Thus, each cycle begins at initial contact with a stance phase and proceeds through a swing phase until the cycle ends with the limb's next initial contact. ${ }^{54.55}$ There are 2 components of the Gait Cycle. The first component is the Stance Phase, normally $60 \%$ of the complete gait cycle. ${ }^{54}$ This means the foot is at least partly in contact with the supportive surface. The second component is called the Swing Phase, during this phase the foot is completely airborne..$^{54}$

The Stance phase is divided into five distinct sub-phases; initial contact, load response, mid-stance, terminal stance, and pre-swing. ${ }^{54}$ The initial contact period occurs at heel strike, which accounts for $10 \%$ of the gait cycle. ${ }^{54}$ In this period, one foot is coming off the floor while 
the other foot is accepting body weight and cushioning and shock absorption. At this time the knee flexes immediately prior to the foot hitting the ground and the foot pronates. ${ }^{54,55}$ The end of the contact period is signaled by the instant the forefoot makes contact. The following sub-phases, load response and midstance, begins at foot flat and consists of single-leg support, which accounts for $40 \%$ of the gait cycle. ${ }^{55}$ During this phase, one leg alone carries the body weight while the other leg goes through the swing phase. Mid stance is the time when the foot and leg provide a stable platform for the body weight to pass over. The terminal phase and preswing phase make up the weight-unloading period of heel-off and toe-off. These sub-phases account for $10 \%$ of the gait cycle. Propulsion begins immediately as the heel lifts. ${ }^{54}$ As the great toe dorsiflexes the windlass mechanism comes into play, tightening the plantarfascia and helping to raise the arch of the foot. ${ }^{54}$ The beginning of the swing phase of gait is signaled by toe off. The swing phase, $40 \%$ of the gait cycle, is divided into three sub-phases; initial swing, midswing, and terminal swing. ${ }^{54,55,57}$ Acceleration occurs during the initial swing. Rapid knee flexion and ankle dorsiflexion occur to allow the swing limb to accelerate forward. Midswing occurs once the swing leg is adjacent to the weight-bearing leg. The final phase occurs as the swinging leg slows down in preparation for initial contact with the floor. ${ }^{54}$

During running, the stance phase decreases and a float phase is present. The float phase, or double unsupported phase, occurs as the double support phase disappears. ${ }^{54}$ The motion occurring at each of the lower extremity joints is similar for walking and running gait, although running requires an increased range of motion. ${ }^{54} \mathrm{~A}$ summary of joint motions and muscle activity during the stance phase of gait is outlined in Table B8 and the swing phase is outlined in Table B9. 
Table B8. Summary of Joint Motions During the Stance Phase of Gait. ${ }^{36,35,44}$

\begin{tabular}{|c|c|c|c|c|}
\hline \multicolumn{5}{|c|}{ HIP } \\
\hline \multirow[b]{2}{*}{ Phase } & \multirow{2}{*}{\multicolumn{2}{|c|}{ Kinematic Motion }} & Kinetic motion & \\
\hline & & & External forces & Internal forces \\
\hline \multirow[t]{2}{*}{ Heel strike } & \multicolumn{2}{|c|}{$\begin{array}{l}\text { 20-40-degress of hip } \\
\text { flexion moving toward } \\
\text { extension }\end{array}$} & $\begin{array}{l}\text { Reaction force in front of } \\
\text { joint; flexion moment } \\
\text { moving toward extension; } \\
\text { forward pelvic rotation }\end{array}$ & $\begin{array}{l}\text { Gluteus maximus and } \\
\text { hamstrings working } \\
\text { eccentrically to resist flexion } \\
\text { moment }\end{array}$ \\
\hline & \multicolumn{2}{|c|}{$\begin{array}{l}\text { Slight adduction and lateral } \\
\text { rotation }\end{array}$} & & $\begin{array}{l}\text { Erector spinae working } \\
\text { eccentrically to resist } \\
\text { forward bend }\end{array}$ \\
\hline \multirow[t]{2}{*}{ Foot flat } & \multirow{2}{*}{\multicolumn{2}{|c|}{$\begin{array}{l}\text { Hip moving into extension, } \\
\text { adduction, medial rotation }\end{array}$}} & Flexion moment & $\begin{array}{l}\text { Gluteus maximus and } \\
\text { hamstrings contracting } \\
\text { concentrically to bring hip } \\
\text { into extension }\end{array}$ \\
\hline & & & & $\begin{array}{l}\text { Erector spinae resisting } \\
\text { trunk flexion }\end{array}$ \\
\hline \multirow[t]{2}{*}{ Midstance } & \multirow{2}{*}{\multicolumn{2}{|c|}{$\begin{array}{l}\text { Moving through neutral } \\
\text { position } \\
\text { Pelvis rotating posteriorly }\end{array}$}} & $\begin{array}{l}\text { Reaction force posterior to } \\
\text { hip joint; extension moment }\end{array}$ & $\begin{array}{l}\text { Iliopsoas working } \\
\text { eccentrically to resist } \\
\text { extension }\end{array}$ \\
\hline & & & & $\begin{array}{l}\text { Gluteus medius contacting in } \\
\text { reverse action to stabilize } \\
\text { opposite pelvis }\end{array}$ \\
\hline Heel off & \multicolumn{2}{|c|}{$\begin{array}{l}10-15 \text {-degress extension of } \\
\text { hip abduction, lateral } \\
\text { rotation }\end{array}$} & $\begin{array}{l}\text { Extension moment } \\
\text { decreasing after double-limb } \\
\text { support begins }\end{array}$ & Iliopsoas activity continuing \\
\hline \multirow[t]{3}{*}{ Toe off } & \multirow{2}{*}{\multicolumn{2}{|c|}{$\begin{array}{l}\text { Moving toward } 10 \text {-degrees } \\
\text { extension, abduction, lateral } \\
\text { rotation }\end{array}$}} & $\begin{array}{l}\text { Decrease of extension } \\
\text { moment }\end{array}$ & $\begin{array}{l}\text { Adductor magnus working } \\
\text { eccentrically to control or } \\
\text { stabilize pelvis }\end{array}$ \\
\hline & & & & Iliopsoas activity continuing \\
\hline & \multicolumn{2}{|c|}{$\begin{array}{r}\text { KNEE } \\
\text { Kinematic Motion }\end{array}$} & Kinetic motion & \\
\hline Phase & Knee & Tibia & External forces & Internal forces \\
\hline Heel strike & $\begin{array}{l}\text { In full } \\
\text { extension } \\
\text { before heel } \\
\text { contact; } \\
\text { flexing as } \\
\text { heel strikes } \\
\text { floor }\end{array}$ & $\begin{array}{l}\text { Slight } \\
\text { lateral } \\
\text { rotation }\end{array}$ & $\begin{array}{l}\text { Rapidly increasing reaction } \\
\text { forces behind knee joint } \\
\text { causing flexion moment }\end{array}$ & $\begin{array}{l}\text { Quadriceps femoris } \\
\text { contracting eccentriacally to } \\
\text { control rapid knee flexion } \\
\text { and to prevent buckling }\end{array}$ \\
\hline
\end{tabular}




\begin{tabular}{|c|c|c|c|c|}
\hline Foot flat & $\begin{array}{l}\text { In } 20 \\
\text { degrees } \\
\text { flexion } \\
\text { moving } \\
\text { toward } \\
\text { extension }\end{array}$ & $\begin{array}{l}\text { Medial } \\
\text { rotation }\end{array}$ & Flexion moment & $\begin{array}{l}\text { After foot is flat, quadriceps } \\
\text { femoris activity becoming } \\
\text { concentric to bring femur } \\
\text { over tibia. }\end{array}$ \\
\hline Midstance & $\begin{array}{l}\text { In } 15 \\
\text { degrees } \\
\text { flexion } \\
\text { moving } \\
\text { toward } \\
\text { extension }\end{array}$ & Neutral & Maximum flexion moment & $\begin{array}{l}\text { Quadriceps femoris activity } \\
\text { decreasing; gastrocnemius } \\
\text { working eccentrically to } \\
\text { control excessive knee } \\
\text { extension }\end{array}$ \\
\hline Heel off & $\begin{array}{l}\text { In } 4 \\
\text { degrees } \\
\text { flexion } \\
\text { moving } \\
\text { toward } \\
\text { extension }\end{array}$ & $\begin{array}{l}\text { Lateral } \\
\text { rotation }\end{array}$ & $\begin{array}{l}\text { Reaction forces moving } \\
\text { anterior to joint; extension } \\
\text { moment }\end{array}$ & $\begin{array}{l}\text { Gastrocnemius beginning to } \\
\text { work concentrically to start } \\
\text { knee flexion }\end{array}$ \\
\hline Toe off & $\begin{array}{l}\text { Moving } \\
\text { from near } \\
\text { full } \\
\text { extension } \\
\text { to } 40 \\
\text { degrees } \\
\text { flexion }\end{array}$ & $\begin{array}{l}\text { Lateral } \\
\text { rotation }\end{array}$ & $\begin{array}{l}\text { Reaction forces moving } \\
\text { posterior to joint as knee } \\
\text { flexes; flexion moment }\end{array}$ & $\begin{array}{l}\text { Quadriceps femoris } \\
\text { contracting eccentrically }\end{array}$ \\
\hline
\end{tabular}

FOOT/ ANKLE

Kinematic Motion Kinetic motion
Phase

Heel strike

Foot flat

Midstance

Heel off

\begin{tabular}{|c|c|c|c|c|}
\hline Foot flat & $\begin{array}{l}\text { Pronation, } \\
\text { adapting to } \\
\text { support surface }\end{array}$ & $\begin{array}{l}\text { Plantar } \\
\text { flexion to } \\
\text { dorsiflexion } \\
\text { over a fixed } \\
\text { foot }\end{array}$ & $\begin{array}{l}\text { Maximum plantar flexion } \\
\text { moment; reaction forces } \\
\text { beginning to shift anterior, } \\
\text { producing a dorsiflexion } \\
\text { moment }\end{array}$ & $\begin{array}{l}\text { Dorsiflexion activity } \\
\text { decreasing tibialis posterior, } \\
\text { flexor hallucis longus, and } \\
\text { flexor digitorum longus } \\
\text { working eccentrically to } \\
\text { control pronation }\end{array}$ \\
\hline Midstance & Neutral & $\begin{array}{l}\text { 3-degrees } \\
\text { of } \\
\text { dorsiflexion }\end{array}$ & Slight dorsiflexion moment & $\begin{array}{l}\text { Plantar flexor muscles } \\
\text { activated to control } \\
\text { dorsiflexion of the tibia and } \\
\text { fibula over a fixed foot, } \\
\text { contracting eccentrically }\end{array}$ \\
\hline Heel off & $\begin{array}{l}\text { Supination as } \\
\text { foot becomes } \\
\text { rigid for push- } \\
\text { off }\end{array}$ & $\begin{array}{l}\text { 15-degrees } \\
\text { dorsiflexion } \\
\text { toward } \\
\text { plantar } \\
\text { flexion }\end{array}$ & $\begin{array}{l}\text { Maximal dorsiflexion } \\
\text { moment }\end{array}$ & $\begin{array}{l}\text { Plantar flexor muscles } \\
\text { beginning to contact } \\
\text { concentrically to prepare for } \\
\text { push-off }\end{array}$ \\
\hline
\end{tabular}

Kinetic motion

\begin{tabular}{llll}
\hline Foot & Ankle & External forces & Internal forces \\
$\begin{array}{lll}\text { Supination at } \\
\text { heel strike }\end{array}$ & $\begin{array}{l}\text { Moving } \\
\text { into plantar } \\
\text { flexion }\end{array}$ & $\begin{array}{l}\text { Reaction forces behind joint } \\
\text { axis; plantar flexion } \\
\text { moment at heel strike }\end{array}$ & $\begin{array}{l}\text { Dorsiflexors contracting } \\
\text { eccentrically to slow plantar } \\
\text { flexion }\end{array}$
\end{tabular}


Toe off

Supination

20-degrees Dorsiflexion moment
plantar

lantar flexor muscles at

flexion peak activity but becoming inactive as foot leaves ground

Table B9. Summary of Joint Motion and Forces during Swing Phase. 35,36,44

\begin{tabular}{|c|c|c|c|c|}
\hline & \multicolumn{2}{|c|}{ Acceleration to Midswing } & \multicolumn{2}{|l|}{$\begin{array}{l}\text { Midswing to } \\
\text { Deceleration }\end{array}$} \\
\hline Joint & $\begin{array}{l}\text { Kinematic } \\
\text { Motion }\end{array}$ & Kinetic Motion & Kinematic Motion & Kinetic Motion \\
\hline Hip & $\begin{array}{l}\text { Slight flexion } \\
\text { (0-degrees to } \\
\text { 15-degrees) } \\
\text { moving to 30- } \\
\text { degrees flexion } \\
\text { and lateral } \\
\text { rotation to } \\
\text { neutral }\end{array}$ & $\begin{array}{l}\text { Hip flexors } \\
\text { working } \\
\text { concentrically to } \\
\text { bring limb } \\
\text { through; } \\
\text { contalateral } \\
\text { gluteus medius } \\
\text { concentrically } \\
\text { contracting to } \\
\text { maintain pelvis } \\
\text { position }\end{array}$ & $\begin{array}{l}\text { Continued flexion at } \\
\text { about 30-degrees to } \\
\text { 40-degrees }\end{array}$ & $\begin{array}{l}\text { Gluteus maximus contacting } \\
\text { eccentrically to slow hip } \\
\text { flexion }\end{array}$ \\
\hline Knee & $\begin{array}{l}\text { 30-60-degrees } \\
\text { knee flexion } \\
\text { and lateral } \\
\text { rotation of tibia } \\
\text { moving toward } \\
\text { neutral }\end{array}$ & $\begin{array}{l}\text { Hamstrings } \\
\text { concentrically } \\
\text { contracting }\end{array}$ & $\begin{array}{l}\text { Moving to near full } \\
\text { extension and slight } \\
\text { lateral tibial rotation }\end{array}$ & $\begin{array}{l}\text { Quadriceps femoris } \\
\text { contracting concentrically } \\
\text { and hamstrings contracting } \\
\text { eccentrically }\end{array}$ \\
\hline Ankle and foot & $\begin{array}{l}\text { 20-degrees } \\
\text { dorsiflexion } \\
\text { and slight } \\
\text { pronation }\end{array}$ & $\begin{array}{l}\text { Dorsiflexors } \\
\text { contracting } \\
\text { concentrically }\end{array}$ & $\begin{array}{l}\text { Ankle in neutral; foot } \\
\text { in slight supination }\end{array}$ & $\begin{array}{l}\text { Dorsiflexors contracting } \\
\text { isometrically }\end{array}$ \\
\hline
\end{tabular}

Lateral Motion: Lateral motion places great demand on the lower extremity and places the athlete at an increased risk of injury. During sidestepping and cutting the knee undergoes combined moments of flexion, valgus, and internal rotation and flexion, varus, and external rotation position putting strain on the ligaments of the knee. ${ }^{55-57}$ As the angles of motion increase so does the forces applied onto the body ${ }^{55}$ External flexion loads placed on the lower extremity during lateral movements are similar to that of running. External varus/valgus forces and internal/external forces are dramatically increased during lateral movements compared to straightforward running. Besier ${ }^{56}$ has quantified the forces applied to the knee during lateral movements versus running. The results of the study showed the load placed on the knee at peak push off was equivalent to $150 \mathrm{Nm}$ for a $75-\mathrm{kg}$ person. ${ }^{56}$ Increased flexion loads are placed on the 
knee during the peak push off for sidestepping and cutting at a 30-degree angle. ${ }^{56}$ Significant difference in forces was found for varus and valgus forces between movements. During sidestepping at 60 degrees, the knee undergoes up to six times more valgus force than during straightforward running, while the varus load is two times greater than running. ${ }^{55-58}$ Sidestepping produced up to four times more internal rotation loading than external rotation loading experienced with running. ${ }^{58,59}$

Research has begun to evaluate the anticipation of movement on the forces applied to the lower extremity, although unplanned movement resembles more the movements that occur during a game. ${ }^{55-57}$ The central nervous system is responsible for controlling muscle activation in these movement planes. The central nervous system has the ability to adjust muscle activation to oppose the force placed onto the joints when a movement or motion is pre-planned. ${ }^{47-49,55-57}$ This action of the CNS is defined as selected activation, where specific muscles are activated to best counter the forces. During un-planned motion, the central nervous system is unable to process the need for muscle activation in time, greatly increasing the forces applied to the joints. ${ }^{56,57}$ This action of the CNS is defined as generalized co-contraction. It is hypothesized that the lack of appropriate postural adjustments is responsible for the increase in joint loads. ${ }^{56}$ Besier $^{57}$ performed a study to determine muscle activation during planned and unplanned cutting. The results show that muscle activation during unanticipated movements only increases $10-20 \% .^{57}$

Kicking: Of all activities, kicking is the most important aspect of the game. On average, during a 90-minute game of soccer, a player has 51 ball contacts. ${ }^{58-60}$ The side-foot kick and the instep kick are two main techniques used for kicking. ${ }^{52,60,61}$ A player using the side-foot kick strikes the ball with the medial aspect of the mid-foot, while the ball is kicked with the dorsum of the foot for an instep kick. ${ }^{60,61}$ 
The stages of kicking are divided into six events: 1) approach angle; 2) plant foot forces; 3) swing limb loading; 4) flexion at the hip and extension at the knee; 5) foot contact with the ball; and 6) follow-through. ${ }^{60}$ The initiation of forward movement begins with the kicking limb knee flexed and the kicking foot at approximately hip height. Swing limb motion and foot placement during the loading phase, before hip flexion and extension at the knee, is a function of age, skill, ability, and the kicker's distance and path to the ball. ${ }^{60,61}$ As the plant foot strikes the ground adjacent to the ball, the swing limb is concurrently involved in hip extension and knee flexion. During “loading” of the swing limb the kicker’s eyes are focused on the ball and not the direction the ball will travel because ball direction is dictated by the support foot position, and ultimately hip position at ball contact. ${ }^{60,61}$ The "loading" of the swing limb allows the hip flexors and the knee extensors to be eccentrically loaded in preparation for the forward movement of the limb into position to strike the ball. ${ }^{60,61}$ As the hip flexors forcefully contract to swing the thigh forward and downward, the leg and foot rotate as a unit. As thigh angular velocity decreases, the leg and foot begin to accelerate due to a momentum shift and support from elastic and contractile components in the knee extensors. ${ }^{60,61}$ The sequential segmental motion and concomitant decrease in angular velocity of the proximal segment while the distal segment increases, is thought to play a critical role in kicking. During follow-though, there is concentric hip flexor activity followed by eccentric activity of the hip extensors. ${ }^{61}$ Epidemiology

Incidence of injury in professional soccer is high, with injury reports for competition presenting rates of up to 67 per 1000 player-hours. ${ }^{3}$ Most soccer related injuries occur to the lower extremity, with an average of $76 \%-87 \%$ of total injury rates. ${ }^{1-7}$ Average severity of injuries ranges from 15 to 24 days, ${ }^{1}$ and recurrences account for $7-25 \%$ of injuries. ${ }^{1,3,4}$ 
The most common injures are muscle strains and ligament sprains. Hawkins and Fuller ${ }^{3}$ examined injuries in four English professional football clubs over two competitive seasons. The overall injury frequency rate was 8.5 injuries/1000 hours. ${ }^{3}$ Strains (37\% match, 53\% training) and sprains ( $21 \%$ match, $18 \%$ training) accounted for the greatest injuries. ${ }^{3}$ Hawkins further studied the injuries sustained in English professional football. ${ }^{4}$ Over two seasons, 6030 injuries were reported, with an average of 1.3 injuries per player per season. ${ }^{4}$ Strains (35\% match, $42 \%$ training) and sprains (20\% match, $18 \%$ training) again accounted for the most common injury. ${ }^{4}$ Nieslen and Yde $^{62}$ found a injury incident rate of $18.5 / 1000$ hours in a Danish soccer club. Within the NCAA, injury rate was four times higher in matches than training (18.75 match, 4.34 training/1000 hours) with approximately two-thirds of all injuries occurring to the lower extremity. ${ }^{2}$ During the 2006 FIFA World Cup Germany 145 injuries were reported resulting in an injury rate of 68.7/1000 hours. ${ }^{7}$ The UEFA Champions League incurred 658 injuries during the 2001-2002 season. ${ }^{63}$ The match injury rate was 30.5/1000 hours verses 5.8/1000 training hours. ${ }^{63}$ Hamstring injuries are accounted for 12\% of the total injuries in English professional football over two seasons. ${ }^{64}$ Dadebo ${ }^{8}$ found forwards are at greatest risk of hamstring strain. The incidence ratio of hamstring strain in the playing positions was 16:1 for forwards, 12:1 for defenders, $11: 1$ for midfielders and goalkeepers were at very low risk with three out of 122. About two thirds of hamstring strain occurred during matches compared with training. Similarly two thirds of injury occurred late during activity. ${ }^{8}$

Etiology

Mechanism of injury within soccer can be divided into two categories - direct contact and non-contact in games and practice. Reports show a greater number of game injuries resulting from contact (61-73\%), whereas the majority of practice injuries (27-47\%) result from non-contact injury mechanisms. ${ }^{2,7}$ Hawkins reported the contrary in that fewer injuries were caused by contact 
mechanism than by non-contact mechanics. ${ }^{65}$ Mechanism of injury can then be further categorized as tackled, running, shooting, tackling. Playing actions of receiving a tackle and making a tackle are categorized as having a substantial injury risk, while a goal catch, goal punch, kick, shot on goal, and set kick are categorized as a significant injury risk. ${ }^{11}$ Match mechanisms of injury rates are: tackled (20-25\%), running (16-18\%), tackling (12-17\%), shooting (17\%), non-contact (810\%). Training mechanism of injury rates are: running (26-30\%), shooting (17\%), turning (1213\%), tackled (7-10\%), and non-contact (11\%). ${ }^{1-7,64,65}$

The mechanism behind injury is complex and multifactorial. ${ }^{8,9}$ Muscle strength imbalance, 9,10,64 inadequate warm up, ${ }^{8,10,64}$ lack of flexibility, ${ }^{9,10,25,64}$ muscle fatigue, ${ }^{9,10,64,66}$ and previous strain/inadequate rehabilitation ${ }^{2,9,10,12,64,66,67}$ are possible factors producing mechanisms of injury. Studies continue to debate the relationship between stretching and injury. One study did show a positive relationship between stretching and injury when multiple interventions were used. ${ }^{9}$ Forwards, who "take off" more often with sudden bursts of speed, have the highest relative risk. There is a greater than average frequency of injuries during the final 15 minutes of the first half and the final 30 minutes of the second half. ${ }^{65,68}$ No evidence of a greater risk of injury was found when soccer was played on artificial turf compared with natural grass. ${ }^{66}$ The way the season is planned is important with regard to injuries. Ekstrand ${ }^{66}$ studied the relation between training and matches at the professional level and found considerable variation in the number of matches played per season in European professional football leagues. Therefore, top level players are obliged to play many matches especially during the final period of the season, ultimately putting themselves are higher risk of injury due to fatigue. ${ }^{66}$ 


\section{Functional Rehabilitation Components}

Functional rehabilitation bridges the gap between traditional physical therapy and field play. ${ }^{1,20}$ After the athlete regains a solid fitness level following injury, functional rehabilitation provides the athlete with specialized conditioning activities specifically designed for their sport and position. ${ }^{1}$ Traditional rehabilitation programs do not always prepare the athlete for sport activities. ${ }^{13}$ The primary objective of functional rehabilitation is to return the athlete to pre-injury

level of activity. ${ }^{13}$ Resorting deficits in strength, flexibility, and power may not be sufficient to return an athlete to competition, therefore the specificity of training involves matching the neuromuscular and physiological demands to the sport. ${ }^{13}$ The goal of functional rehabilitation is to enhance integrated, multi-dimensional movement that requires acceleration, deceleration and dynamic stabilization. ${ }^{1,13,19,20,24,27-29}$ The objective of functional rehabilitation is to return the athlete to his or her preinjury activity level while minimizing the risk of reinjury. ${ }^{20}$

Functional rehabilitation is designed to restore functional stability, using dynamic mechanism, and sport specific skills. ${ }^{1,20}$ The first objective of a program is to restore functional stability. ${ }^{20}$ Functional stability is the ability to control the translation of the particular joint during dynamic functional activities. Functional stability refers to the integration of both primary and secondary joint stabilizers to permit normal joint kinematics during dynamic activities. It is necessary to restore functional stability prior to activities such as acceleration, deceleration, twisting, and cutting maneuvers. $1,13,19,20,24,27-29$

Strength, flexibility, and range of motion are necessary to restore functional stability along

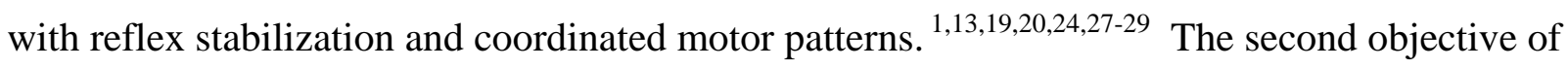
functional rehabilitation and training is to restore sport-specific skills and movement patterns. ${ }^{20}$ Agility and sport-specific activities are included to refine the physiologic and psychological 
parameters necessary to return to preinjury levels of functional performance. Functional rehabilitation achieves this goal with focus on biomechanics by analyzing sport-specific movements and progressing from simple to complex motions. ${ }^{20}$ Dysfunction of the kinetic chain is rarely an isolation event. Functional strength interplay of many muscles about a joint is responsible for the coordinated control of movement. If the core is weak, abnormal arthrokinematics are produced. ${ }^{20,32}$ If one muscle weakens, tightens, or changes its speed of activation the synergists, stabilizers, and neutralizers have to compensate. This compensation, is referred to as Sherrington's Law of Reciprocal Inhibition. ${ }^{20}$

Flexibility: Stretching is traditionally used as part of a warm-up to increase range of motion as well as to reduce the risk of injury. Stretching of muscles is widely incorporated into warm-up and cool-down exercises, training and rehabilitation to increase one’s flexibility. ${ }^{21-23}$ Muscle tightness affects the normal length-tension relationship, which impacts the normal force couple relationship. ${ }^{24}$ Altered arthrokinematics affect the synergistic function of the kinetic chain, which leads to abnormal pressure distribution over articular surfaces and soft tissues. ${ }^{24}$ Muscle tightness also leads to reciprocal inhibition. ${ }^{24}$ Muscle imbalances throughout the lumbopelvic-hip complex can affect the entire kinetic chain. ${ }^{20}$

All stretching techniques are based on the stretch reflex. Muscle contains mechanoreceptors that, when stimulated, inform the central nervous system of what is happening to that muscle. Muscle spindles and the Golgi Tendon Organs are two receptors sensitive to changes in muscle length. ${ }^{53}$ When a muscle is stretched, the muscle spindles send sensory impulses to the spinal cord that inform the central nervous system that a stretch is being placed on the muscle. When the stretch lasts longer than six seconds, the Golgi Tendon Organs respond to the change in length and the increase in tension again by firing sensory impulses to the spinal cord. 
The impulses of the Golgi Tendon Organs cause a reflex relaxation of the antagonist muscle, therefore increasing range of motion. ${ }^{53}$

Flexibility is defined as the ability to move a joint or series of joints smoothly throughout a full range of motion. ${ }^{53}$ Limited flexibility has been shown to predispose an athlete to injury by resulting in uncoordinated or awkward movements. Maintaining normal muscle length requires regular stretching to prevent muscle stiffness, to benefit from the decreased risk of musculoskeletal injury, and for enhanced physical performance. ${ }^{23,41,53}$ Active range of motion, or dynamic flexibility, refers to the degree to which a joint can be moved through mid-range of motion by a muscle contraction. ${ }^{21}$ Passive range of motion, or static flexibility, refers to the degree to which a joint may be passively moved to the endpoints in the range of motion. ${ }^{21}$ Despite the importance of stretching and the common goal of increasing flexibility, much controversy exists as to which stretching technique is the most effective, primarily between static and dynamic techniques.

Several studies have been conducted to determine the most effective parameters of static stretching for duration, frequency, repetitions, daily dose, and length of program. Static stretching is defined as a passive stretch of an antagonist muscle using maximal stretch and holding. ${ }^{21,53,69}$ Dynamic stretching uses the momentum of a body segment to lengthen the muscle. ${ }^{21,53}$ Research suggests dynamic stretching to be disadvantageous because of the activation of the stretch reflex causes the stretching muscle to contact, therefore no increase in range of motion. ${ }^{21}$ Suggested stretching duration varies greatly from 10 s, 15 s, and 30 s to 60 s. Frequencies in the research range from 1 to 3 times per day and up to 5 days a week. ${ }^{69}$ The length of a flexibility program also varies from a single day to 8 weeks, with 6-weeks being the most commonly suggested program length. Chan $^{70}$ conducted a study addressing flexibility and passive resistance of the hamstrings using two different static stretching protocols. The finding of this study indicated that the 
flexibility of the hamstring muscle group can be improved under static stretching within 4-weeks, although the hold time is questionable. Davis ${ }^{69}$ evaluated the effectiveness between three different stretching techniques. The study compared hamstring flexibility using active self-stretch, manual static stretch, and proprioceptive neuromuscular facilitation stretch. The effectiveness of the stretching techniques used depended upon the length of the stretching program. At the 4-week period, all three stretching techniques produced statistically significant improvements to flexibility. ${ }^{69}$ Further results showed that static stretching was the only effective technique for increasing hamstring length when using one 30-second stretch 3 days per week for 4 weeks. ${ }^{70}$ Ferreira $^{71}$ also found gains in flexibility with a regimen of four sets of static stretching held for 30s at six weeks. LaRoche ${ }^{72}$ found an increase in flexibility with both static and dynamic stretching following a 4-week program.

Within the research on flexibility, controversy also exists on the effect stretching has on athletic performance. While some research studies suggested maintaining flexibility can prevent musculoskeletal injuries, other research suggested that stretching can inhibit performance and effect muscle strength, endurance, agility and power. ${ }^{22,23,73}$ Kokkonen ${ }^{74}$ performed a study measuring the effect of static stretching upon exercise performance. All subjects were tested using sit and reach, 20-m sprint, vertical jump, standing long jump, knee extension and knee flexion strength and endurance and $\mathrm{VO}_{2 \text { peak. }}$ Subjects were divided into a non-stretch and stretch group. The results showed that 40 minutes of static stretching three times per week for 10 weeks increased flexibility, strength, endurance, and power in the lower extremity. McMillian ${ }^{41}$ found similar results with an increase in performance with dynamic stretching versus static stretching. Fletcher ${ }^{73}$ also reported similar results with increased sprint performance with dynamic stretching than static stretching. Nelson ${ }^{23}$ performed a study in attempt to show the effect of stretching in 
inhibiting muscle strength endurance performance. The results indicated that there is a possible

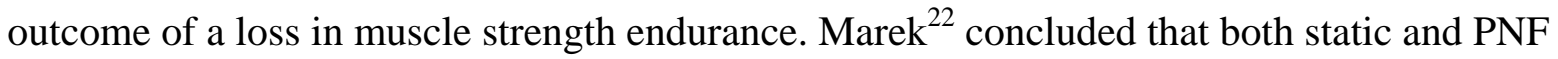
stretching cause small deficits in strength, power and muscle activation. However, Little and Williams ${ }^{24}$ found static stretching to not be detrimental to high speed performance when included in a warm-up for professional soccer players, they suggest dynamic stretching to be most effective as preparation for high-speed performance. In regard to injury, Pope ${ }^{76}$ found no statistically significant effect of static stretching on prevention of injury to the lower-limb while Cross $^{77}$ suggested the incorporation of static stretching does correlate with a decreased rate of lower-limb injury.

Sensorimotor Facilitation: The term sensorimotor facilitation, or proprioception, refers to the cumulative neural input to the central nervous system from the mechanoreceptors in the joint capsules, ligaments, muscle tendons, and skin. ${ }^{30}$ The goal of sensorimotor facilitation is to further increase joint stability. ${ }^{30,42}$ Proprioception is considered a specialized variation of the sensory modality of touch and encompasses the sensations of joint movement and joint position. ${ }^{30}$ Proprioception relates to mechanoreceptive sensation, which encompasses static and dynamic position sense. ${ }^{19,42,78}$ Dynamic joint stability can be defined as the ability of appropriately activated muscles to stabilize a joint together with the support of mechanical stabilizers. ${ }^{42}$ Conscious proprioception is essential for prior joint function in sports. Unconscious proprioception promotes muscles function and initiates reflex stabilization. Initial injury results in partial deafferentation and sensory deficits. ${ }^{19}$ The coupling effect of ligamentous trauma resulting in mechanical instability and proprioception deficits contributes to functional instability, which could ultimately lead to further microtrauma and reinjury. ${ }^{19}$ Methods to improve proprioception after injury or surgery could improve function and decrease the risk of reinjury. Afferent input is altered after 
joint injury and may remain altered after joint reconstruction. ${ }^{19,42}$ Afferent information for finetuning of movements is provided by proprioceptive, visual, vestibular, and somatosensory receptors. ${ }^{42}$ Proprioceptive rehabilitation may allow the patient to retrain altered afferent pathways resulting in enhanced sensation of joint movement. ${ }^{19}$

The assessment of neuromuscular control includes the measurement of cortical, spinal reflex, and brainstem pathways. ${ }^{19,42}$ At the spinal level, reflexes mediate movement patterns that are received from higher levels of the central nervous system. This action provides for reflex joint stabilization during conditions of abnormal stress about the articulation and has significant implication for rehabilitation. ${ }^{19}$ The muscle spindles play a major role in the control of muscular movement by adjusting activity in the lower motor neurons. Partial deafferentation of joint afferent receptors has also been suggested to alter the musculature's ability to provide co-contraction joint stabilization by antagonistic and synergistic muscles, thus resulting in the potential for reinjury. ${ }^{19,42}$ The brain stem is the second level of motor control. Joint afferent is relayed to maintain posture and balance of the body. The input to the brain stem relative to body position emanates in the joint proprioceptors, the vestibular centers in the ears and the eyes. The third aspect of motor control involves the highest level of CNS function and is mediated by cognitive awareness of body position and movement. These higher centers initiate and program motor commands for voluntary movement. Movements that are repeated can be stored as central commands and can be performed without continuous reference to consciousness. Each of these three levels of motor control must be addressed specifically during neuromuscular and proprioceptive rehabilitation. ${ }^{19,42}$

Sensorimotor facilitation training begins early in the rehabilitation program with such simple tasks as balance training and joint repositioning and becomes increasingly more challenging as the patient progresses. ${ }^{42}$ Once functional rehabilitation is reached, the objectives are 
to refine joint position awareness, which initiates muscle reflex stabilization to prevent reinjury. ${ }^{19}$ Activities need to be very functional and related to both injury reduction and performance enhancement. Exercise need to include consciously mediated pattern sequences and sudden alteration of joint positions that initiate reflex muscle contraction. ${ }^{19,42}$ Balancing on an unstable platform while the athlete performs a sport specific skill integrate both neural pathways and maximally stimulate kinesthetic awareness. Sensorimotor facilitation is integrated into functional rehabilitation through the use of unstable training implements such as stability balls, wobble boards, foam pads, and balance discs to reduce or eliminate an individual's points of contact with solid ground. ${ }^{79}$

Yaggie $^{80}$ studied the influence of a balance-training protocol, using the Both Sides Up balance trainer (BOSU), in dynamic stance and functional performance in healthy, recreationally active individuals. Postural sway assessment and three functional tasks of balance on the BOSU, vertical jump, and shuttle run were measured. Following training, the results showed improvements in total sway indicated that training may influence proprioceptive input, reaction time, and specified muscular strength. No improvements were found in power skills. Mattacola ${ }^{30}$ examined the effects of a six-week strength and proprioception-training program on clinical measures of dynamic balance. Results showed that the program had positively influenced the subjects' ability to balance dynamically.

Muscular strength, endurance, and power: By definition, strength is the ability of a muscle to generate force against some resistance. ${ }^{1}$ Functional strength is the ability of the neuromuscular system to reduce force, produce force, and dynamically stabilize the kinetic chain during functional movements on demands in a smooth, coordinated fashion. ${ }^{38}$ Muscular endurance is defined as the ability to perform repetitive muscular contractions against resistance for an extended period of time. 
As muscular strength increases, muscular endurance also increases. A muscle is capable of three types of contraction including isometric contraction, concentric contraction, and eccentric contraction. ${ }^{38}$ An isometric contraction occurs when the muscle contacts to increase tension with no change in muscle length. A concentric contraction occurs when the muscle shortens in length, as a contraction is developed to overcome resistance. An eccentric contraction occurs when the resistance is greater than the muscular force being produced, as the muscle lengthens. Muscular strength is proportional to the cross-sectional diameter of the muscle fibers; the muscle fiber in turn increases in size with strength training. Hypertrophy is defined as this increase in muscle size. ${ }^{23}$ Muscular strength can be increased through a variety of resistance training techniques including isometric exercise, progressive resistance exercise, isokinetic training, circuit training, and plyometric exercise. No matter the chosen technique, muscular strength will only be achieved through exercise with a muscle overload. Muscular overload is achieved by working the muscle at a higher level than it is accustomed to. ${ }^{23,38}$

Muscular strengthening and endurance activates are often near completion when the functional program begins. Traditional rehabilitation focuses on isolated muscular strength gains on single planes of motion. Functional rehabilitation focuses on strength gains in tri-planar motions which require acceleration, deceleration, and dynamic stabilization. ${ }^{38}$ The advantage of functional rehabilitation for muscular strength and endurance is that the exercises are performed in a sportspecific movement patterns using loads similar to that in soccer. ${ }^{1,39}$ Two cardinal principles of training are specificity and overload. ${ }^{39}$ These traditional principles are incorporated within functional rehabilitation. Research shows that an injury needs to be trained and rehabilitated in the same manner of mechanism of injury. The hamstring muscles are most often injured in high speed or high intensity situations, the muscle group should be rehabilitated at a high speed, high strength, 
eccentric load. ${ }^{8}$ In an average soccer match a player can run about 10-17 km over a 100 minute time frame. ${ }^{1,29}$ Therefore, it is imperative to develop game endurance of the injured limb and supporting musculature. Closed kinetic chain (CKC) activities are highly recommended as the integral component of functional rehabilitation. ${ }^{19} \mathrm{CKC}$ exercises permit the kinetic chain to be exercised together while reproducing the axial orientation of walking and running. This integration of agonist, antagonist, and synergist muscle activity necessary for both stabilization and ambulation is the fundamental rationale for using closed-chain exercise during functional rehabilitation. CKC exercises also reduce loads on the patellofemoral and tibiofemoral joints. CKC exercises are very specific to the functional demands placed on the lower extremity during sport activities. During these activities, the body moves over the foot resulting in simultaneous movement of all joint of the lower extremity.

Core stabilization: The core is the lumbopelvic-hip complex, consisting of 29 muscles, where a person's center of gravity is located and all movement begins. ${ }^{20,32-35}$ An efficient core allows the length-tension relationship of functional agonists and antagonists to remain normal, which in turn allows the force couple relationship in the lumbopelvic-hip complex to remain normal. ${ }^{20}$ In an efficient state, each structural component of the core distributes weight, absorbs force, and transfers ground reaction forces. ${ }^{20}$ The term core stabilization describes muscular control and muscular capacity of the lumbo-pelvic-hip complex to maintain functional stability. ${ }^{20,36,81}$ The core's stabilization system should function optimally to effectively use the strength, power, neuromuscular control, and muscular endurance of those extremity muscles. ${ }^{32}$ If the extremity muscles are strong and the core is weak, not enough force will be created to produce efficient movement; inefficient movements lead to injury. ${ }^{20}$ The core serves as the center of the functional kinetic chain, ${ }^{36}$ therefore proximal stability is requisite for distal mobility of the 
extremities and implies that successful extremity movement relies on trunk stability. ${ }^{81}$ The stress imposed and the force produced within the trunk are often associated with inertia from the lower extremities through the trunk during sport-specific movements, therefore special attention to strengthening and stabilizing the core is deemed necessary. A dynamic core stabilization training program is an important component of a functional rehabilitation program. ${ }^{20,32-37}$ A core stabilization program will improve dynamic postural control, ensure appropriate muscular balance and joint arthrokinematics around the lumbopelvic-hip complex, allow for the expression of dynamic functional strength, and improve neuromuscular efficiency throughout the entire kinetic chain. ${ }^{36}$

Research suggests that the knee is often "victim of core instability." ${ }^{81}$ Clinicians believe the benefits of a core stabilization program include enhancing performance, correcting postural imbalances, preventing injury, and aiding in the corrective treatment of trunk injuries. Core stability is a multifactor process dependent on rapid activation of the primary spinal stabilizer muscles, coordinated muscle co-contraction, sufficient strength of volitional muscles, and requisite endurance. Core strength provides an athlete with the stability necessary to function in all three planes of motion. The core controls the external forces that cause the spine to extend, laterally flex and rotate. The core has also been reported to increase the stability of the spine through cocontraction with the lumbar extensors. ${ }^{36,81}$ Research shows the abdominal muscles control excessive anterior pelvic tilt, and the hip abductors and external rotators assist in maintaining a level pelvis. The muscles of the hip are also found to affect the ability of the quadriceps and hamstrings to generate force or resist force. ${ }^{81}$

The rehabilitation program should emphasize the entire muscle contraction spectrum, focusing on force production (concentric contractions), force reeducation (eccentric contractions), 
and dynamic stabilization (isometric contractions.) The program should consist of the most challenging exercises the individual can control. ${ }^{20}$ The following are key concepts for proper exercise progression: allow to fast, simple to complex, known to unknown, low force to high force, eyes open to eyes closed, static to dynamic, correct execution to increased reps/sets/intensity. ${ }^{20}$ Basic core stability exercise principles have been outlined in research. Warm-up exercises include the "cat" and "camel" stretches. ${ }^{36}$ A core strengthening program begins with the recognition of the neutral spine position and learning to activate the abdominal wall musculature. The literature has named the "big 3 " exercises to begin a program. ${ }^{22}$ These include the curl-up, side bridge, and quadruped position with alternating arm/leg raises. ${ }^{22}$ Prone planks and bridging can also be incorporated at this stage. Progression to physio-ball exercise can begin once the individual has demonstrated good control. Advancement of exercises includes performing a variety of movement patterns in the three cardinal planes of movements, sagittal, frontal, and transverse. These exercises should mimic functional movements that require acceleration, deceleration, and dynamic stabilization. The use of an unstable surface, such as a BOSU or Dyna Disk, can be used to further advance the exercises. ${ }^{36}$

Although research on core stabilization is plentiful, there is limited research to show that improvement of core strength will transfer to improvements in athletic performance. ${ }^{20}$ Leetan $^{81}$ et al found that isometric hip strength measures particularly hip external rotators, are accurate predictors of back and lower extremity injury. Leetan found improvements in core strength did decrease the risk for male and female athletes, although much higher gains were found in females. ${ }^{81}$

Functional activity progression: Functional activity progression consists of agility and running and kicking progression. Agility is incorporated to restore pre-injury neuromuscular joint 
receptors, allowing the athlete to return to activity while reducing the risk of reinjury. ${ }^{19,28}$ Soccer requires skills of acceleration, maximal speed, and agility. ${ }^{1,28}$ Acceleration is the rate of changes in velocity that allows a player to reach maximum velocity in a minimum amount of time. Maximum speed is the maximal velocity at which a player can sprint. Agility is the ability to change direction and start and stop quickly. ${ }^{19,28}$

The functional activity training progression should begin with forward running and progress to activities that require cutting, turning, acceleration and deceleration. ${ }^{19,28}$ Figure eightrunning, carioca, backward running, box running and vertical jumping are agility activities often used in functional progression. ${ }^{19,28,40}$ This progress can further be divided into five phases of functional activity progression ${ }^{19}$ The beginning phase consists of walking and running. Activity should be performed on flat/straight surfaces. Phase II encourages turning and changing of direction during running. Activities include figure eight running, large to small circles, slow to fast speed. Speed should be increased as the athlete's confidence and ability permits. The third phase further prepares the athlete for return to sport by reproducing the stress demands that will be placed upon the lower extremity during normal activity. ${ }^{19}$ Cutting and agility-proprioception and acceleration-deceleration activities will simulate that of what the athlete will experience with a return to play. ${ }^{19,28,40}$ Activities such as the shuttle-run, four-corner run, carioca maneuver, and reaction-cutting maneuvers can be incorporated. The final phase is functional performance testing. The F-MARC test battery was developed to closely relate to the soccer player's normal activity. ${ }^{82}$ The battery outlined eight tests in relation to the most important soccer techniques. Juggling foot, juggling body, speed dribbling, long passing, short passing, shooting (dead ball), shooting (from a pass), heading. ${ }^{82}$ Power, speed, and endurance tests were designed to assess player's physical condition/fitness level. The tests consist of: Two-footed vertical jump, triple hop, long kick, long- 
throw in, four-line sprint, twelve-minute run. Hägglund et $\mathrm{al}^{12}$ has outlined a 10 -step functional rehabilitation progression for soccer: 1) Straight forward jog, 2) figure eight jog, 3) zigzag jog, 4) jog with 90-degree turns, 5) jog with 180-degree turns, 6) jog with 360-degree turns, 7) individual

ball drills, 8) shooting, jumping, and sprinting, 9) team training, and 10) match play. ${ }^{12}$ Progression to the consecutive step is granted once the athlete can complete the exercise without pain and swelling at the injured site. Regaining the ability to kick is essential for soccer athletes to return to play.

\section{CONCLUSION}

Functional rehabilitation is an extension of the traditional elements of therapy. The purpose of functional rehabilitation is to return the athlete to highly complex movement patterns present within their specific sport. ${ }^{1,13}$ Functional rehabilitation is defined as multifaceted rehabilitation designed to replicate the nature of the game. Functional rehabilitation must include acceleration, deceleration, and proprioceptive activity in a multi-planar fashion. The functional rehabilitation program is designed to progress the athlete from simple activities, such as walking or jogging, to highly complex sport-specific activities that require refined levels of proprioceptive acuity. The exercises within a functional rehabilitation program should emphasize dynamic flexibility, strength, power, sensorimotor facilitation, core stabilization and functional activity progression. 


\section{APPENDIX C}

\section{ADDITONAL METHODS}

Table C1. Initial E-mail to Gauge Interest

Your help and expertise is needed!

You have been hand selected to participate in this research study based on your experience with soccer and functional rehabilitation. My name is Sarah Leslie and I am a Graduate Athletic Training Student at West Virginia University, as well as a Graduate Assistant ATC at Waynesburg University. I will be conducting a study with the primary investigator Michelle A. Sandrey PhD, ATC to fulfill requirements for a Master's thesis and to complete a MS degree in Athletic Training. Both are affiliated with West Virginia University.

I am writing you to gauge your interest in participation of this research study titled: Development of a Soccer Specific Functional Rehabilitation Program Using the Modified Delphi Technique. The purpose of this study will be to develop a soccer specific functional rehabilitation program using a select panel of professional soccer Certified Athletic Trainers and Physical Therapists along with researchers to generate consensus on the exercise components. The intent is to use these exercises in conjunction with traditional rehabilitation to ready the athlete for the demands of sport prior to their return. This functional rehabilitation exercise program will be generalizable to all lower quarter injuries and focus on the multi-planar movement of soccer and to the prevention of re-injury.

Ultimately, the goal is to use this information to determine a soccer specific functional rehabilitation program, but in order to accomplish this, I am asking for your expertise in this area. This is an excellent opportunity for you to take part in research that will help improve the continuity in which Certified Athletic Trainers and Physical Therapists nationwide rehabilitate lower extremity injuries.

The entire process will include two rounds of questionnaires. You will receive the first round questionnaire and a demographic questionnaire. You will return the first round questionnaire. Once the results have been analyzed you will receive the same first round questionnaire with results. You will again return this questionnaire. It will take roughly 20 minutes to complete each questionnaire round.

Your participation in this research is extremely important and will provide you with the opportunity to help develop a soccer specific functional rehabilitation program that can be utilized by clinicians at every level. Your participation in this study will not affect your employment status, and if you are willing to participate in this study your responses are completely confidential.

If you are willing to participate please respond to this e-mail by including your mailing address. I would like to thank you in advance for your willingness to participate and share your soccer knowledge.

Kind Regards, Sarah R Leslie, ATC, Sleslie2@mix.wvu.edu 
Dear Selected Participant,

You have been hand selected to participate in this research study based on your experience with soccer specific functional rehabilitation. My name is Sarah Leslie and I am a Graduate Athletic Training Student at West Virginia University, as well as, a Graduate Assistant ATC at Waynesburg University. I will be conducting a study with the primary investigator Michelle A. Sandrey PhD, ATC to fulfill requirements for a Master's thesis and to complete an MS degree in Athletic Training. Both are affiliated with West Virginia University.

The design behind this research is a modified Delphi Technique. The process as a whole involves two rounds of online questionnaires. Initially, you will receive the link to one questionnaire. This will involve functional rehabilitation exercise components using the Likert scale with 5 being "strongly agree” and 1 being "strongly disagree”. Completion of the questionnaire should approximately 20 minutes. You will have the opportunity to provide feedback and add additional comments on the proposed exercise components to be included in the functional rehabilitation program. The second round of the modified Delphi technique involves issuing a second proposed functional rehabilitation questionnaire with responses to the first questionnaire. Again, you will complete the Likert scale and provide feedback on the revised proposed exercise components to be included in a soccer specific functional rehabilitation program. Please go to the following website to take the survey:

http://www.surveymonkey.com/s.aspx?sm=FDmsSwp4zbQWdsmAE68nAA_3d_3d

This is a completely voluntary activity and all responses are guaranteed to be anonymous and confidential, as a number system will be instituted so anonymity is secured. You are not required to answer every question and you have the right to withdraw any data you submit at any time.

Your job status will not be affected by failure to participate. Please respond to the online questionnaire as soon as possible, with a deadline of February 12, 2009. The quicker the responses, the sooner we can send out the second questionnaire.

If you have any questions or concerns please contact Sarah Leslie (586) 899-3262 or at (724) 852-3304 or by email at SLeslie2@mix.wvu.edu, or Dr. Michelle Sandrey, Graduate Athletic Training Program Director at West Virginia University, at (304) 293-3295 x 5220 or at msandrey@mail.wvu.edu.

Sincerely,

Sarah R Leslie, ATC

* West Virginia University Institutional Review Board acknowledgment of this study is on file 
Demographic Information. Directions: Circle the statement that best responds to the answer of the question unless otherwise specified.

1. Please indicate the highest degree you have attained.
a. Bachelor's
b. Master's
c. Ph. D./Ed. D/Other doctorate
d. M.D./D.O.
e. Other:

2. What credentials do you currently hold?
a. ATC
b. CSCS
c. SCS
d. OCS
e. PES
f. PT
g. Other:

3. How long have you been practicing as a certified athletic trainer or physical therapist?
a. 1-4 years
b. $5-10$ years
c. $>10$ years

4. How long have you been practicing as certified athletic trainer or physical therapist working primarily with soccer?
a. 1-2 years
b. 2-4 years
c. 5-10
d. $>10$ years

5. In what setting(s) do you practice more than $50 \%$ of the time?
a. Academic
b. Athletic Training Room
c. Sports Medicine or Outpatient Clinic
d. Other:

6. In what other settings do you work? (Circle all that apply)

a. Academic

b. Athletic Training Room

c. Sports Medicine or Outpatient Clinic

d. Other: 
7. How many presentations have you given at professional meetings?
a. 0
b. $1-2$
c. 3-4
d. $5+$

8. How many studies do you have published in the literature?

a. 0

b. $1-2$

c. 3-4

d. $5+$

* West Virginia University Institutional Review Board acknowledgment of this study is on file 
The Development of a Soccer Specific Functional Rehabilitation Program for Using the Modified Delphi Technique

\section{Round One Questionnaire}

Included in this questionnaire are exercises to be considered in the development of a functional rehabilitation program for soccer players. The exercise components are divided into: Dynamic Flexibility exercises, Combination Sequencing which includes exercises to train sensorimotor facilitation, muscular strength, and core stabilization, and Functional Activity Progression.

Each item has a corresponding Likert scale. The scale selection ranges from strongly disagree (1) to strongly agree (5). After reading the item, indicate if you agree or disagree with this exercise component being included.

Please provide additional comments and exercises to be considered following each of the sections. Your comments are key to the development of this functional rehabilitation program.

Thank you for your participation. 
The exercise components within the dynamic warm-up are to be performed prior to the functional rehabilitation program.

\begin{tabular}{|lccccc|}
\hline Dynamic Warm-up & SD & D & N & A & SA \\
\hline 1. Walking lunge with torso rotation & 1 & 2 & 3 & 4 & 5 \\
2. Walking side-lunge & 1 & 2 & 3 & 4 & 5 \\
3. Walking hurdler & 1 & 2 & 3 & 4 & 5 \\
4. Walking piriformis stretch & 1 & 2 & 3 & 4 & 5 \\
5. Forward leg swings & 1 & 2 & 3 & 4 & 5 \\
6. Lateral leg swings & 1 & 2 & 3 & 4 & 5 \\
7. High knee hug & 1 & 2 & 3 & 4 & 5 \\
8. Inverted hamstrings & 1 & 2 & 3 & 4 & 5 \\
9. Butt kick hug & 1 & 2 & 3 & 4 & 5 \\
10. Iliotibial band cross-over & 1 & 2 & 3 & 4 & 5 \\
\hline
\end{tabular}
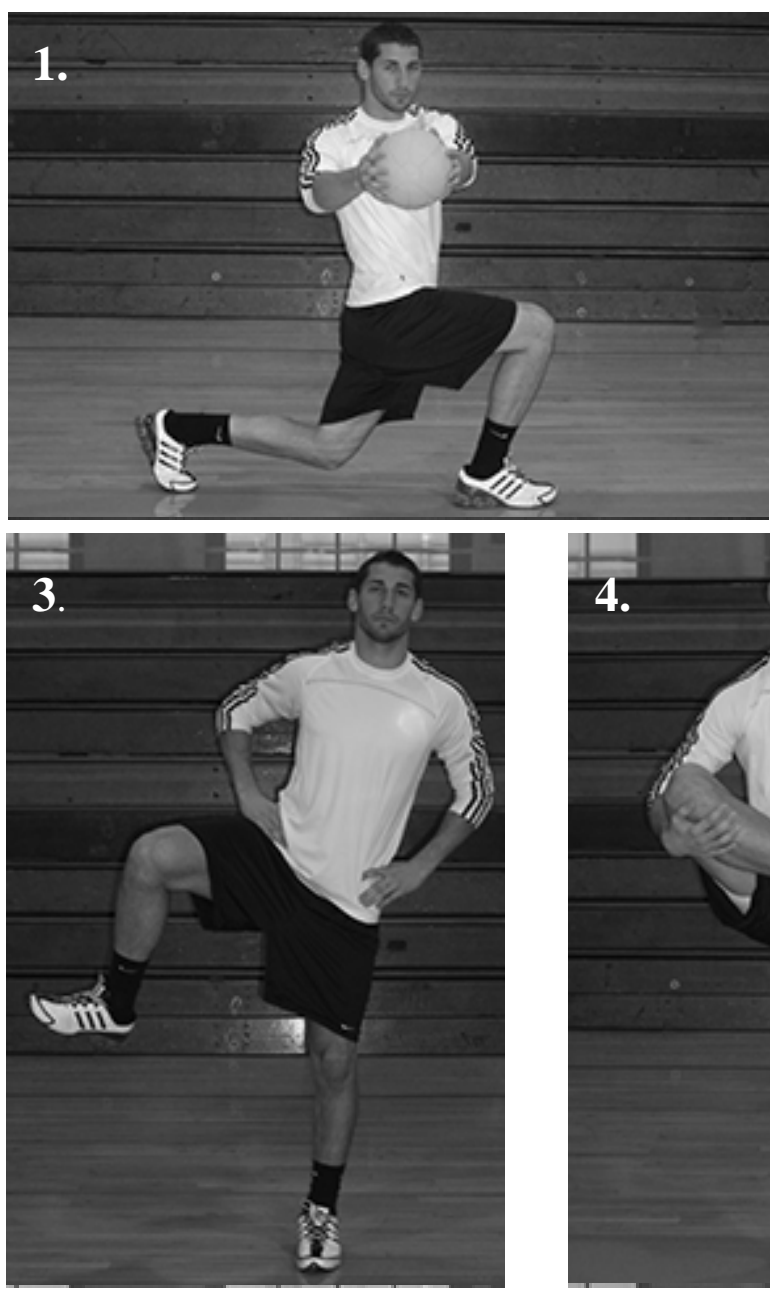
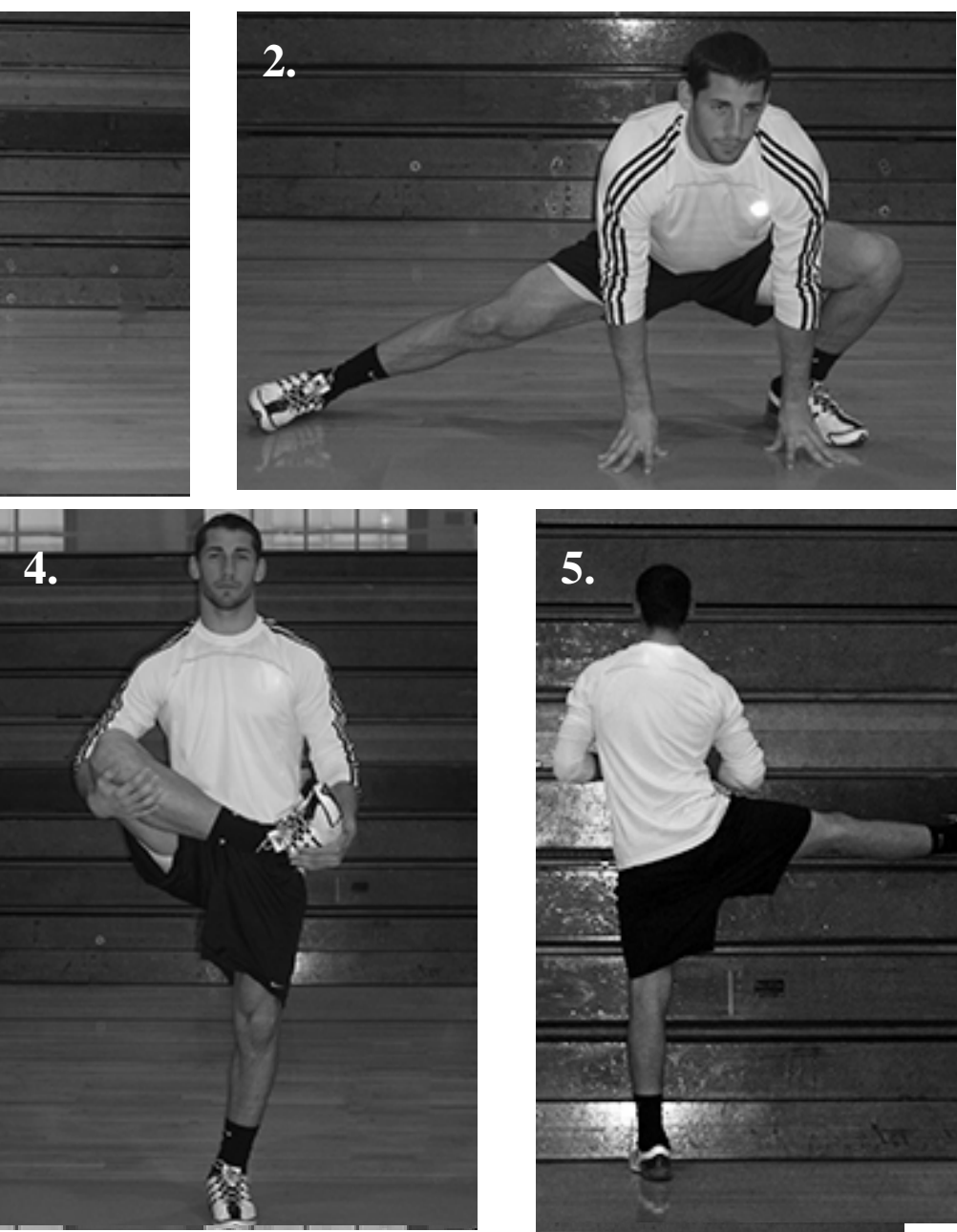

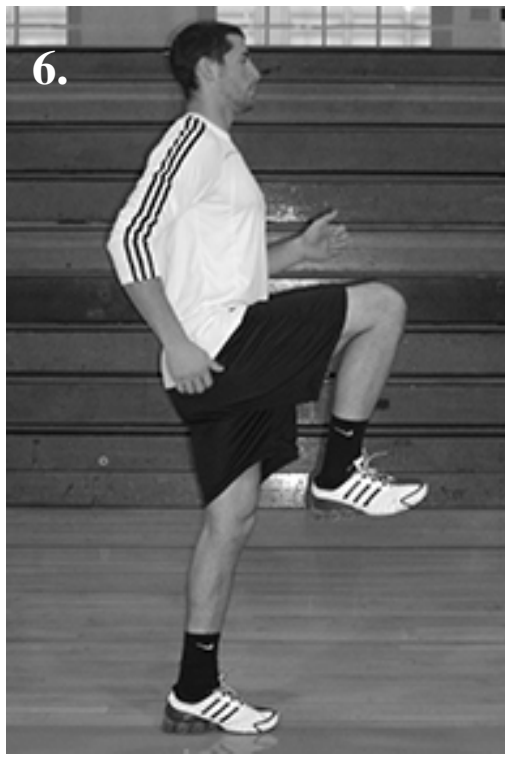



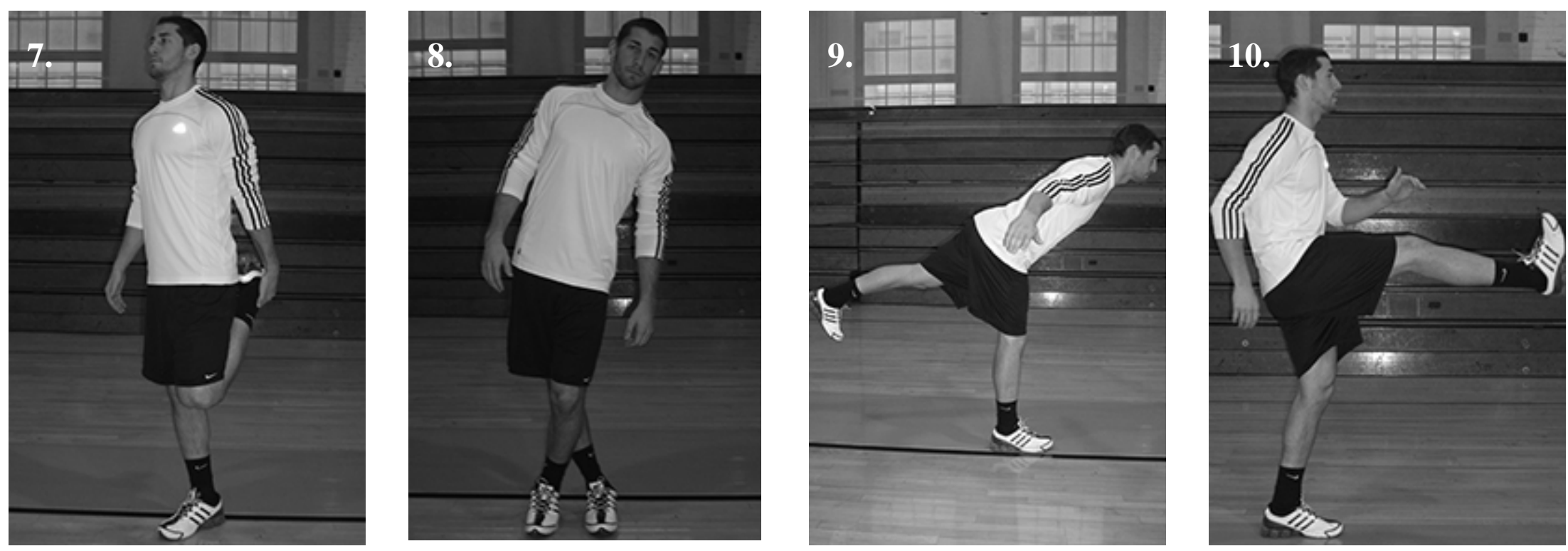

Additional Comments: 
The exercise components listed are progressive within this specific section only. Single leg balance exercises are performed as a combination of sensorimotor facilitation, strength and core stabilization exercises.

\section{Key:}

SLB: single leg balance 90-90: $90^{\circ}$-shoulder abduction with $90^{\circ}$-elbow flexion

MB: medicine ball

\section{Single Leg Balance Sequencing}

11. SLB on stable surface with 90-90 MB toss

12. SLB on unstable surface with $90-90$ MB toss

13. SLB on unstable surface with MB chest passes

14. SLB with dry kick

15. SLB with resisted kick

16. SLB with resisted ball kick

17. SLB with ball kick on unstable surface

18. SLB with resisted ball kick on unstable surface

19. SLB on unstable surface with juggling

20. SLB with header

21. SLB on unstable surface with header

When should these exercise components be progressed?

22. Mastery of current exercise?

23. Mastery of stable surface?

24. Mastery of resistive exercise?

$\begin{array}{ccccc}\text { SD } & \text { D } & \text { N } & \text { A } & \text { SA } \\ 1 & 2 & 3 & 4 & 5 \\ 1 & 2 & 3 & 4 & 5 \\ 1 & 2 & 3 & 4 & 5 \\ 1 & 2 & 3 & 4 & 5 \\ 1 & 2 & 3 & 4 & 5 \\ 1 & 2 & 3 & 4 & 5 \\ 1 & 2 & 3 & 4 & 5 \\ 1 & 2 & 3 & 4 & 5 \\ 1 & 2 & 3 & 4 & 5 \\ 1 & 2 & 3 & 4 & 5 \\ 1 & 2 & 3 & 4 & 5 \\ - & - & - & - & - \\ 1 & 2 & 3 & 4 & 5 \\ 1 & 2 & 3 & 4 & 5 \\ 1 & 2 & 3 & 4 & 5\end{array}$

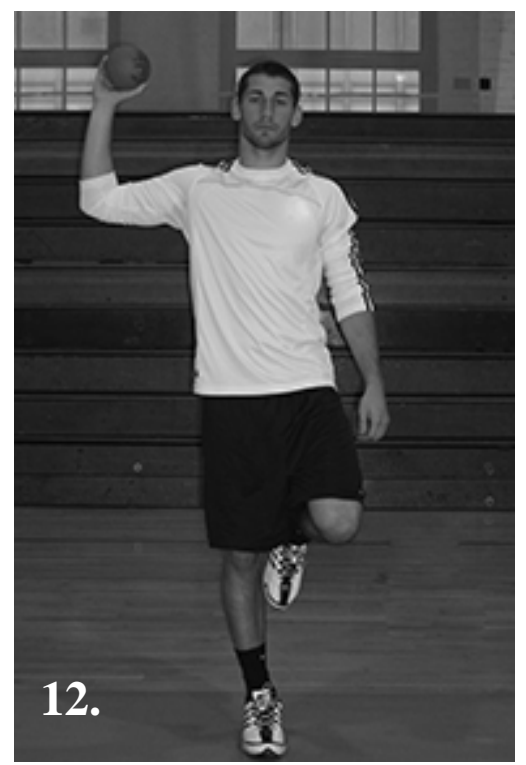

Additional Comments: 
The exercise components listed are progressive within this specific section only. Squat exercises are performed as a combination of sensorimotor

facilitation, strength and core stabilization exercises.

Key:

SL: Single Leg MB: Medicine Ball SB: Swiss Ball

\begin{tabular}{|c|c|c|c|c|c|}
\hline Squat sequencing & SD & $\mathbf{D}$ & $\mathbf{N}$ & $\mathbf{A}$ & SA \\
\hline 25. Front-squat with weighted bar & 1 & 2 & 3 & 4 & 5 \\
\hline 26. Back-squat with weighted bar & 1 & 2 & 3 & 4 & 5 \\
\hline 27. Squat with soccer ball throw-in & 1 & 2 & 3 & 4 & 5 \\
\hline 28. Squat with MB throw-in & 1 & 2 & 3 & 4 & 5 \\
\hline 29. Squat with header & 1 & 2 & 3 & 4 & 5 \\
\hline 30. SL squat with throw-in & 1 & 2 & 3 & 4 & 5 \\
\hline 31. SL squat with MB throw-in & 1 & 2 & 3 & 4 & 5 \\
\hline 32. SL squat with header & 1 & 2 & 3 & 4 & 5 \\
\hline 33. Squat on unstable surface with MB throw-in & 1 & 2 & 3 & 4 & 5 \\
\hline 34. SL squat on unstable surface with MB throw-in & 1 & 2 & 3 & 4 & 5 \\
\hline 35. SL squat on unstable surface with header & 1 & 2 & 3 & 4 & 5 \\
\hline 36. Squat to forward lunge & 1 & 2 & 3 & 4 & 5 \\
\hline 37. Squat to lateral lunge & 1 & 2 & 3 & 4 & 5 \\
\hline 38. SL squat to forward lunge on unstable surface & 1 & 2 & 3 & 4 & 5 \\
\hline 39. SL squat on unstable surface to forward lunge on unstable surface & 1 & 2 & 3 & 4 & 5 \\
\hline 40. SL squat to lateral lunge on unstable surface & 1 & 2 & 3 & 4 & 5 \\
\hline When should these exercise components be progressed? & - & - & - & - & - \\
\hline 41. Mastery of current exercise? & 1 & 2 & 3 & 4 & 5 \\
\hline 42. Mastery of stable surface? & 1 & 2 & 3 & 4 & 5 \\
\hline 43. Mastery of unstable surface? & 1 & 2 & 3 & 4 & 5 \\
\hline
\end{tabular}

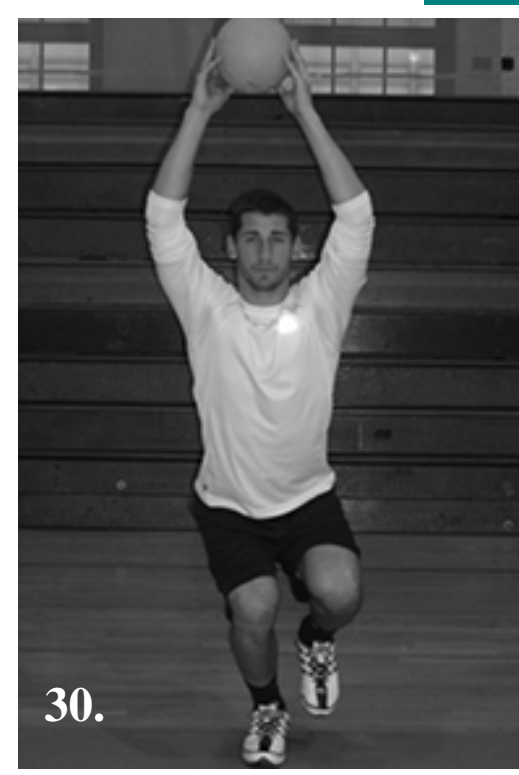

Additional Comments: 
The exercise components listed are progressive within this specific section only. Heel raise exercises are performed as a combination of sensorimotor facilitation, strength and core stabilization exercises.

\section{Key:}

MB: Medicine Ball

SL: Single Leg

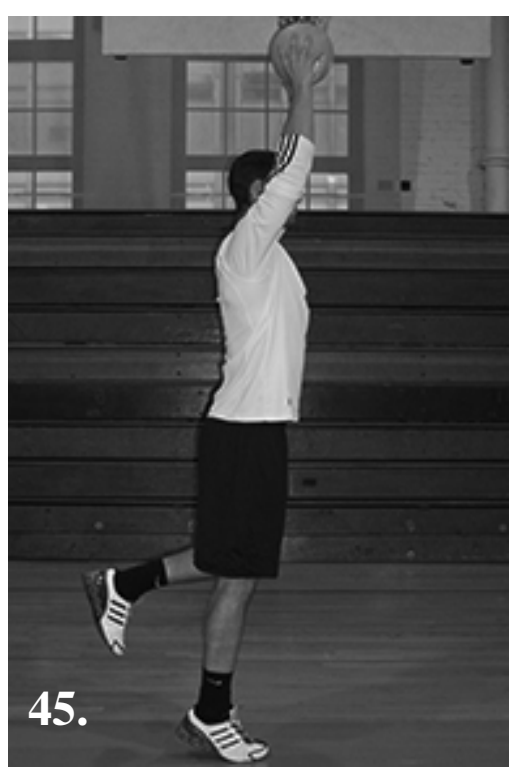

\begin{tabular}{|lccccc|}
\hline Heel Raise Sequencing & SD & D & N & A & SA \\
\hline 44. Two-legged heel raise with MB throw-in & 1 & 2 & 3 & 4 & 5 \\
45. SL heel raise with MB throw-in & 1 & 2 & 3 & 4 & 5 \\
46. SL heel raise with MB throw-in on unstable & 1 & 2 & 3 & 4 & 5 \\
47. Heel raise with header & 1 & 2 & 3 & 4 & 5 \\
48. SL heel raise with header & 1 & 2 & 3 & 4 & 5 \\
When should these exercise components be progressed? & - & - & - & - & - \\
49. Mastery of current exercise? & 1 & 2 & 3 & 4 & 5 \\
50. Mastery of stable surface? & 1 & 2 & 3 & 4 & 5 \\
\hline
\end{tabular}

Additional Comments:

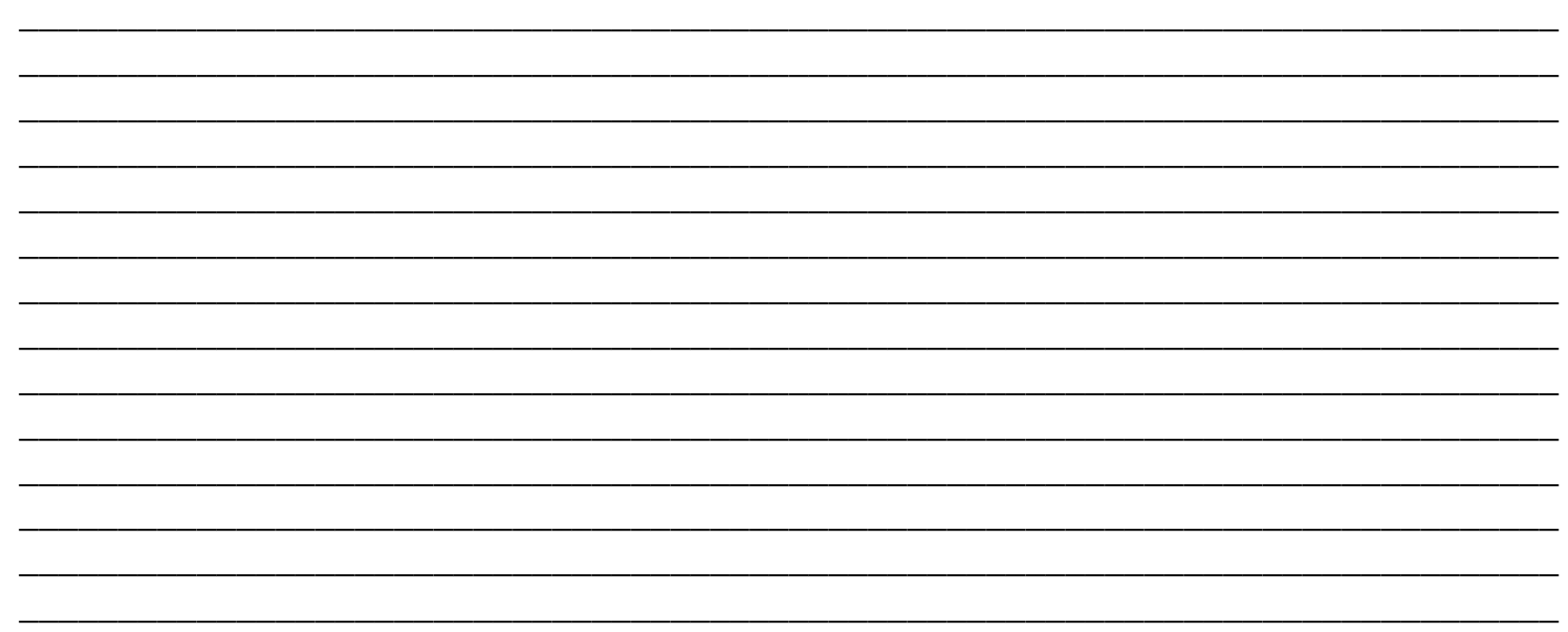


The exercise components listed are progressive within this specific section only.

Lunge exercises are performed as a combination of sensorimotor

facilitation, strength and core stabilization exercises.

Key:

$\mathbf{M B}=$ Medicine Ball $\mathbf{S B}=$ Swiss Ball

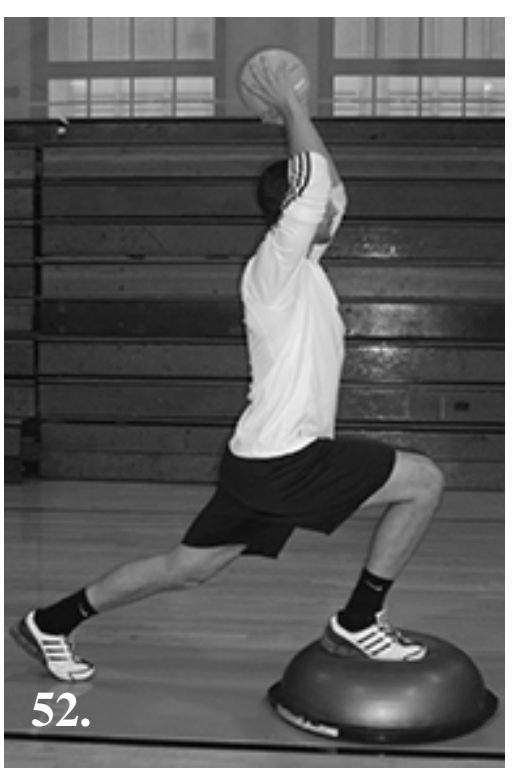

Lunge Sequencing

SD $\quad \mathbf{D} \quad \mathbf{N} \quad$ A $\quad$ SA

51. Forward lunge with MB throw-in

52. Forward lunge onto unstable surface with MB throw-in

$\begin{array}{lllll}1 & 2 & 3 & 4 & 5\end{array}$

53. Lateral lunge with MB throw-in

54. Lateral lunge onto unstable surface

$\begin{array}{lllll}1 & 2 & 3 & 4 & 5\end{array}$

55. Resisted forward lunge with MB throw in

56. Resisted lateral lunge with MB throw-in

57. Forward lunge onto SB

58. Forward lunge onto SB with MB toss

59. Lateral lunge onto SB

When should these exercise components be progressed?

60. Mastery of current exercise?

61. Mastery of stable surface?

62. Mastery of unstable surface?

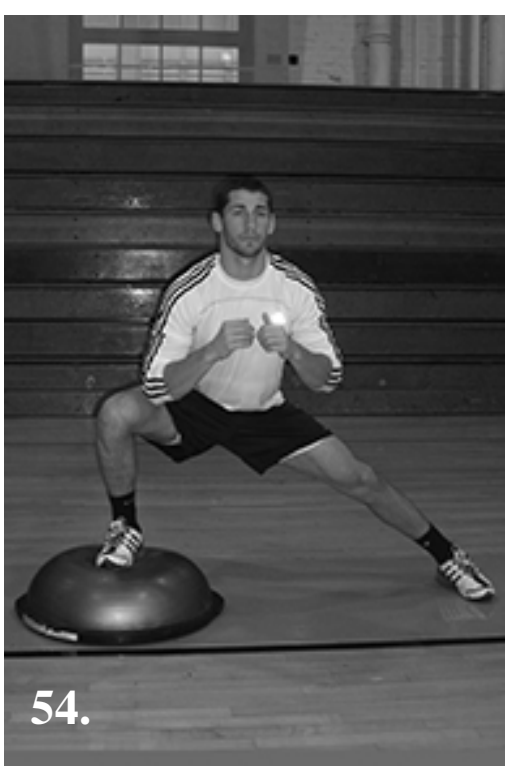

Additional Comments:

$\begin{array}{ccccc}1 & 2 & 3 & 4 & 5 \\ 1 & 2 & 3 & 4 & 5 \\ 1 & 2 & 3 & 4 & 5 \\ 1 & 2 & 3 & 4 & 5 \\ 1 & 2 & 3 & 4 & 5 \\ 1 & 2 & 3 & 4 & 5 \\ 1 & 2 & 3 & 4 & 5 \\ - & - & - & - & - \\ 1 & 2 & 3 & 4 & 5 \\ 1 & 2 & 3 & 4 & 5 \\ 1 & 2 & 3 & 4 & 5\end{array}$


The exercise components listed are not progressive in order. Core stabilization exercises are performed as a combination of sensorimotor facilitation, strength and core stabilization exercises.

Key:

MB: Medicine Ball

SB: Swiss Ball

SL: Single Leg

\begin{tabular}{|c|c|c|c|c|c|}
\hline Core Stabilization & SD & D & $\mathbf{N}$ & A & SA \\
\hline 63. Diagonal chops with MB & 1 & 2 & 3 & 4 & 5 \\
\hline 64. Diagonal chops with MB on unstable surface & 1 & 2 & 3 & 4 & 5 \\
\hline 65. Marching on SB with foot traps & 1 & 2 & 3 & 4 & 5 \\
\hline 66. Marching on SB with MB throw in plus resisted leg extension & 1 & 2 & 3 & 4 & 5 \\
\hline 67. Marching on SB with MB throw-in & 1 & 2 & 3 & 4 & 5 \\
\hline 68. Marching on SB with juggling & 1 & 2 & 3 & 4 & 5 \\
\hline 69. Side-plank & 1 & 2 & 3 & 4 & 5 \\
\hline 70. Side-plank with resisted hip flexion & 1 & 2 & 3 & 4 & 5 \\
\hline 71. Side-plank on SB & 1 & 2 & 3 & 4 & 5 \\
\hline 72. Side-plank on SB with resisted hip flexion & 1 & 2 & 3 & 4 & 5 \\
\hline 73. Plank with forearms on SB & 1 & 2 & 3 & 4 & 5 \\
\hline 74. SL plank with forearms on SB & 1 & 2 & 3 & 4 & 5 \\
\hline 75. SL plank with forearms on SB with weight at ankle & 1 & 2 & 3 & 4 & 5 \\
\hline 76. Plank roll-outs on SB & 1 & 2 & 3 & 4 & 5 \\
\hline 77. Plank with feet on SB & 1 & 2 & 3 & 4 & 5 \\
\hline 78. Plank with feet on SB with abdominal rolls & 1 & 2 & 3 & 4 & 5 \\
\hline 79. Plank with feet on SB with roll, pike, pushup & 1 & 2 & 3 & 4 & 5 \\
\hline 80. Supine SB rear overhead throw with MB & 1 & 2 & 3 & 4 & 5 \\
\hline 81. Russian twist with MB & 1 & 2 & 3 & 4 & 5 \\
\hline 82. 6 inch hold & 1 & 2 & 3 & 4 & 5 \\
\hline 83. V sit ups & 1 & 2 & 3 & 4 & 5 \\
\hline 84. Jack knife sit ups & 1 & 2 & 3 & 4 & 5 \\
\hline 85. Crunch on SB with MB toss & 1 & 2 & 3 & 4 & 5 \\
\hline 86. Kneeling balance on SB with MB throw in & 1 & 2 & 3 & 4 & 5 \\
\hline 87. Standing on SB & 1 & 2 & 3 & 4 & 5 \\
\hline 88. Russian eccentric hamstrings & 1 & 2 & 3 & 4 & 5 \\
\hline 89. SL stance figure eight ball pass & 1 & 2 & 3 & 4 & 5 \\
\hline
\end{tabular}




\section{When should these exercise components be progressed?}

90. Mastery of current exercise?

\section{Mastery of neutral spine?}
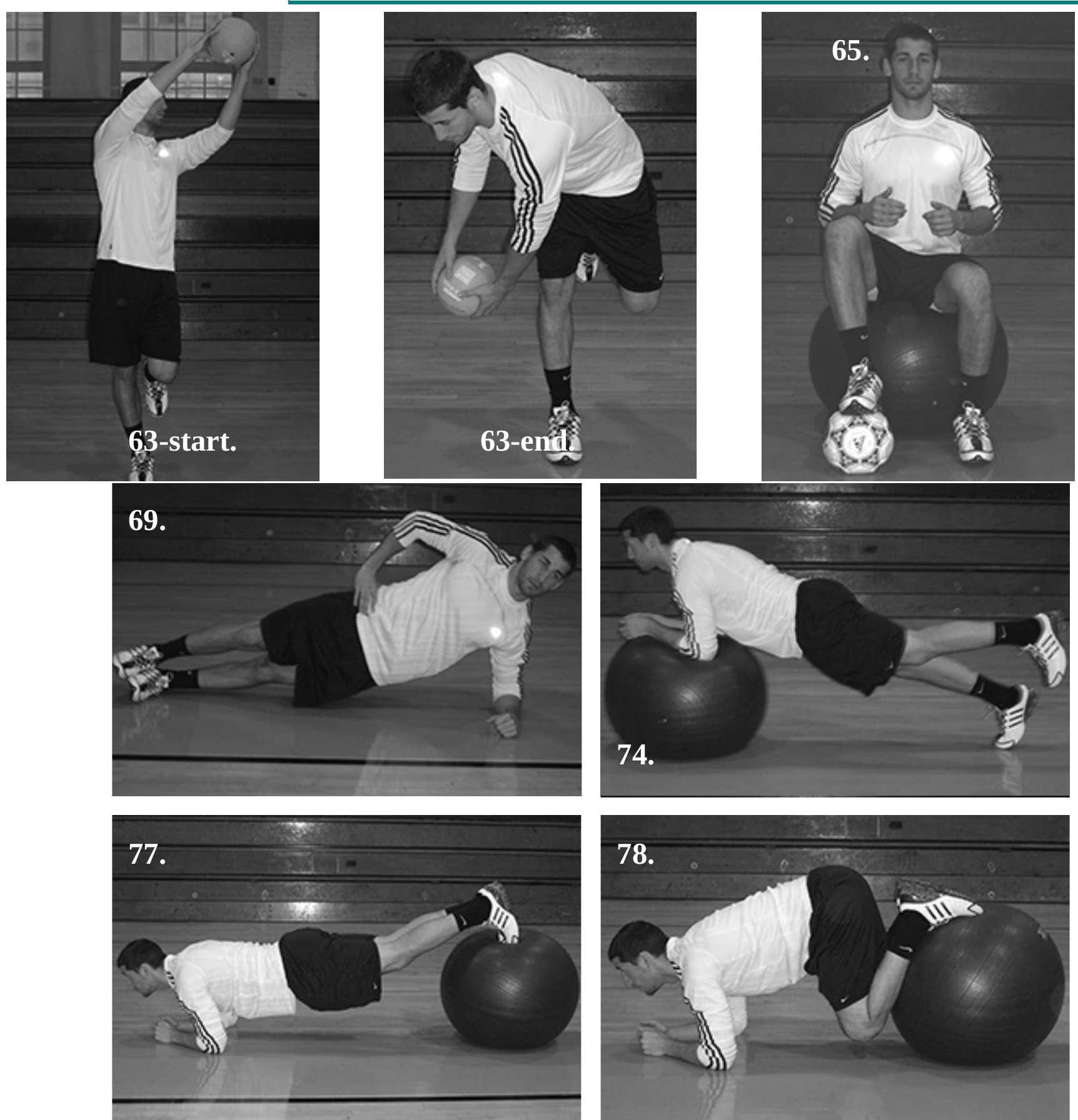

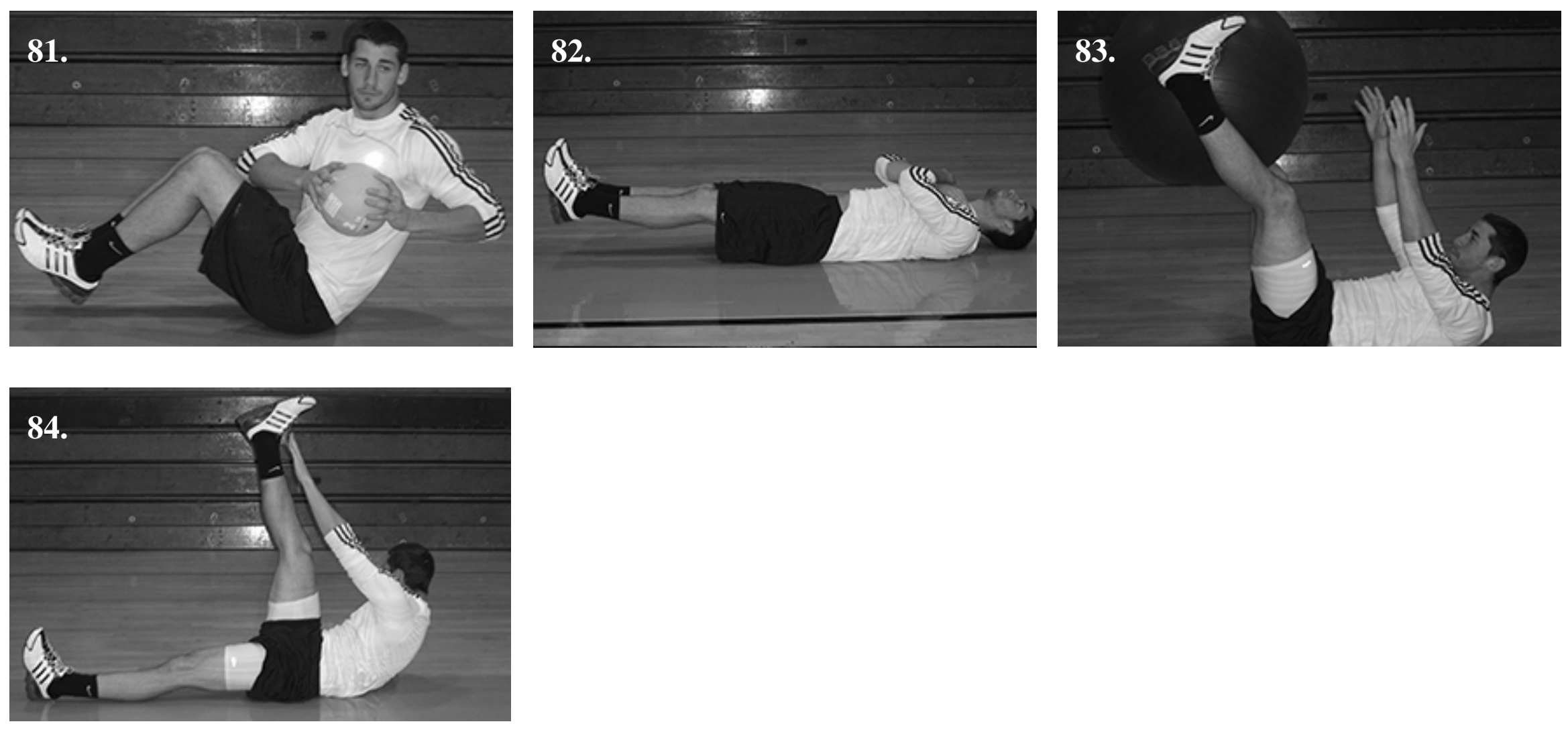

Additional Comments: 
The exercise components listed are not progressive in order.

Plyometric

exercises are

performed as a

combination of

strength and core

stabilization

exercises.

Key:

SL: Single Leg

MB: Medicine Ball

\begin{tabular}{|lccccc|}
\hline Plyometrics & SD & D & N & A & SA \\
\hline 92. SL step-up with MB throw-in & 1 & 2 & 3 & 4 & 5 \\
93. SL step-up with resistance with MB throw-in & 1 & 2 & 3 & 4 & 5 \\
94. SL step up onto unstable surface with MB throw-in & 1 & 2 & 3 & 4 & 5 \\
\hline 95. SL resisted step-up onto unstable surface with MB throw & 1 & 2 & 3 & 4 & 5 \\
96. Depth box jumps with MB throw-in & 1 & 2 & 3 & 4 & 5 \\
97. Depth box jumps with header & 1 & 2 & 3 & 4 & 5 \\
98. Squat jump to header & 1 & 2 & 3 & 4 & 5 \\
\hline 99. Lunge jump to header & 1 & 2 & 3 & 4 & 5 \\
100. Lateral lunge with explosive ball save (keeper specific) & 1 & 2 & 3 & 4 & 5 \\
101. Pullover with MB & 1 & 2 & 3 & 4 & 5 \\
\hline 102. Pullover pass with MB & 1 & 2 & 3 & 4 & 5 \\
\hline 103. Pullover with sit-up & 1 & 2 & 3 & 4 & 5 \\
104. Overhead to Feet MB & 1 & 2 & 3 & 4 & 5 \\
105. Knee Throw & 1 & 2 & 3 & 4 & 5 \\
106. Kick toss & 1 & 2 & 3 & 4 & 5 \\
\hline 107. Sit-up toss & 1 & 2 & 3 & 4 & 5 \\
\hline 108. Backward MB throw & 1 & 2 & 3 & 4 & 5 \\
109. Kneeling throw & 1 & 2 & 3 & 4 & 5 \\
110. Over and Through the Legs with MB & 1 & 2 & 3 & 4 & 5 \\
111. Hurdler Extension with MB & 1 & 2 & 3 & 4 & 5 \\
112. Front Toss & 1 & 2 & 3 & 4 & 5 \\
113. Leg Toss & 1 & 2 & 3 & 4 & 5 \\
114. Heel Toss with MB & 1 & 2 & 3 & 4 & 5 \\
115. Lateral hops over cone & 1 & 2 & 3 & 4 & 5 \\
116. Forward/Backward hops over cone & 1 & 2 & 3 & 4 & 5 \\
117. SL hops over cone & 1 & 2 & 3 & 4 & 5 \\
118. Vertical Jumps with header & 1 & 2 & 3 & 4 & 5 \\
119. Scissors jumps & 1 & 2 & 3 & 4 & 5 \\
120. Resisted slide board and catch & 1 & 2 & 3 & 4 & 5 \\
\hline
\end{tabular}



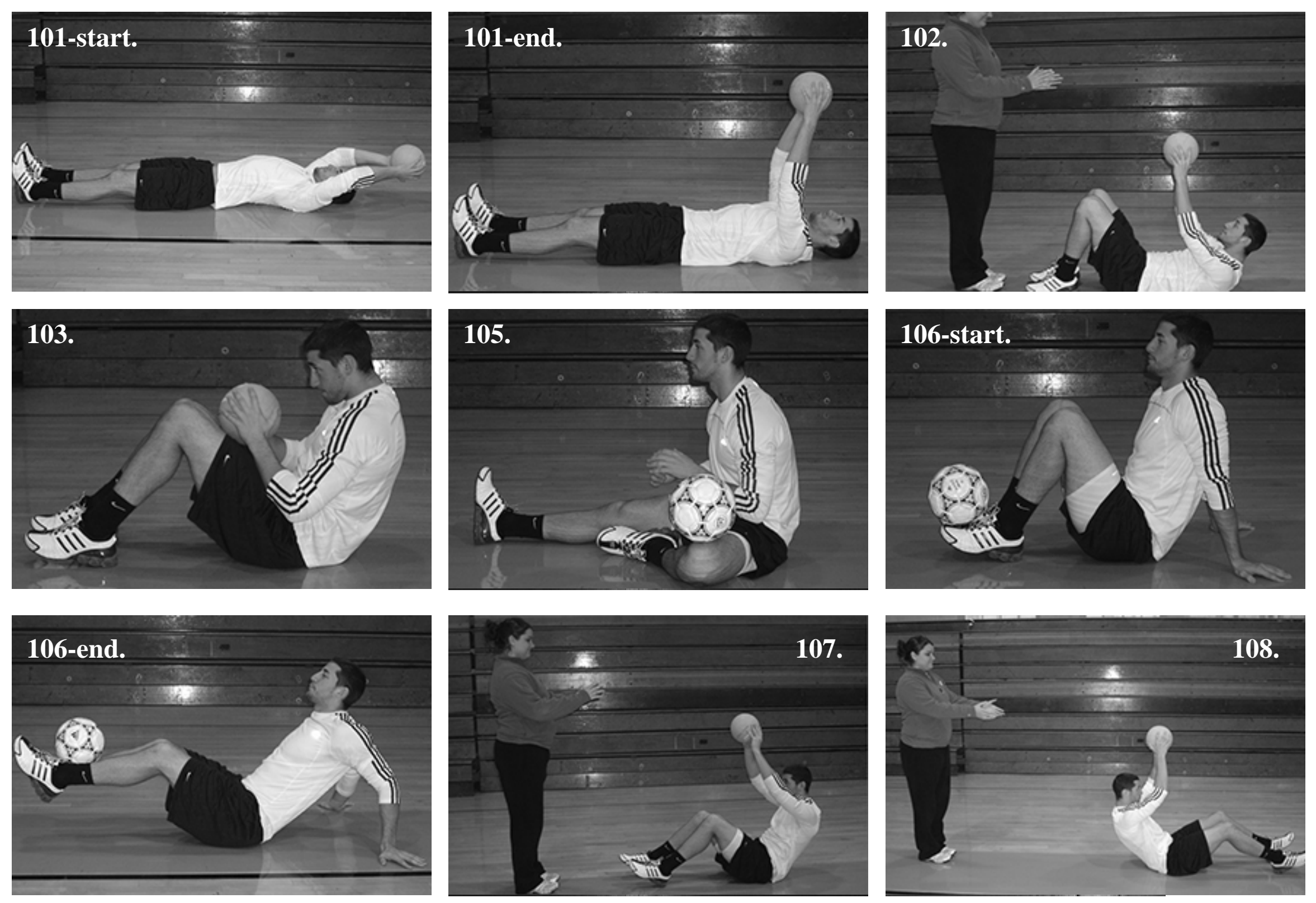

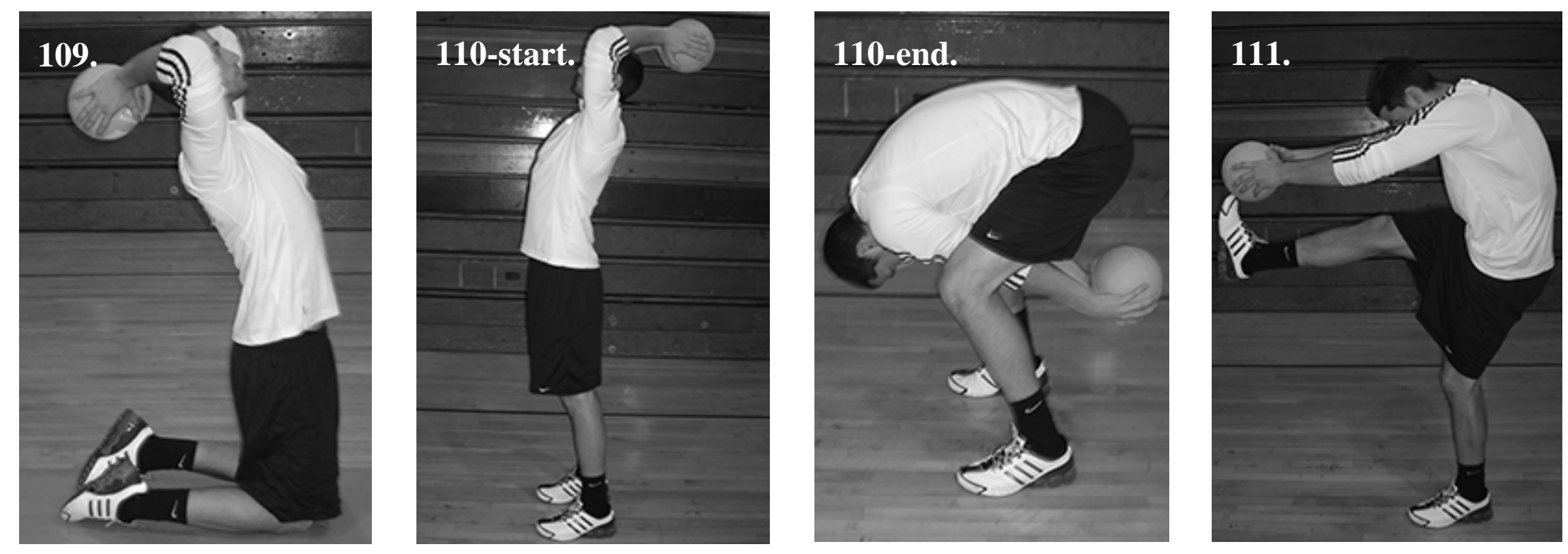

Additional Comments: 


\begin{tabular}{|c|c|c|c|c|c|}
\hline Kicking Progression & SD & D & $\mathbf{N}$ & A & SA \\
\hline 121. Dry kick with weight shift & 1 & 2 & 3 & 4 & 5 \\
\hline 122. Dry kick with resistance & 1 & 2 & 3 & 4 & 5 \\
\hline 123. Kick stationary ball: short distance & 1 & 2 & 3 & 4 & 5 \\
\hline 124. Kick stationary ball: long distance & 1 & 2 & 3 & 4 & 5 \\
\hline 125. Kick moving ball: short distance & 1 & 2 & 3 & 4 & 5 \\
\hline 126. Kick moving ball: long distance & 1 & 2 & 3 & 4 & 5 \\
\hline 127. Knee traps to kicks & 1 & 2 & 3 & 4 & 5 \\
\hline 128. Kick to juggling & 1 & 2 & 3 & 4 & 5 \\
\hline 129. Chest pass to kick to header & 1 & 2 & 3 & 4 & 5 \\
\hline 130. Dry kick with plant onto unstable surface & 1 & 2 & 3 & 4 & 5 \\
\hline 131. Resisted kick with plant onto unstable surface & 1 & 2 & 3 & 4 & 5 \\
\hline 132. Stationary ball kick with plant onto unstable surface & 1 & 2 & 3 & 4 & 5 \\
\hline 133. Moving ball kick with plant onto unstable surface & 1 & 2 & 3 & 4 & 5 \\
\hline When should these exercise components be progressed? & - & - & - & - & - \\
\hline 134. Mastery of current exercise? & 1 & 2 & 3 & 4 & 5 \\
\hline
\end{tabular}

\begin{tabular}{|lccccc|}
\hline Anaerobic and Aerobic Progression & SD & D & N & A & SA \\
\hline 135. Fartleks & 1 & 2 & 3 & 4 & 5 \\
136. 50/50 Interval Training & 1 & 2 & 3 & 4 & 5 \\
137. Bike & 1 & 2 & 3 & 4 & 5 \\
138. Elliptical & 1 & 2 & 3 & 4 & 5 \\
139. Stair Climber & 1 & 2 & 3 & 4 & 5 \\
140. Treadmill & 1 & 2 & 3 & 4 & 5 \\
141. 1-mile endurance & 1 & 2 & 3 & 4 & 5 \\
142. 2-mile endurance & 1 & 2 & 3 & 4 & 5 \\
When should these exercise components be progressed? & - & - & - & - & - \\
143. 50\% max heart rate maintained for specified time & 1 & 2 & 3 & 4 & 5 \\
144. 60\% max heart rate maintained for specified time & 1 & 2 & 3 & 4 & 5 \\
\hline
\end{tabular}


The following sections are

Functional

Activity

Progression.

These exercises

are not

progressive in

order.
145. 70\% max heart rate maintained for specified time

146. 80\%+ max heart rate maintained for specified time

147. Completion of 15 minutes of specified aerobic training

148. Completion of 20 minutes of specified aerobic training

149. Completion of 30+ minutes of specified aerobic training

$\begin{array}{lllll}1 & 2 & 3 & 4 & 5 \\ 1 & 2 & 3 & 4 & 5 \\ 1 & 2 & 3 & 4 & 5 \\ 1 & 2 & 3 & 4 & 5 \\ 1 & 2 & 3 & 4 & 5\end{array}$

\begin{tabular}{|c|c|c|c|c|c|}
\hline Agility Progression & SD & $\mathbf{D}$ & $\mathbf{N}$ & A & SA \\
\hline 150. Figure eight runs & 1 & 2 & 3 & 4 & 5 \\
\hline 151. Zigzag runs & 1 & 2 & 3 & 4 & 5 \\
\hline 152. T-run & 1 & 2 & 3 & 4 & 5 \\
\hline 153. SL dot hop Bounding & 1 & 2 & 3 & 4 & 5 \\
\hline 154. Two-legged dot hop & 1 & 2 & 3 & 4 & 5 \\
\hline 155. Ladder line run & 1 & 2 & 3 & 4 & 5 \\
\hline 156. Ladder line sprint and backpedal & 1 & 2 & 3 & 4 & 5 \\
\hline 157. Ladder line shuffles & 1 & 2 & 3 & 4 & 5 \\
\hline 158. Pro-Agility Run & 1 & 2 & 3 & 4 & 5 \\
\hline 159. Box Runs & 1 & 2 & 3 & 4 & 5 \\
\hline 160. Carioca Runs & 1 & 2 & 3 & 4 & 5 \\
\hline 161. 20-minute run with dribbling & 1 & 2 & 3 & 4 & 5 \\
\hline 162. Zigzag runs with dribbling & 1 & 2 & 3 & 4 & 5 \\
\hline 163. T-run with dribbling & 1 & 2 & 3 & 4 & 5 \\
\hline 164. Up and back dot run with dribbling & 1 & 2 & 3 & 4 & 5 \\
\hline 165. Ladder line run with dribbling & 1 & 2 & 3 & 4 & 5 \\
\hline 166. Box Runs with dribbling & 1 & 2 & 3 & 4 & 5 \\
\hline 167. Figure eight runs with dribbling & 1 & 2 & 3 & 4 & 5 \\
\hline 168. Fartleks with dribbling & 1 & 2 & 3 & 4 & 5 \\
\hline
\end{tabular}


Additional Comments:

THANK YOU FOR YOUR TIME AND EFFORT IN COMPLETION OF THIS QUESTIONNAIRE 
Greetings Again,

This is a reminder that the questionnaire on the development of a soccer specific functional rehabilitation program can be completed by FEBURARY $12^{\text {th }} \mathbf{2 0 0 9}$ for participation in the study: Development of a Soccer Specific Functional Rehabilitation Program Using the Modified Delphi Technique. This is an excellent opportunity for you to take part in research to develop a functional rehabilitation program for lower extremity injuries of soccer players. I will be conducting this research study with the primary investigator Michelle A. Sandrey PhD, ATC to fulfill requirements for a Master's thesis and to complete an MS degree in Athletic Training.

For those of you who have already submitted your responses or are in the process, I apologize for this interruption and thank you for your participation. For those of you who no longer have the original information,

\section{Please go to the following website to take the survey:} http://www.surveymonkey.com/s.aspx?sm=FDmsSwp4zbQWdsmAE68nAA_3d_3d

I encourage all of you to take a few minutes to fill out the questionnaire. Your expert opinion is very important in developing this exercise program!

This is a completely voluntary activity and all responses are guaranteed to be anonymous and confidential, as a number system will be instituted so anonymity is secured. You are not required to answer every question, and you have the right to withdraw any data you submit at any time. Your job status will not be affected by failure to participate.

If you have any questions or concerns please contact Sarah Leslie (586) 899-3262 or at (724) 852-3304 or by email at sleslie2@mix.wvu.edu, or Dr. Michelle Sandrey, Graduate Athletic Training Program Director at West Virginia University, at (304) 293-3295 x 5220 or at msandrey@mail.wvu.edu.

Thank you for your participation in this study!

Sincerely, Sarah Leslie, ATC

* West Virginia University Institutional Review Board acknowledgment of this study is on file 
Dear Participant,

Thank you for your participation in the study Development of a Soccer Specific Functional Rehabilitation Program Using the Modified Delphi Technique. Your first round responses were very informative and helpful in completing this research. The second round questionnaire will be the final step in developing a soccer specific functional rehabilitation program. This is your opportunity to see the results of the first round as well as the additional comments. Your final responses are very important and will be beneficial to help athletic trainers and physical therapists when designing their own functional rehabilitation program. I will be conducting this study with the primary investigator Michelle A. Sandrey PhD, ATC to fulfill requirements for a Master's thesis and to complete an MS degree in Athletic Training from West Virginia University.

Please go to the following website to take the survey:

http://www.surveymonkey.com/s.aspx?sm=SjqT3mv9oOg9xALkMheuOg_3d_3d

Please rank the components and additional comments of panel and provide feedback where you see fit. Please submit your responses by March 9, 2009. Again, responses are anonymous based on the implemented numerical system, and your participation remains completely voluntary. Your job status will not be affected by failure to participate.

If you have any questions or concerns please contact Sarah Leslie (586) 899-3262 or at (724) 852-3304 or by email at sleslie2@mix.wvu.edu, or Dr. Michelle Sandrey, Graduate Athletic Training Program Director at West Virginia University, at (304) 293-3295 x 5220 or at msandrey@mail.wvu.edu.

Sincerely,

Sarah R Leslie, ATC

* West Virginia University Institutional Review Board acknowledgment of this study is on file 


\section{Round 2: Development of a Soccer Specific Functional Rehabilitation Program}

\section{Introduction}

The Development of a Soccer Specific Functional Rehabilitation Program Using the Modified Delphi Technique

Round Two:

Included in this questionnaire are exercises to be considered in the development of a functional rehabilitation program for soccer players with the statistical results from Round 1. The questions presented are those asked during Round 1 followed by a series of numbers. The numbers represent the Frequency and Number of Responses from Round 1.

\section{For Example:}

Walking lunge with torso rotation: $0.0 \%(0), 18.8 \%(3), 25.0 \%(4), 25.0 \%(4), 31.3 \%(5), 3.69,16$. The numbers represent the statistics, respectively: Strongly Disagree, Disagree, Neutral, Agree, Strongly Agree, followed by the rating average and response count.

Please take these numbers into consideration as you rate each exercise again. The additional comments from Round 1 are also provided following the exercises in each section. Please rate these responses as well as providing any additional exercises/feedback in the comment box.

Thank you greatly for your time and participation!

\section{Dynamic Flexibility}

The exercise components within the dynamic warm- up are to be performed prior to the functional rehabilitation program. 


\section{Round 2: Development of a Soccer Specific Functional Rehabilitation Program}

\section{Dynamic Flexibility}

1. Walking lunge with torso rotation: $0.0 \%$ (0) $18.8 \%$ (3)

$25.0 \%$ (4) $25.0 \%$ (4) $31.3 \%(5)$

3.6916

2. Walking side-lunge: $0.0 \%(0)$

$14.3 \%$ (2) $28.6 \%$ (4) $35.7 \%$ (5)

$21.4 \%$ (3) 3.6414

3. Walking hurdler: $0.0 \%(0)$

$14.3 \%$ (2) $21.4 \%$ (3) $28.6 \%$ (4)

$35.7 \%(5) 3.8614$

4. Walking piriformis stretch: $7.1 \%$

(1) $7.1 \%$ (1) $21.4 \%$ (3) $50.0 \%$ (7)

$14.3 \%$ (2) 3.5714

5. Forward leg swings: $0.0 \%(0)$

$14.3 \%$ (2) $7.1 \%$ (1) $35.7 \%$ (5)

$42.9 \%$ (6) 4.0714

6. Lateral leg swings: $0.0 \%(0)$

$15.4 \%$ (2) $15.4 \%$ (2) $38.5 \%$ (5)

$30.8 \%$ (4) 3.8513

7. High knee hug: $0.0 \%(0)$

$15.4 \%$ (2) $15.4 \%$ (2) $38.5 \%$ (5)

$30.8 \%$ (4) 3.8513

8. Inverted hamstrings: $0.0 \%(0)$

$7.1 \%$ (1) $21.4 \%$ (3) $35.7 \%$ (5)

$35.7 \%$ (5) 4.0014

9. Butt kick hug: $0.0 \%$ (0) $15.4 \%$

(2) $23.1 \%$ (3) $53.8 \%$ (7) $7.7 \%$ (1)

3.5413

10. Iliotibial band cross-over:

$0.0 \%$ (0) $23.1 \%$ (3) $15.4 \%$ (2)

$46.2 \%$ (6) $15.4 \%$ (2) 3.5413

\#1 is more of a functional exercise

than a dynamic flex movement.

\#9 should include a contrlateral

reach \#10 could be more dynamic

in nature.

I feel that walking lunge should be

part of the functional rehab

\section{Strongly Disagree}

$\bigcirc$

Disagree

$\bigcirc$

$\bigcirc$

$\bigcirc$

$\bigcirc$

$\bigcirc$

$\bigcirc$

$\bigcirc$

$\bigcirc$

○

$\bigcirc$

$\bigcirc$

program not part of the dynamic

warm up.

Hip ext into split stance $w /$ trunk

ext df foot move in toe pop's

(raises) I also feels like

addressing the hip flxrs, low abs

0

0
Neutral

Agree

0

0

0

0

0

0

0

0

0

0

0

0

0

0

0

0

0

0

0

0

0

0

0

0

0 


\section{Round 2: Development of a Soccer Specific Functional Rehabilitation Program}

and calfs are important.

$1,2,5,6,8$, and 10 are all great

warmy/dynamic movements.

$\bigcirc$

0

$\bigcirc$

Please write any additional comments

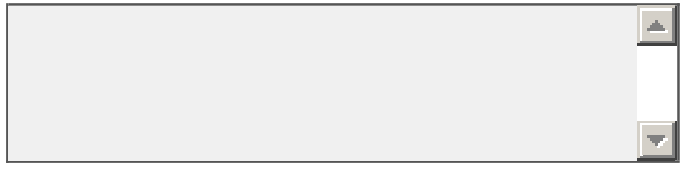

\section{Single Leg Balance Sequencing}

The exercise components listed are progressive within this specific section only. Single leg balance exercises are performed as a combination of sensorimotor facilitation, strength and core stabilization exercises.

Key:

SLB: single leg balance

90- 90: 90ㅇ - shoulder abduction with 90- elbow flexion

MB: medicine ball

\section{Single Leg Balance Sequencing}

11. SLB on stable surface with 90 $90 \mathrm{MB}$ toss: $14.3 \%$ (2) $7.1 \%$ (1)

$28.6 \%$ (4) $35.7 \%$ (5) $14.3 \%$ (2)

3.2914

12. SLB on unstable surface with

90-90 MB toss: $15.4 \%$ (2) $15.4 \%$

(2) $38.5 \%$ (5) $30.8 \%$ (4) $0.0 \%(0)$

Strongly Disagree

Disagree

Neutral

Agree

$\bigcirc$

$\bigcirc$

$\bigcirc$

Strongly Agree

2.8513

13. SLB on unstable surface with

MB chest passes: $7.7 \%$ (1) $7.7 \%$

(1) $23.1 \%$ (3) $46.2 \%$ (6) $15.4 \%$

(2) 3.5413

14. SLB with dry kick: $7.7 \%$ (1)

$0.0 \%$ (0) $15.4 \%$ (2) $61.5 \%$ (8)

$15.4 \%$ (2) 3.7713

15. SLB with resisted kick: $0.0 \%$

(0) $9.1 \%$ (1) $27.3 \%$ (3) $54.5 \%$ (6)

$9.1 \%$ (1) 3.6411

16. SLB with resisted ball kick:

$7.7 \%$ (1) $7.7 \%$ (1) $23.1 \%$ (3)

$38.5 \%$ (5) $23.1 \%$ (3) 3.6213

17. SLB with ball kick on unstable

surface: $0.0 \%(0) 0.0 \%(0) 23.1 \%$

$\begin{array}{lll}0 & 0 & 0 \\ 0 & 0 & 0 \\ 0 & 0 & 0 \\ 0 & 0 & 0 \\ 0 & 0 & 0 \\ 0 & 0 & 0\end{array}$

0

$\bigcirc$

O $\quad 0$

0

O

0

0

O

$O$

0

O $\quad 0$

0

0

0 


\section{Round 2: Development of a Soccer Specific Functional Rehabilitation Program}

(3) $30.8 \%$ (4) $46.2 \%$ (6) 4.2313

18. SLB with resisted ball kick on

unstable surface:

$18.2 \%$ (2) $9.1 \%$ (1) $36.4 \%$ (4)

$18.2 \%$ (2) $18.2 \%$ (2) 3.0911

19. SLB on unstable surface with

juggling: $8.3 \%$ (1) $25.0 \%$ (3)

$8.3 \%$ (1) $41.7 \%$ (5) $16.7 \%$ (2)

3.3312

20. SLB with header: $0.0 \%(0)$

$16.7 \%$ (2) $16.7 \%$ (2) $41.7 \%$ (5)

$25.0 \%$ (3) 3.7512

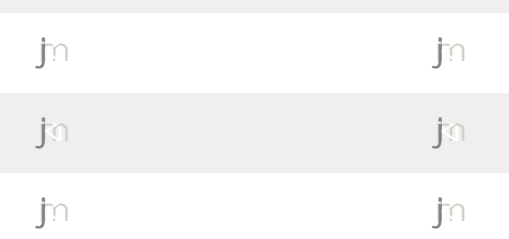

$\bigcirc$

0

0

0

0

0

$\bigcirc$

$\bigcirc$

$\bigcirc$

$\bigcirc$

$\bigcirc$

0

$\bigcirc$

$\bigcirc$

21. SLB on unstable surface with

header:

$0.0 \%(0) 33.3 \%(4) 8.3 \%(1)$

$41.7 \%$ (5) $16.7 \%$ (2) 3.4212

When should these exercise

components be progressed?

22. Mastery of current exercise?:

$0.0 \%(0) 0.0 \%(0) 7.7 \%(1)$

$46.2 \%$ (6) $46.2 \%$ (6) 4.3813

23. Mastery of stable surface?

$0.0 \%(0) 0.0 \%(0) 8.3 \%(1)$

$41.7 \%$ (5) $50.0 \%$ (6) 4.4212

24. Mastery of resistive exercise?

$8.3 \%$ (1) $16.7 \%$ (2) $25.0 \%$ (3)

$25.0 \%$ (3) $25.0 \%$ (3)

Is resisted kick with a resistance

cord? How do you have a resisted

ball kick? if score is lower than

neutral it's b/c it is not safe.

Is this assuming they can already perform SLB under control for a

minute without a ball? Would

probably have them do stable SLB

with header before attempting the

kicking, resisted kick, resisted

unstable kick?

Would do the Mb unstable before the $90-90 \mathrm{mb}$ unstable. would do 20, 21, 19.

Q12-13. unilateral 90-90 MB toss not reflective of soccer demands.

○

$\bigcirc$

$\bigcirc$

O

$\bigcirc$

0

$\bigcirc$

0

0

0

O

0

O

○

0

0

0

O

0

0

0

0

0

0

O

O

O

O

O

0

0

0

0

0

Suggest bilateral throw to mimic

throw-in mechanics. Q22-24.

Exercises should be pogressed

after mastery of current exercise 


\section{Round 2: Development of a Soccer Specific Functional Rehabilitation Program}

progressing from a stable to non-

stable surface, and then from

stable resisted to non-stable non-

resisted exercises.

Please write any additional comments

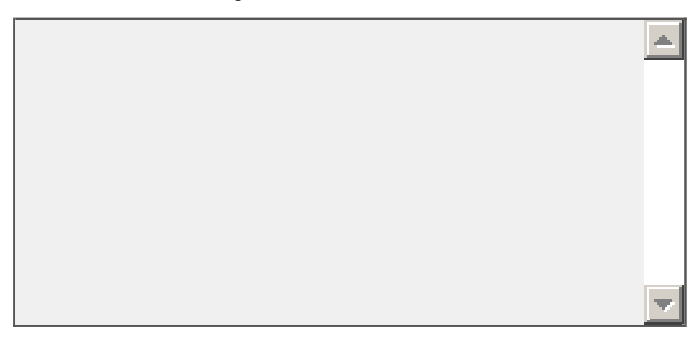

4. Squat Sequencing

The exercise components listed are progressive within this specific section only. Squat exercises are performed as a combination of sensorimotor facilitation, strength and core stabilization exercises.

Key:

SL: Single Leg

MB: Medicine Ball

SB: Swiss Ball 


\section{Round 2: Development of a Soccer Specific Functional Rehabilitation Program}

\section{Squat Sequencing}

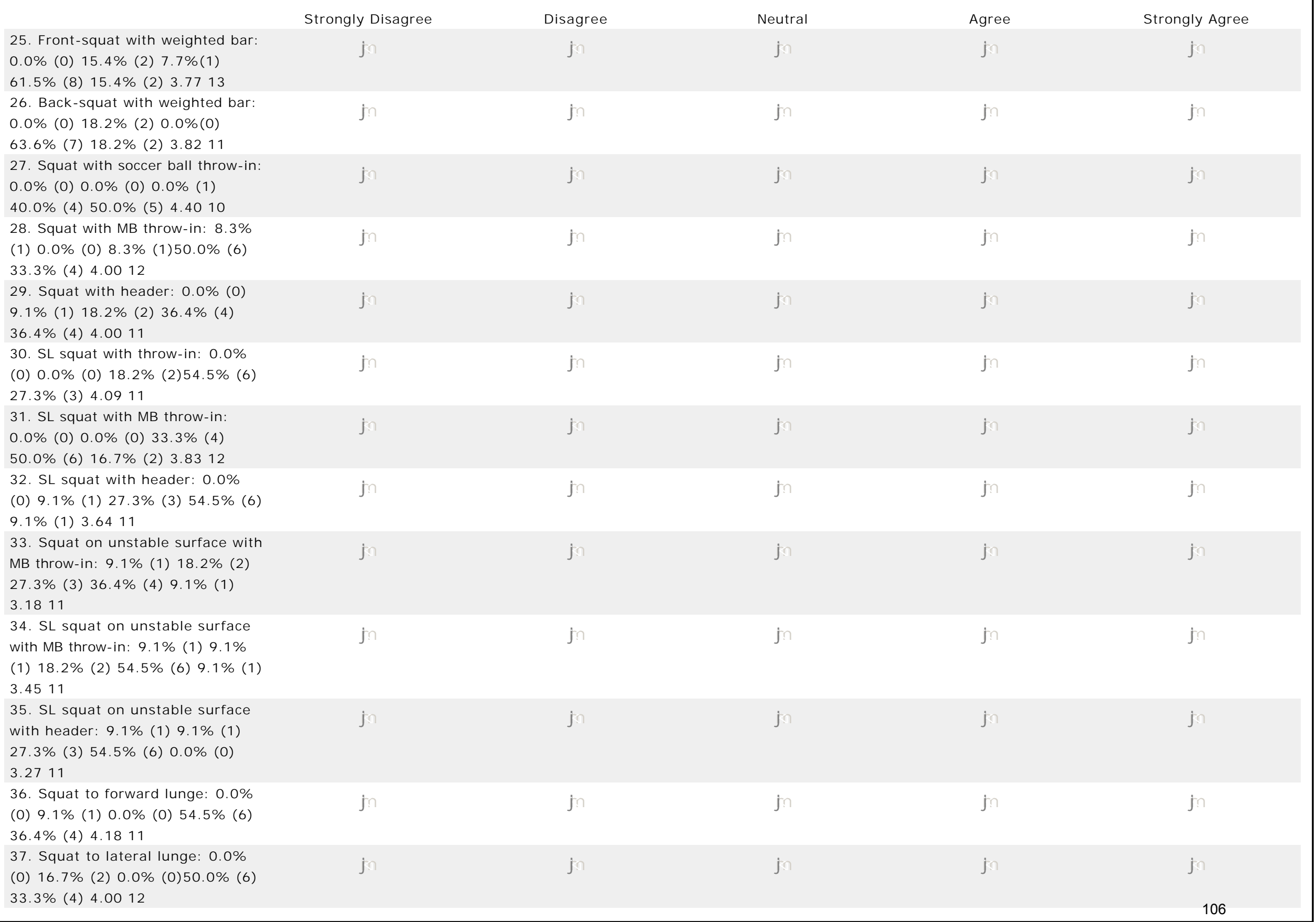




\section{Round 2: Development of a Soccer Specific Functional Rehabilitation Program}

38. SL squat to forward lunge on unstable surface: $9.1 \%$ (1) $0.0 \%$ $\mathrm{O}$

(0) $18.2 \%$ (2) $45.5 \%$ (5) $27.3 \%$

(3) 3.8211

39. SL squat on unstable surface

to forward lunge on unstable

$\bigcirc$

0

0

0

(2) $9.1 \%(1) 0.0 \%(0) 18.2 \%$

(2) $54.5 \%$ (6) $18.2 \%$ (2) 3.7311

40. SL squat to lateral lunge on

unstable surface:

$9.1 \%$ (1) $0.0 \%(0) 9.1 \%(1)$

$63.6 \%$ (7) $18.2 \%$ (2) 3.8211

When should these exercise

components be progressed?

41. Mastery of current exercise?;

$8.3 \%$ (1) $0.0 \%$ (0) $0.0 \%(0)$

$50.0 \%$ (6) $41.7 \%$ (5) 4.1712

42. Mastery of stable surface?:

$0.0 \%(0) 0.0 \%(0) 9.1 \%(1)$

$36.4 \%$ (4) $54.5 \%$ (6) 4.4511

43. Mastery of unstable surface?

$0.0 \%(0) 0.0 \%(0) 10.0 \%(1)$

$50.0 \%(5) 40.0 \%$ (4) 4.3010

Combination movements are

great but, If you are on SL leg how

do you combine the exercise?

Strength exercises should be

mastered with resistance, and

then unstabble surface. I think

you are trying to get too creative

to make this sport specific.

Would have SL squat alone before

adding header. Would do 33 .

before SL progression. Would do

36 and 37 before SL progression

Would do a SL squat to forward

lunge on stable surface, before

adding unstable surface, and add

unstable surface to squat to lunge

progression if doing it with $\mathrm{SL}$

squat.

Would do 32 before 30,31 would

do 35 before 33, 34 .

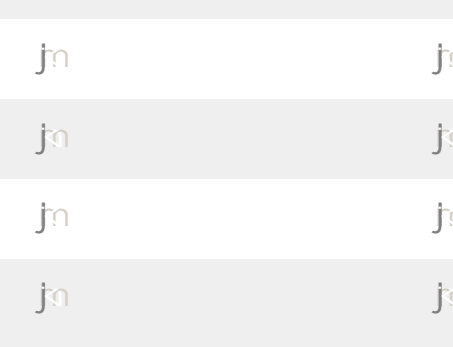

0

0

0

O

$\bigcirc$

O

0

0

0

0

0

0

0

O

O

○

O

O

0

0

$\bigcirc$

$\bigcirc$

$\bigcirc$

$\bigcirc$

Q41-43. Exercises progression

same as previously stated.

Please write any additonal comments

$\begin{array}{ll}0 & 0 \\ 0 & 0\end{array}$

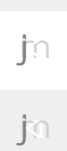

0 


\section{Round 2: Development of a Soccer Specific Functional Rehabilitation Program}

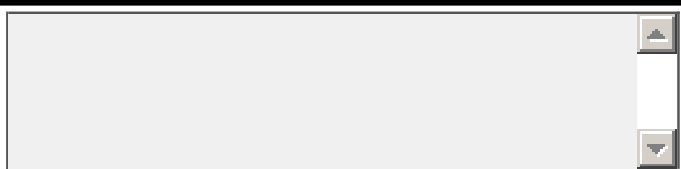

\section{Heel Raise Sequencing}

The exercise components listed are progressive within this specific section only. Heel raise exercises are performed as a combination of sensorimotor facilitation, strength and core stabilization exercises.

Key:

MB: Medicine Ball

SL: Single Leg

\section{Heel Raise Sequencing}

44. Two-legged heel raise with MB throw-in: $8.3 \%$ (1) $0.0 \%$ (0)

$33.3 \%$ (4) $25.0 \%$ (3) $33.3 \%$ (4) 3.7512

45. SL heel raise with MB throw-in: $10.0 \%$ (1) $0.0 \%$ (0) $20.0 \%$ (2)

$40.0 \%$ (4) $30.0 \%$ (3) 3.8010

46. SL heel raise with MB throw-in on unstable:

$9.1 \%$ (1) $0.0 \%$ (0) $27.3 \%$ (3)

$54.5 \%$ (6) $9.1 \%$ (1) 3.5511

47. Heel raise with header: $0.0 \%$

(0) $18.2 \%$ (2) $18.2 \%$ (2) $45.5 \%$

(5) $18.2 \%$ (2) 3.6411

48. SL heel raise with header:

$0.0 \%$ (0) $20.0 \%$ (2) $10.0 \%$ (1)

$60.0 \%$ (6) $10.0 \%$ (1) 3.6010

When should these exercise

components be progressed?

$0.0 \%$ (0) $25.0 \%$ (1) $0.0 \%$ (0)

$50.0 \%$ (2) $25.0 \%$ (1) 3.754

49. Mastery of current exercise?:

$0.0 \%(0) 0.0 \%(0) 0.0 \%(0)$

$63.6 \%$ (7) $36.4 \%$ (4) 4.3611

50 . Mastery of stable surface?:

$9.1 \%$ (1) $0.0 \%$ (0) $9.1 \%(1)$

Strongly Disagree

$\begin{array}{cc}0 & 0 \\ 0 & 0 \\ 0 & 0 \\ 0 & 0 \\ 0 & 0 \\ 0 & 0 \\ 0 & 0 \\ 0 & 0 \\ 0 & 0 \\ 0 & 0\end{array}$

Neutral

Agree

$\bigcirc^{\text {Neutra }}$

$\bigcirc$

Strongly Agree

$45.5 \%$ (5) $36.4 \%$ (4) 4.0011 


\section{Round 2: Development of a Soccer Specific Functional Rehabilitation Program}

47,48 before 45,46

Q49-50. Exercises pogression

same as previously stated
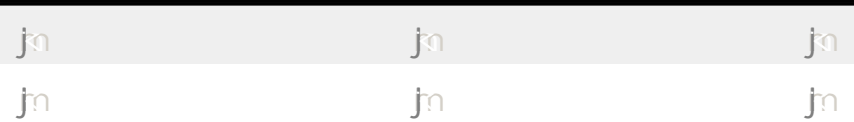

although non-resisted.

Please write any additional comments

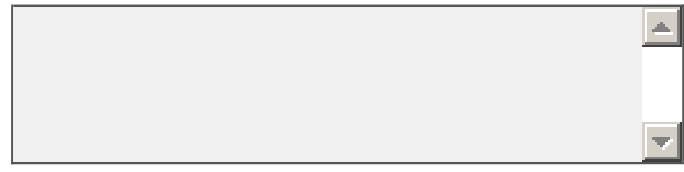

\section{Lunge Sequencing}

The exercise components listed are progressive within this specific section only. Lunge exercises are performed as a combination of sensorimotor facilitation, strength and core stabilization exercises.

Key:

$\mathrm{MB}=$ Medicine Ball

$\mathrm{SB}=$ Swiss Ball

\section{Lunge Sequencing}

51. Forward lunge with MB throw-

in: $9.1 \%$ (1) $0.0 \%$ (0) $18.2 \%$ (2)

$36.4 \%$ (4) $36.4 \%$ (4) 3.9111

52. Forward lunge onto unstable

surface with MB throw-in:

$9.1 \%$ (1) $9.1 \%$ (1) $27.3 \%$ (3)

$27.3 \%$ (3) $27.3 \%$ (3) 3.5511

53. Lateral lunge with $M B$ throw-in:

$8.3 \%(1) 0.0 \%(0) 16.7 \%$ (2)

$58.3 \%$ (7) $16.7 \%$ (2) 3.7512

54. Lateral lunge onto unstable

surface:

$0.0 \%(0) 0.0 \%(0) 18.2 \%(2)$

$63.6 \%$ (7) $18.2 \%$ (2) 4.0011

55. Resisted forward lunge with MB

throw in: $9.1 \%$ (1) $18.2 \%$ (2)

$18.2 \%$ (2) $36.4 \%$ (4) $18.2 \%$ (2)

3.3611

56. Resisted lateral lunge with MB

throw-in: $8.3 \%$ (1) $8.3 \%$ (1)

$33.3 \%(4) 41.7 \%(5) 8.3 \%$ (1)

Strongly Disagree

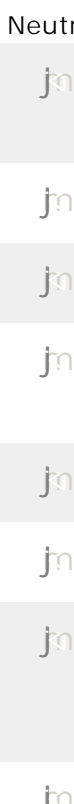

0
0
0
0
0

Agree

0

0

0

0

0

0

0

0
0

trongly Agree

$O$

0

0

0

0

0

0 


\section{Round 2: Development of a Soccer Specific Functional Rehabilitation Program}

3.3312

57. Forward lunge onto SB: $7.7 \%$

(1) $7.7 \%$ (1) $15.4 \%$ (2) $30.8 \%$ (4)

$38.5 \%$ (5) 3.8513

58. Forward lunge onto SB with MB

toss: $16.7 \%$ (2) $16.7 \%$ (2) $8.3 \%$

(1) $33.3 \%$ (4) $25.0 \%$ (3) 3.3312

59. Lateral lunge onto SB: $9.1 \%$

(1) $9.1 \%$ (1) $9.1 \%$ (1) $45.5 \%$ (5)

$27.3 \%$ (3) 3.7311

When should these exercise

components be progressed?

60 . Mastery of current exercise?:

$0.0 \%(0) 0.0 \%(0) 8.3 \%(1)$

$41.7 \%$ (5) $50.0 \%(6) 4.4212$

61 . Mastery of stable surface?:

$0.0 \%$ (0) $0.0 \%$ (0) $9.1 \%$ (1)

$36.4 \%$ (4) $54.5 \%$ (6) 4.4511

62 . Mastery of unstable surface?

$8.3 \%$ (1) $0.0 \%(0) 8.3 \%$ (1)

$50.0 \%$ (6) $33.3 \%$ (4) 4.0012

A throw in is not functional in a

lunge position

Q60-62. Exercises pogression

same as previously stated.

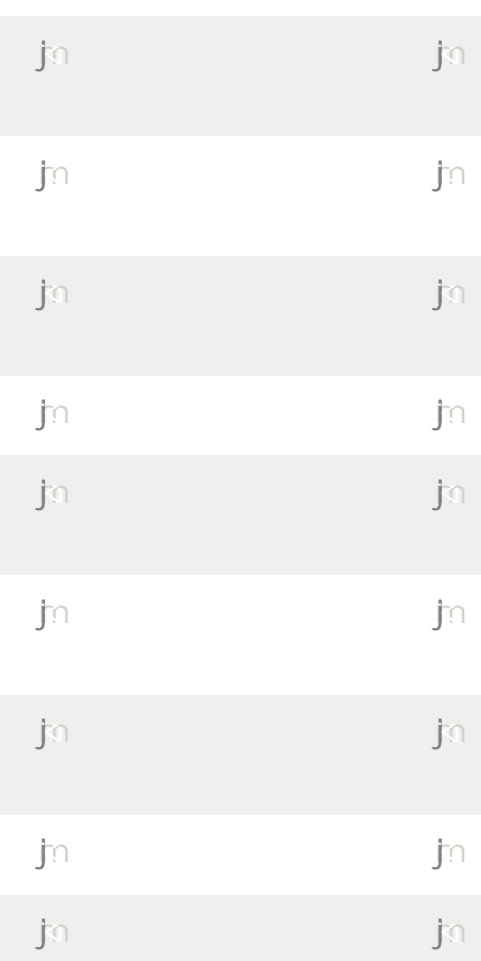

$\bigcirc$

0

$\bigcirc$

0

$\bigcirc$

$\bigcirc$

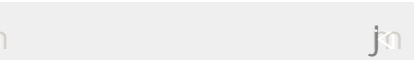

$\bigcirc$

$\bigcirc$

0

$\bigcirc$

$\bigcirc$

$\bigcirc$

$\bigcirc$

$\bigcirc$

0

$\bigcirc$

$\bigcirc$

0

$0 \quad 0$

$\bigcirc$

$\bigcirc$

Please write any additonal comments

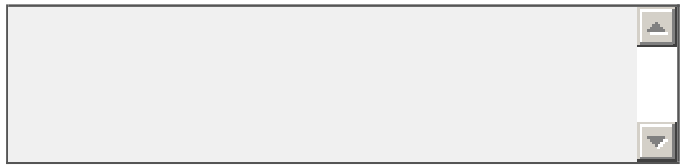

\section{Core Stabilization}

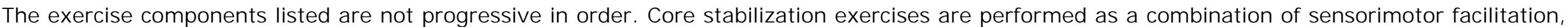
strength and core stabilization exercises.

Key:

MB: Medicine Ball SB: Swiss Ball

SL: Single Leg 


\section{Round 2: Development of a Soccer Specific Functional Rehabilitation Program}

Core Stabilization

63. Diagonal chops with MB: $7.7 \%$

(1) $0.0 \%$ (0) $7.7 \%$ (1) $46.2 \%$ (6)

$38.5 \%$ (5) 4.0813

64. Diagonal chops with MB on unstable surface: $0.0 \%(0) 8.3 \%$

(1) $16.7 \%$ (2) $50.0 \%$ (6) $25.0 \%$

(3) 3.9212

65. Marching on SB with foot traps:

$0.0 \%$ (0) $20.0 \%$ (2) $30.0 \%$ (3)

$30.0 \%$ (3) $20.0 \%$ (2) 3.5010

66. Marching on SB with MB throw

in plus resisted leg extension:

$9.1 \%$ (1) $18.2 \%$ (2) $36.4 \%$ (4)

$18.2 \%(2) 18.2 \%(2) 3.1811$

67. Marching on SB with MB throw-

in: $8.3 \%$ (1) $33.3 \%$ (4) $16.7 \%$ (2)

$33.3 \%(4) 8.3 \%$ (1) 3.0012

68. Marching on SB with juggling:

$9.1 \%$ (1) $27.3 \%$ (3) $0.0 \%$ (0)

$63.6 \%$ (7) $0.0 \%$ (0) 3.1811

69. Side-plank: $0.0 \%(0) 7.7 \%$ (1)

$7.7 \%$ (1) $38.5 \%$ (5) $46.2 \%$ (6)

4.2313

70. Side-plank with resisted hip

flexion: $0.0 \%$ (0) $9.1 \%$ (1) $9.1 \%$

(1) $54.5 \%$ (6) $27.3 \%$ (3) 4.0011

71. Side-plank on SB: $0.0 \%(0)$

$0.0 \%$ (0) $0.0 \%$ (0) $72.7 \%$ (8)

$27.3 \%$ (3) 4.2711

72. Side-plank on SB with resisted

hip flexion: $0.0 \%$ (0) $9.1 \%$ (1)

$9.1 \%$ (1) $63.6 \%$ (7) $18.2 \%$ (2)

3.9111

73. Plank with forearms on SB:

$0.0 \%(0) 0.0 \%$ (0) $9.1 \%$ (1)

$45.5 \%$ (5) $45.5 \%$ (5) 4.3611

74. SL plank with forearms on SB:

$0.0 \%(0) 0.0 \%(0) 9.1 \%$ (1)

$45.5 \%$ (5) $45.5 \%$ (5) 4.3611

75. SL plank with forearms on SB

with weight at ankle: $0.0 \%(0)$

Strongly Disagree

Disagree

Neutral

Agree

Strongly Agree

O

0

O

O

O

O

O

O

O

$\bigcirc$

with weight at ankle: $0.0 \%$ (0)
$10.0 \%$ (1) $20.0 \%$ (2) $50.0 \%$ (5)

$\begin{array}{ll}0 & 0 \\ 0 & 0 \\ 0 & 0 \\ 0 & 0 \\ 0 & 0 \\ 0 & 0 \\ 0 & 0 \\ 0 & 0 \\ 0 & 0 \\ 0 & 0 \\ 0 & 0\end{array}$

$\bigcirc$

O

O

O

$\bigcirc$

0

$\bigcirc$

$\bigcirc$

$\bigcirc$

$\bigcirc$

O

0

0

0

O

0

0

$\bigcirc$

0

0

0

0

0

0

0

0

0

0

0

0

O

O

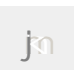




\section{Round 2: Development of a Soccer Specific Functional Rehabilitation Program}

$20.0 \%(2) 3.8010$

76. Plank roll-outs on SB: $0.0 \%$

(0) $0.0 \%(0) 0.0 \%(0) 70.0 \%(7)$

O

$\bigcirc$

$\bigcirc$

$\bigcirc$

0

$30.0 \%$ (3) 4.3010

77. Plank with feet on SB: $0.0 \%$

(0) $0.0 \%$ (0) $8.3 \%$ (1) $50.0 \%$ (6)

$\bigcirc$

$41.7 \%$ (5) 4.3312

78. Plank with feet on SB with

abdominal rolls:

$0.0 \%(0) 0.0 \%(0) 0.0 \%(0)$

$54.5 \%$ (6) $45.5 \%$ (5) 4.4511

79. Plank with feet on SB with roll

pike, pushup: $0.0 \%$ (0) $18.2 \%$ (2)

$\bigcirc$

0

0

0

$18.2 \%$ (2) $36.4 \%$ (4) $27.3 \%$ (3)

3.7311

80. Supine SB rear overhead throw

with MB: $10.0 \%$ (1) $40.0 \%$ (4)

$20.0 \%$ (2) $20.0 \%$ (2) $10.0 \%$ (1)

2.8010

81. Russian twist with MB: $0.0 \%$

(0) $9.1 \%$ (1) $0.0 \%$ (0) $72.7 \%$ (8)

$18.2 \%$ (2) 4.0011

82. 6 inch hold: $18.2 \%$ (2) $0.0 \%$

(0) $18.2 \%$ (2) $45.5 \%$ (5) $18.2 \%$

(2) 3.4511

83. $V$ sit ups: $0.0 \%(0) 10.0 \%(1)$

$10.0 \%$ (1) $60.0 \%$ (6) $20.0 \%$ (2)

3.9010

84. Jack knife sit ups: $0.0 \%(0)$

$10.0 \%$ (1) $30.0 \%$ (3) $50.0 \%$ (5)

$10.0 \%$ (1) 3.6010

85. Crunch on SB with MB toss:

$0.0 \%(0) 0.0 \%$ (0) $30.0 \%$ (3)

$50.0 \%$ (5) $20.0 \%$ (2) 3.9010

86. Kneeling balance on SB with

MB throw in: $9.1 \%$ (1) $18.2 \%$ (2)

○

O

O

○

$\bigcirc$

0

0

0

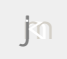

0

O

$\bigcirc$

$\bigcirc$

$36.4 \%$ (4) $27.3 \%$ (3) $9.1 \%$ (1)

3.0911

87. Standing on SB: $18.2 \%$ (2)

$18.2 \%$ (2) $36.4 \%$ (4) $27.3 \%$ (3)

$0.0 \%(0) 2.7311$

88. Russian eccentric hamstrings:

$0.0 \%(0) 0.0 \%(0) 0.0 \%(0)$

$45.5 \%$ (5) $54.5 \%$ (6) 4.5511

89. SL stance figure eight ball

pass: $0.0 \%$ (0) $9.1 \%$ (1) $9.1 \%$ (1)

$\bigcirc$

O

$\bigcirc$

$\bigcirc$

$\bigcirc$

$\bigcirc$

$\bigcirc$

$\bigcirc$

$\bigcirc$

$\bigcirc$

○

$\bigcirc$

○

○

$\bigcirc$

O

○

O

$\bigcirc$

○

O

$\bigcirc$

$\bigcirc$

$\bigcirc$

$\bigcirc$

$\bigcirc$

$\bigcirc$

$\bigcirc$

$\bigcirc$

$\bigcirc$

$\bigcirc$

$\bigcirc$

$\bigcirc$

$\bigcirc$

$\bigcirc$

$\bigcirc$

$\bigcirc$

$\bigcirc$

$\bigcirc$

$\bigcirc$

$54.5 \%$ (6) $27.3 \%$ (3) 4.0011

$\bigcirc$

$\bigcirc$

$\bigcirc$

O

$\bigcirc$

$\bigcirc$

O 


\section{Round 2: Development of a Soccer Specific Functional Rehabilitation Program}

When should these exercise

components be progressed?

O

90. Mastery of current exercise?

$0.0 \%(0) 0.0 \%(0) 8.3 \%(1)$

$41.7 \%$ (5) $50.0 \%$ (6) 4.4212

91. Mastery of neutral spine: $9.1 \%$

(1) $0.0 \%(0) 18.2 \%$ (2) $27.3 \%$ (3)

$45.5 \%$ (5) 4.0011

Neutral pelvis is the most

important. A balance abdominal

and lumbar muscle contraction is

the key for advancement of any

exercises.

Would do plank on forearms

before side plank.
$O$

$\bigcirc$

$\bigcirc$

$\bigcirc$

0
0

0

0

0

0

$\bigcirc$

$\bigcirc$ $\bigcirc$

$\bigcirc$

Please write any additonal comments

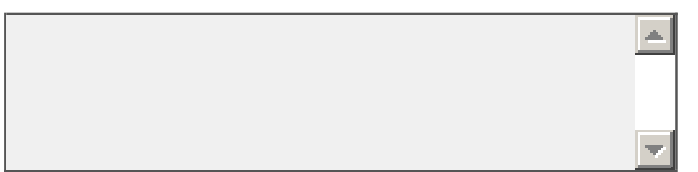

\section{Plyometric exercises}

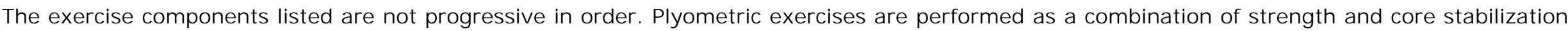
exercises.

Key:

SL: Single Leg

MB: Medicine Ball 


\section{Round 2: Development of a Soccer Specific Functional Rehabilitation Program}

Plyometric Exercises

92. SL step-up with MB throw-in: $9.1 \%$ (1) $9.1 \%$ (1) $18.2 \%$ (2)

$45.5 \%$ (5) $18.2 \%$ (2) 3.5511

93. SL step-up with resistance with

MB throw-in: $8.3 \%$ (1) $25.0 \%$ (3)

$16.7 \%$ (2) $33.3 \%$ (4) $16.7 \%$ (2)

3.2512

94. SL step up onto unstable

surface with MB throw-in: $9.1 \%$ (1)

\section{Strongly Disagree}

$\bigcirc$

0

$18.2 \%$ (2) $18.2 \%$ (2) $45.5 \%$ (5)

$9.1 \%$ (1) 3.2711

95. SL resisted step-up onto

unstable surface with MB throw:

$9.1 \%$ (1) $18.2 \%$ (2) $36.4 \%$ (4)

$36.4 \%$ (4) $0.0 \%(0) 3.0011$

96. Depth box jumps with MB

throwin: $8.3 \%$ (1) $16.7 \%(2)$

$33.3 \%$ (4) $33.3 \%$ (4) $8.3 \%$ (1)

3.1712

97. Depth box jumps with header

$0.0 \%(0) 0.0 \%(0) 8.3 \%(1)$

$66.7 \%$ (8) $25.0 \%$ (3) 4.1712

98. Squat jump to header: $0.0 \%$

(0) $0.0 \%(0) 0.0 \%(0) 40.0 \%$ (4)

$60.0 \%$ (6) 4.6010

99. Lunge jump to header: $0.0 \%$

(0) $0.0 \%(0) 16.7 \%$ (2) $58.3 \%$ (7)

$25.0 \%$ (3) 4.0812

100. Lateral lunge with explosive

ball save (keeper specific): $0.0 \%$

(0) $0.0 \%(0) 0.0 \%(0) 81.8 \%(9)$

$18.2 \%$ (2) 4.1811

101. Pullover with MB: $8.3 \%$ (1)

$16.7 \%$ (2) $25.0 \%$ (3) $25.0 \%$ (3)

$25.0 \%$ (3) 3.4212

102. Pullover pass with MB: $9.1 \%$

(1) $18.2 \%$ (2) $18.2 \%$ (2) $36.4 \%$

(4) $18.2 \%$ (2) 3.3611

103. Pullover with sit-up: $0.0 \%(0)$

$27.3 \%(3) 0.0 \%$ (0) $63.6 \%$ (7)

$9.1 \%$ (1) 3.5511

104. Overhead to Feet MB: $0.0 \%$

(0) $9.1 \%$ (1) $9.1 \%$ (1) $72.7 \%$ (8)

$9.1 \%(1) 3.8211$

O

$\bigcirc$
Neutral

Disagree

0

Agree

$\bigcirc$

$\bigcirc$

O

O

$\bigcirc$

O

0

$\bigcirc$

0

$\bigcirc$

0

0

$O$

$\bigcirc$

0

0

0

$\bigcirc$

0

0

0

$\bigcirc$

$\bigcirc$

0

0

0

0

0

$\bigcirc$

0

0

0

O

0

$\bigcirc$

0

$\bigcirc$

0

0

0 


\section{Round 2: Development of a Soccer Specific Functional Rehabilitation Program}

105. Knee Throw: $0.0 \%$ (0) $20.0 \%$

(2) $30.0 \%$ (3) $50.0 \%$ (5) $0.0 \%(0)$

3. 3010

106. Kick toss: $0.0 \%(0) 18.2 \%$

(2) $18.2 \%$ (2) $45.5 \%$ (5) $18.2 \%$

(2) 3.6411

107. Sit-up toss: $0.0 \%(0) 0.0 \%$

(0) $27.3 \%$ (3) $63.6 \%$ (7) $9.1 \%$ (1)

3.8211

108. Backward MB throw: $0.0 \%$ (0)

$9.1 \%$ (1) $18.2 \%$ (2) $54.5 \%$ (6)

O

O

O

○

O

$18.2 \%$ (2) 3.8211

109. Kneeling throw: $0.0 \%(0)$

$9.1 \%$ (1) $27.3 \%$ (3) $45.5 \%$ (5)

$18.2 \%$ (2) 3.7311

110. Over and Through the Legs

with MB: $9.1 \%$ (1) $27.3 \%$ (3)

$18.2 \%$ (2) $27.3 \%$ (3) $18.2 \%$ (2)

3.1811

111. Hurdler Extension with MB

$0.0 \%$ (0) $9.1 \%$ (1) $36.4 \%$ (4)

$36.4 \%$ (4) $18.2 \%$ (2) 3.6411

112. Front Toss: $0.0 \%$ (0) $9.1 \%$

(1) $36.4 \%$ (4) $36.4 \%$ (4) $18.2 \%$

(2) 3.6411

113. Leg Toss: $0.0 \%$ (0) $9.1 \%$ (1)

$18.2 \%$ (2) $63.6 \%$ (7) $9.1 \%$ (1)

3.7311

114. Heel Toss with MB: $0.0 \%(0)$

$18.2 \%$ (2) $18.2 \%$ (2) $54.5 \%$ (6)

$9.1 \%$ (1) 3.5511

115. Lateral hops over cone: $0.0 \%$

(0) $8.3 \%$ (1) $0.0 \%$ (0) $41.7 \%$ (5)

$50.0 \%$ (6) 4.3312

116. Forward/Backward hops over

cone:

$0.0 \%(0) 0.0 \%(0) 0.0 \%(0)$

$54.5 \%$ (6) $45.5 \%$ (5) 4.4511

117. SL hops over cone: $0.0 \%(0)$

$0.0 \%$ (0) $8.3 \%$ (1) $41.7 \%$ (5)

$50.0 \%$ (6) 4.4212

118. Vertical Jumps with header:

$0.0 \%(0) 0.0 \%(0) 0.0 \%$ (0)

$45.5 \%$ (5) $54.5 \%$ (6) 4.5511

119. Scissors jumps: $0.0 \%(0)$

$0.0 \%(0) 0.0 \%$ (0) $72.7 \%$ (8)
O

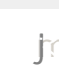

$\bigcirc$

$\bigcirc$

0

0

0

0

$\bigcirc$

O

0

O

0

$\bigcirc$

$\bigcirc$ $\bigcirc$

$\bigcirc$

0

0

O

0

$\bigcirc$

$\bigcirc$

$O$

$\bigcirc$

$O$

0

0

$\bigcirc$

$O$ $\bigcirc$

0

0

0

O

0

0

0

0

0

0

0

0

0

0
0

0

0

0

0

$\bigcirc$

$\bigcirc$

0

$O$

0

$\bigcirc$

0

0

O

O 


\section{Round 2: Development of a Soccer Specific Functional Rehabilitation Program}

$27.3 \%$ (3) 4.2711

120. Resisted slide board and catch: $0.0 \%$ (0) $9.1 \%$ (1) $27.3 \%$

(3) $36.4 \%$ (4) $27.3 \%$ (3) 3.8211

$\mathrm{SL}$ exercises are not plyometric

adding a throw in takes away from

$\bigcirc$

$\bigcirc$

the exercise and makes it more

unspecific to proper form.

Would do SL step up w/resistance

before adding a MB throw in.

Please write any additonal comments

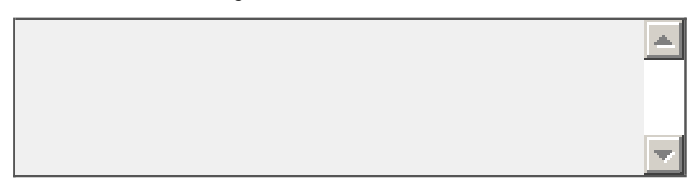

$\bigcirc$

$\bigcirc$

O
O

O

$\bigcirc$ $\bigcirc$

$\bigcirc$

O

\section{Functional Activity Progression}

The following sections are Functional Activity Progression. These exercises are not progressive in order.

\section{Functional Activity Progression}

Kicking Progression

121. Dry kick with weight shift:

$0.0 \%(0) 0.0 \%(0) 0.0 \%(0)$

Strongly Disagree

Disagree

$50.0 \%$ (5) $50.0 \%$ (5) 4.5010

122. Dry kick with resistance:

$9.1 \%$ (1) $0.0 \%$ (0) $9.1 \%$ (1)

$54.5 \%$ (6) $27.3 \%$ (3) 3.9111

123. Kick stationary ball, short distance: $0.0 \%(0) 0.0 \%$ (0) $8.3 \%$

(1) $41.7 \%$ (5) $50.0 \%$ (6) 4.4212

124. Kick stationary ball, long

distance: $0.0 \%(0) 8.3 \%$ (1) $0.0 \%$

(0) $41.7 \%$ (5) $50.0 \%$ (6) 4.3312

125. Kick moving ball: short

distance: $8.3 \%$ (1) $0.0 \%$ (0) $0.0 \%$

(0) $41.7 \%$ (5) $50.0 \%$ (6) 4.2512

126. Kick moving ball: long

distance: $0.0 \%(0) 0.0 \%(0) 0.0 \%$

(0) $45.5 \%$ (5) $54.5 \%$ (6) 4.5511

127. Knee traps to kicks: $0.0 \%(0)$

$18.2 \%$ (2) $9.1 \%$ (1) $36.4 \%$ (4)

$36.4 \%$ (4) 3.9111

$0_{0}^{\text {Neutral }}$

0

0

0

0

0

0

0

0

$\bigcirc$

$\bigcirc$

)

(1)

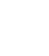

$\bigcirc$ $\bigcirc$

$\bigcirc$

0

O

0

0

0

0 


\section{Round 2: Development of a Soccer Specific Functional Rehabilitation Program}

128. Kick to juggling: $0.0 \%(0)$ $0.0 \%$ (0) $9.1 \%$ (1) $63.6 \%(7)$

$27.3 \%$ (3) 4.1811

129. Chest pass to kick to header:

$0.0 \%$ (0) $9.1 \%$ (1) $9.1 \%$ (1)

C

$54.5 \%$ (6) $27.3 \%$ (3) 4.0011

130. Dry kick with plant onto

unstable surface: $0.0 \%(0) 10.0 \%$

(1) $0.0 \%(0) 60.0 \%(6) 30.0 \%(3)$

4.1010

131. Resisted kick with plant onto

unstable surface: $0.0 \%$ (0) $10.0 \%$

(1) $10.0 \%$ (1) $50.0 \%$ (5) $30.0 \%$

(3) 4.0010

132. Stationary ball kick with plant

onto unstable surface:

O

$\bigcirc$

$\bigcirc$

$\bigcirc$

0

$0.0 \%(0) 9.1 \%$ (1) $0.0 \%(0)$

$54.5 \%$ (6) $36.4 \%$ (4) 4.1811

133. Moving ball kick with plant

onto unstable surface:

$0.0 \%$ (0) $18.2 \%$ (2) $9.1 \%$ (1)

$36.4 \%$ (4) $36.4 \%$ (4) 3.9111

When should these exercise

components be progressed?

134. Mastery of current exercise?

$0.0 \%(0) 0.0 \%(0) 8.3 \%(1)$

$58.3 \%$ (7) $33.3 \%$ (4) 4.2512

Anaerobic and Aerobic

Progression: $0.0 \%(0) 0.0 \%(0)$

$0.0 \%(0) 0.0 \%(0) 100.0 \%$ (2)

5.002

135. Fartleks: $0.0 \%(0) 0.0 \%(0)$

$9.1 \%$ (1) $45.5 \%$ (5) $45.5 \%$ (5)

4.3611

136. 50/50 Interval Training:

$0.0 \%(0) 0.0 \%(0) 9.1 \%(1)$

$63.6 \%$ (7) $27.3 \%$ (3) 4.1811

137. Bike: $0.0 \%(0) 0.0 \%(0)$

$27.3 \%$ (3) $54.5 \%$ (6) $18.2 \%$ (2)

3.9111

138. Elliptical: $0.0 \%(0) 9.1 \%(1)$

$18.2 \%$ (2) $54.5 \%$ (6) $18.2 \%$ (2)

3.8211

139. Stair Climber: $0.0 \%$ (0) $9.1 \%$

(1) $45.5 \%$ (5) $27.3 \%$ (3) $18.2 \%$

(2) 3.5511 $\bigcirc$

O

O

$\bigcirc$

$\bigcirc$

O

0

$\bigcirc$

0

0

$\bigcirc$

0

0

0

$O$

0

$O$

0

0

$O$

$\bigcirc$

0

$\bigcirc$

0

0

0

O

O

0

0

0
0
$O$

O

0
O 


\section{Round 2: Development of a Soccer Specific Functional Rehabilitation Program}

140. Treadmill: $9.1 \%$ (1) $0.0 \%$ (0)

$9.1 \%$ (1) $54.5 \%$ (6) $27.3 \%$ (3)

$\mathrm{O}$

3.9111

141. 1 -mile endurance: $0.0 \%(0)$

$9.1 \%(1) 0.0 \%(0) 72.7 \%(8)$

$18.2 \%$ (2) 4.0011

142. 2 -mile endurance: $0.0 \%(0)$

$9.1 \%$ (1) $27.3 \%$ (3) $45.5 \%$ (5)

$18.2 \%$ (2) 3.7311

When should these exercise

components be progressed?

143. $50 \%$ max heart rate

maintained for specified time:

$9.1 \%$ (1) $18.2 \%$ (2) $9.1 \%$ (1)

$45.5 \%$ (5) $18.2 \%$ (2) 3.4511

144. $60 \%$ max heart rate

maintained for specified time:

$10.0 \%$ (1) $20.0 \%$ (2) $20.0 \%$ (2)

$30.0 \%$ (3) $20.0 \%$ (2) 3.3010

145. $70 \%$ max heart rate

maintained for specified time:

$9.1 \%(1) 0.0 \%$ (0) $18.2 \%$ (2)

$36.4 \%$ (4) $36.4 \%$ (4) 3.9111

146. $80 \%+\max$ heart rate

maintained for specified time:

$11.1 \%$ (1) $0.0 \%$ (0) $33.3 \%$ (3)

$22.2 \%$ (2) $33.3 \%$ (3) 3.679

147. Completion of 15 minutes of

specified aerobic training: $10.0 \%$

(1) $0.0 \%$ (0) $30.0 \%$ (3) $50.0 \%$ (5)

$10.0 \%$ (1) 3.5010

148. Completion of 20 minutes of

specified aerobic training:

$10.0 \%$ (1) $0.0 \%$ (0) $20.0 \%$ (2)

$60.0 \%$ (6) $10.0 \%$ (1) 3.6010

149. Completion of $30+$ minutes

of specified aerobic training:

$9.1 \%(1) 0.0 \%(0) 18.2 \%(2)$

$54.5 \%$ (6) $18.2 \%$ (2) 3.7311

Agility Progression

150. Figure eight runs: $0.0 \%(0)$

$0.0 \%(0) 0.0 \%(0) 45.5 \%$ (5)

$54.5 \%$ (6) 4.5511

151. Zigzag runs: $0.0 \%$ (0) $0.0 \%$

(0) $0.0 \%$ (0) $45.5 \%$ (5) $54.5 \%$ (6)

4.5511

C

$\bigcirc$

$\bigcirc$

$\bigcirc$

0

0

0

O

0

0

0

○

\section{$\mathrm{O}$}

$\mathrm{O}$

Prog

0

0

0

0

0

0

0

0

0

0

0

0

0

0

0

O

O

O

O

O

0

0

0

0

$\bigcirc$

○

$\bigcirc$

O 


\section{Round 2: Development of a Soccer Specific Functional Rehabilitation Program}

152. T-run: $0.0 \%(0) 18.2 \%(2)$

$0.0 \%(0) 45.5 \%(5) 36.4 \%(4)$

4.0011

153. SL dot hop Bounding: $0.0 \%$

(0) $0.0 \%$ (0) $9.1 \%$ (1) $63.6 \%(7)$

$27.3 \%$ (3) 4.1811

154. Two-legged dot hop: $0.0 \%$

(0) $0.0 \%(0) 0.0 \%$ (0) $72.7 \%$ (8)

0

$\bigcirc$

$27.3 \%$ (3) 4.2711

155. Ladder line run: $0.0 \%(0)$

$0.0 \%(0) 0.0 \%(0) 63.6 \%(7)$

$36.4 \%$ (4) 4.3611

156. Ladder line sprint and

backpedal: $0.0 \%(0) 0.0 \%(0)$

$0.0 \%$ (0) $63.6 \%$ (7) $36.4 \%$ (4)

4.3611

157. Ladder line shuffles: $0.0 \%$

(0) $0.0 \%(0) 9.1 \%$ (1) $54.5 \%$ (6)

$36.4 \%$ (4) 4.2711

158. Pro-Agility Run: $0.0 \%(0)$

$0.0 \%$ (0) $9.1 \%$ (1) $63.6 \%$ ( 7 )

$27.3 \%$ (3) 4.1811

159. Box Runs: $0.0 \%(0) 0.0 \%(0)$

$27.3 \%$ (3) $45.5 \%$ (5) $27.3 \%$ (3)

4.0011

160. Carioca Runs: $0.0 \%$ (0) $0.0 \%$

(0) $18.2 \%$ (2) $45.5 \%$ (5) $36.4 \%$

(4) 4.1811

161. 20-minute run with dribbling:

$9.1 \%$ (1) $27.3 \%$ (3) $27.3 \%$ (3)

$9.1 \%$ (1) $27.3 \%$ (3) 3.1811

162. Zigzag runs with dribbling:

$0.0 \%(0) 0.0 \%(0) 0.0 \%(0)$

$54.5 \%$ (6) $45.5 \%$ (5) 4.4511

163. T-run with dribbling: $0.0 \%(0)$

$18.2 \%$ (2) $9.1 \%$ (1) $45.5 \%$ (5)

$27.3 \%$ (3) 3.8211

164. Up and back dot run with

dribbling:

$0.0 \%(0) 9.1 \%$ (1) $18.2 \%(2)$

$45.5 \%$ (5) $27.3 \%$ (3) 3.9111

165. Ladder line run with dribbling:

$10.0 \%$ (1) $0.0 \%$ (0) $20.0 \%$ (2)

$40.0 \%$ (4) $30.0 \%$ (3) 3.8010

166. Box Runs with dribbling:

$0.0 \%(0) 0.0 \%(0) 20.0 \%(2)$

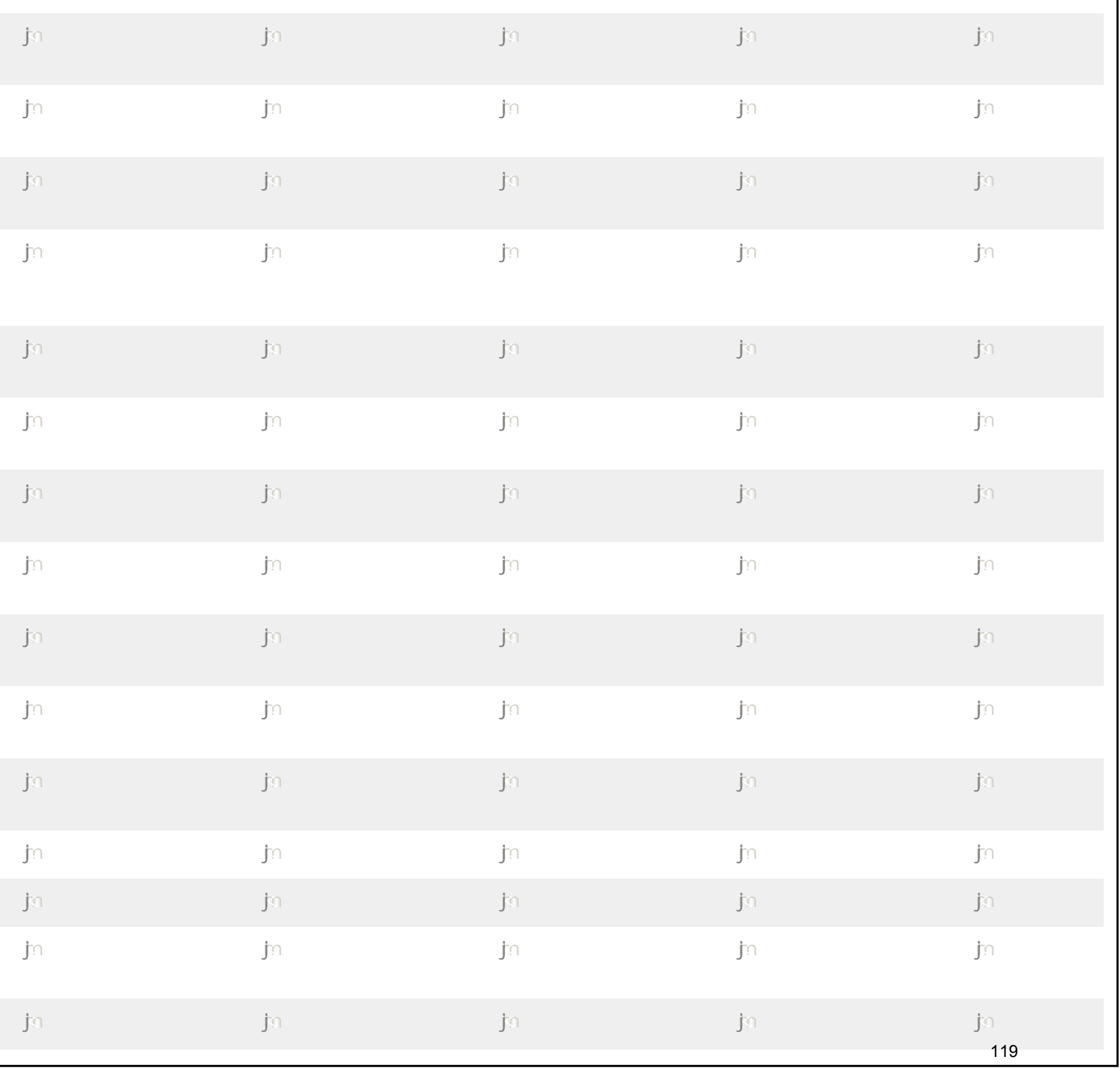




\section{Round 2: Development of a Soccer Specific Functional Rehabilitation Program}

$50.0 \%$ (5) $30.0 \%$ (3) 4.1010

167. Figure eight runs with

dribbling: $0.0 \%(0) 10.0 \%$ (1)

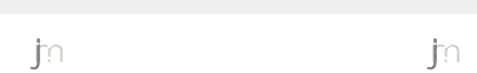

$\bigcirc$

$\bigcirc$

$\bigcirc$

$10.0 \%$ (1) $50.0 \%$ (5) $30.0 \%$ (3)

4.0010

168. Fartleks with dribbling: $0.0 \%$

(0) $18.2 \%$ (2) $9.1 \%$ (1) $36.4 \%$ (4)

$36.4 \%$ (4) 3.9111

dry kick???????? this page of the

questionaire looses focus of the

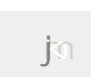

0

$\circlearrowleft$

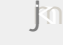

$\bigcirc$

project.

Please write any additonal comments

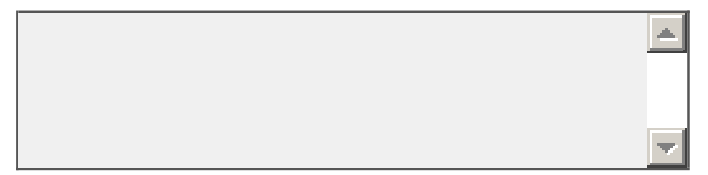


Greetings Again,

This is a reminder that the questionnaire can be submitted by March 9, 2009 for participation in the study Development of a Soccer Specific Functional Rehabilitation Program Using the Modified Delphi Technique This is an excellent opportunity for you to take part in research to develop a functional rehabilitation program for lower extremity injuries of soccer players. I will be conducting this research study with the primary investigator Michelle A. Sandrey PhD, ATC to fulfill requirements for a Master's thesis and to complete an MS degree in Athletic Training.

For those of you who have already submitted your questionnaire or are in the process, I apologize for this interruption and thank you for your participation. For those of you who no longer have the original information, please go to the following website to take the survey: http://www.surveymonkey.com/s.aspx?sm=SjqT3mv9oOg9xALkMheuOg_3d_3d

Your expert opinion is very important in developing this exercise program. The second round questionnaire will be the final step in developing a soccer specific functional rehabilitation program. This is your opportunity to see the results of the first round as well as rate and comment on the additional responses. Your final responses are very important and will be beneficial to help athletic trainers and physical therapists when designing their own functional rehabilitation program.

If you have any questions or concerns please contact Sarah Leslie (586) 899-3262 or at (724) 852-3304 or by email at sleslie2@mix.wvu.edu, or Dr. Michelle Sandrey, Graduate Athletic Training Program Director at West Virginia University, at (304) 293-3295 x 5220 or at msandrey@mail.wvu.edu.

Thank you for your participation!

Kind regards,

Sarah Leslie, ATC

* West Virginia University Institutional Review Board acknowledgment of this study is on file 
APPENDIX D

ADDITIONAL RESULTS

Table D1. Highest Degree Attained

\begin{tabular}{lcc} 
Degree & Number & Percent \\
Bachelor's & 1 & 6.3 \\
Master's & 8 & 50.0 \\
Ph. D./Ed. D/Other doctorate & 6 & 37.5 \\
M.D./D.O. & 2 & 12.5 \\
Other & 0 & 0 \\
\hline
\end{tabular}

Table D2. Professional Credentials Held

\begin{tabular}{lcc}
\hline Credentials & Number & Percent \\
ATC & 9 & 64.3 \\
PT & 4 & 28.6 \\
CSCS & 6 & 42.9 \\
PES & 2 & 14.3 \\
None of the Above/ Researcher & 1 & 7.1 \\
Other & 5 & 35.7 \\
\hline
\end{tabular}

Table D3. Length Participating in Primary Profession

\begin{tabular}{lcc} 
Years & Number & Percent \\
1-4 years & 5 & 31.3 \\
5-9 years & 2 & 12.5 \\
$10+$ years & 9 & 56.3 \\
\hline
\end{tabular}

Table D4. Length of Time Practicing as ATC or PT in soccer

\begin{tabular}{lcc}
\hline Years & Number & Percent \\
1-4 years & 5 & 33.3 \\
5-9 years & 3 & 20.0 \\
10+ years & 5 & 33.3 \\
Not Applicable & 2 & 13.3 \\
Key: ATC= Athletic Trainer Certified; PT= Physical Therapist & & \\
\hline
\end{tabular}

Table D5. Practice Setting More Than 50\% of Time

\begin{tabular}{lcc}
\hline Setting & Number & Percent \\
Academic/Research & 5 & 31.3 \\
Athletic Training Room & 7 & 43.8 \\
Sports Medicine or Outpatient Clinic & 4 & 25.0 \\
Other & 0 & 0 \\
\hline
\end{tabular}


Table D6. Additional Work Setting

\begin{tabular}{lcc}
\hline Setting & Number & Percent \\
Academic/ Research & 4 & 26.7 \\
Athletic Training Room & 1 & 6.7 \\
Sports Medicine or Outpatient Clinic & 6 & 40.0 \\
Other & 1 & 6.7 \\
None & 5 & 33.3 \\
\hline
\end{tabular}

Table D7. Presentations at Professional Meetings

\begin{tabular}{lcc}
\hline Number & Number & Percent \\
0 & 1 & 6.3 \\
$1-2$ & 2 & 25.0 \\
$3-4$ & 1 & 6.3 \\
$5+$ & 10 & 62.5 \\
\hline
\end{tabular}

Table D8. Number of Publications

\begin{tabular}{lcc}
\hline Number & Number & Percent \\
0 & 3 & 18.8 \\
$1-2$ & 3 & 18.8 \\
$3-4$ & 1 & 6.3 \\
$5+$ & 9 & 56.3 \\
\hline
\end{tabular}


Table D9. Percentage Distribution and Mean Scores for First and Second Round - Dynamic Flexibility

\begin{tabular}{|c|c|c|c|c|c|c|c|c|c|c|c|c|c|}
\hline \multirow[b]{2}{*}{ Exercise Component } & \multicolumn{3}{|c|}{1} & \multicolumn{2}{|c|}{2} & \multicolumn{2}{|c|}{3} & \multicolumn{2}{|c|}{4} & \multicolumn{2}{|c|}{5} & \multicolumn{2}{|c|}{ Mean } \\
\hline & Round & $\mathrm{R} 1$ & $\mathrm{R} 2$ & $\mathrm{R} 1$ & $\mathrm{R} 2$ & $\mathrm{R} 1$ & $\mathrm{R} 2$ & $\mathrm{R} 1$ & $\mathrm{R} 2$ & $\mathrm{R} 1$ & $\mathrm{R} 2$ & $\mathrm{R} 1$ & $\mathrm{R} 2$ \\
\hline Walking Lunge with Torso Rotation* & & 0.0 & 0.0 & 21.4 & 0.0 & 28.6 & 10.0 & 14.3 & 70.0 & 0.0 & 20.0 & 3.64 & 4.10 \\
\hline Walking Side-Lunge* & & 0.0 & 0.0 & 16.7 & 0.0 & 33.4 & 9.1 & 25.0 & 72.4 & 25.0 & 18.2 & 3.58 & 4.00 \\
\hline Walking Hurdler* & & 0.0 & 0.0 & 16.7 & 0.0 & 25.0 & 22.2 & 16.7 & 55.6 & 41.7 & 22.2 & 3.38 & 4.00 \\
\hline Walking Piriformis Stretch & & 8.3 & 11.1 & 8.3 & 11.1 & 25.0 & 22.2 & 41.7 & 44.4 & 16.7 & 11.1 & 3.50 & 3.33 \\
\hline Forward Leg Swings & & 0.0 & 0.0 & 16.7 & 0.0 & 8.3 & 18.2 & 25.0 & 36.4 & 50.0 & 45.5 & 4.08 & 4.27 \\
\hline Lateral Leg Swings* & & 0.0 & 0.0 & 18.2 & 0.0 & 18.2 & 18.2 & 27.3 & 27.3 & 36.4 & 54.5 & 3.82 & 4.36 \\
\hline High Knee Hug & & 0.0 & 0.0 & 18.2 & 0.0 & 18.2 & 20.0 & 27.3 & 70.0 & 36.4 & 10.0 & 3.82 & 3.9 \\
\hline Inverted Hamstrings & & 0.0 & 0.0 & 8.3 & 11.1 & 25.0 & 22.2 & 25.0 & 44.4 & 41.7 & 22.2 & 4.00 & 3.77 \\
\hline Butt Kick Hug & & 0.0 & 0.0 & 18.2 & 0.0 & 27.3 & 44.4 & 45.5 & 44.4 & 9.1 & 11.1 & 3.45 & 3.66 \\
\hline Iliotibial Band Cross-Over & & 0.0 & 0.0 & 27.3 & 0.0 & 18.2 & 44.4 & 36.4 & 55.6 & 18.2 & 0.0 & 3.45 & 3.55 \\
\hline
\end{tabular}

Key: R= Round; *= change between rounds, meeting consensus in R2; highlight= included in program

Table D10. Percentage Distribution and Mean Scores for First and Second Round - Single Leg Balance Sequencing

\begin{tabular}{|c|c|c|c|c|c|c|c|c|c|c|c|c|}
\hline \multirow[b]{2}{*}{ Exercise Component } & \multicolumn{2}{|c|}{1} & \multicolumn{2}{|c|}{2} & \multicolumn{2}{|c|}{3} & \multicolumn{2}{|c|}{4} & \multicolumn{2}{|c|}{5} & \multicolumn{2}{|c|}{ Mean } \\
\hline & $\mathrm{R} 1$ & $\mathrm{R} 2$ & $\mathrm{R} 1$ & $\mathrm{R} 2$ & $\mathrm{R} 1$ & $\mathrm{R} 2$ & $\mathrm{R} 1$ & $\mathrm{R} 2$ & $\mathrm{R} 1$ & $\mathrm{R} 2$ & $\mathrm{R} 1$ & $\mathrm{R} 2$ \\
\hline Stable surface with $90-90 \mathrm{MB}$ toss & 16.7 & 0.0 & 8.3 & 0.0 & 25.0 & 28.6 & 33.3 & 71.4 & 16.7 & 0.0 & 3.25 & 3.71 \\
\hline Unstable surface with $90-90 \mathrm{MB}$ toss & 18.2 & 0.0 & 18.2 & 0.0 & 36.4 & 28.6 & 27.3 & 71.4 & 0.0 & 0.0 & 2.73 & 3.71 \\
\hline Unstable surface with MB chest pass & 9.1 & 0.0 & 9.1 & 0.0 & 27.3 & 37.5 & 45.5 & 62.5 & 9.1 & 0.0 & 3.36 & 3.63 \\
\hline With dry kick & 9.1 & 0.0 & 0.0 & 0.0 & 18.2 & 25.0 & 54.5 & 75.0 & 18.2 & 0.0 & 3.73 & 3.75 \\
\hline Resisted dry kick & 0.0 & 0.0 & 11.1 & 14.3 & 33.3 & 28.6 & 44.4 & 42.9 & 11.1 & 14.3 & 3.56 & 3.57 \\
\hline Resisted ball kick & 9.1 & 0.0 & 9.1 & 14.3 & 9.1 & 0.0 & 45.5 & 71.4 & 27.3 & 14.3 & 3.73 & 3.86 \\
\hline Ball kick on unstable surface & 0.0 & 0.0 & 0.0 & 0.0 & 18.2 & 12.5 & 27.3 & 50.0 & 54.5 & 37.5 & 4.36 & 4.25 \\
\hline Resisted ball kick on unstable surface & 22.2 & 0.0 & 11.1 & 16.7 & 22.2 & 16.7 & 22.2 & 33.3 & 22.2 & 33.3 & 3.11 & 3.83 \\
\hline Unstable surface with juggling & 10.0 & 0.0 & 30.0 & 14.3 & 10.0 & 28.6 & 30.0 & 57.1 & 20.0 & 0.0 & 3.20 & 3.43 \\
\hline With header* & 0.0 & 0.0 & 20.0 & 0.0 & 20.0 & 14.3 & 40.0 & 71.4 & 20.0 & 14.3 & 3.60 & 4.00 \\
\hline Unstable surface with header & 0.0 & 0.0 & 0.0 & 0.0 & 9.1 & 22.2 & 54.5 & 44.4 & 36.4 & 33.3 & 4.27 & 3.80 \\
\hline Progression with mastery of stable surface & 0.0 & 0.0 & 0.0 & 12.5 & 10.0 & 0.0 & 50.0 & 50.0 & 40.0 & 37.5 & 4.30 & 4.13 \\
\hline Progression with mastery of resistive exercise & 10.0 & 0.0 & 20.0 & 0.0 & 30.0 & 42.9 & 20.0 & 57.1 & 20.0 & 0.0 & 3.20 & 3.57 \\
\hline
\end{tabular}

Key: R= Round; MB= Medicine Ball; SL= Single Leg; *= change between rounds, meeting consensus in R2; highlight= included in program 
Table D11. Percentage Distribution and Mean Scores for First and Second Round - Squat Sequencing

\begin{tabular}{|c|c|c|c|c|c|c|c|c|c|c|c|c|}
\hline \multirow[b]{2}{*}{$\underline{\text { Exercise Component }}$} & \multicolumn{2}{|c|}{1} & \multicolumn{2}{|c|}{2} & \multicolumn{2}{|c|}{3} & \multicolumn{2}{|c|}{4} & \multicolumn{2}{|c|}{5} & \multicolumn{2}{|c|}{ Mean } \\
\hline & $\mathrm{R} 1$ & $\mathrm{R} 2$ & $\mathrm{R} 1$ & $\mathrm{R} 2$ & $\mathrm{R} 1$ & $\mathrm{R} 2$ & $\mathrm{R} 1$ & $\mathrm{R} 2$ & $\mathrm{R} 1$ & $\mathrm{R} 2$ & $\mathrm{R} 1$ & $\mathrm{R} 2$ \\
\hline Front squat with weighted bar & 0.0 & 0.0 & 18.2 & 0.0 & 0.0 & 25.0 & 63.6 & 75.0 & 18.2 & 0.0 & 3.82 & 3.75 \\
\hline Back-squat with weighted bar & 0.0 & 0.0 & 22.2 & 0.0 & 0.0 & 22.2 & 55.6 & 66.7 & 22.2 & 11.1 & 3.78 & 3.89 \\
\hline With soccer ball throw-in & 0.0 & 0.0 & 0.0 & 0.0 & 12.5 & 0.0 & 25.0 & 85.7 & 62.5 & 14.3 & 4.50 & 4.14 \\
\hline With MB throw-in & 10.0 & 0.0 & 0.0 & 0.0 & 10.0 & 0.0 & 40.0 & 35.7 & 40.0 & 14.3 & 4.00 & 4.14 \\
\hline With header & 0.0 & 0.0 & 11.1 & 0.0 & 11.1 & 28.6 & 33.3 & 57.1 & 44.4 & 14.3 & 4.11 & 3.86 \\
\hline SL with soccer ball throw-in & 0.0 & 0.0 & 0.0 & 0.0 & 22.2 & 0.0 & 44.4 & 75.0 & 33.3 & 14.3 & 4.11 & 4.00 \\
\hline SL with MB throw-in & 0.0 & 0.0 & 0.0 & 0.0 & 40.0 & 42.9 & 40.0 & 57.1 & 20.0 & 0.0 & 3.80 & 3.57 \\
\hline SL with header & 0.0 & 0.0 & 11.1 & 0.0 & 22.2 & 42.9 & 55.6 & 57.1 & 11.1 & 0.0 & 3.67 & 3.57 \\
\hline Unstable surface with MB throw-in* & 11.1 & 0.0 & 11.1 & 0.0 & 33.3 & 12.5 & 33.3 & 75.0 & 11.1 & 12.5 & 3.22 & 4.00 \\
\hline SL on unstable surface with MB throw-in & 11.1 & 0.0 & 11.1 & 0.0 & 22.2 & 14.3 & 44.4 & 85.7 & 11.1 & 0.0 & 3.33 & 3.86 \\
\hline SL on unstable surface with header & 11.1 & 0.0 & 11.1 & 0.0 & 33.3 & 33.3 & 44.4 & 66.7 & 0.0 & 0.0 & 3.11 & 3.67 \\
\hline To forward lunge & 0.0 & 0.0 & 0.0 & 0.0 & 0.0 & 0.0 & 55.6 & 85.7 & 44.4 & 14.3 & 4.44 & 4.14 \\
\hline To lateral lunge & 0.0 & 0.0 & 10.0 & 0.0 & 0.0 & 14.3 & 50.0 & 71.4 & 40.0 & 14.3 & 4.20 & 4.00 \\
\hline SL to forward lunge on unstable surface & 11.1 & 0.0 & 0.0 & 0.0 & 11.1 & 28.6 & 44.4 & 57.1 & 33.3 & 14.3 & 3.89 & 3.86 \\
\hline $\begin{array}{l}\text { SL on unstable surface to forward lunge on } \\
\text { unstable surface }\end{array}$ & 11.1 & 0.0 & 0.0 & 0.0 & 11.1 & 42.9 & 55.6 & 42.9 & 22.2 & 14.3 & 3.78 & 3.71 \\
\hline SL to lateral lunge on unstable surface* & 11.1 & 0.0 & 0.0 & 0.0 & 11.1 & 40.0 & 55.6 & 20.0 & 22.2 & 40.0 & 3.78 & 4.00 \\
\hline Progression with mastery of current exercise & 10.0 & 0.0 & 0.0 & 0.0 & 0.0 & 0.0 & 50.0 & 77.8 & 40.0 & 22.2 & 4.10 & 4.22 \\
\hline Progression with mastery of stable surface & 0.0 & 0.0 & 0.0 & 0.0 & 11.1 & 0.0 & 44.4 & 50.0 & 44.4 & 50.0 & 4.33 & 4.50 \\
\hline Progression with mastery of unstable surface & 0.0 & 0.0 & 0.0 & 0.0 & 12.5 & 0.0 & 50.0 & 75.0 & 37.5 & 25.0 & 4.25 & 4.25 \\
\hline
\end{tabular}

Key: R= Round; MB= Medicine Ball; SL= Single Leg; *= change between rounds, meeting consensus in R2; highlight= included in program 
Table D12. Percentage Distribution and Mean Scores for First and Second Round - Heel Raise Sequencing

\begin{tabular}{|c|c|c|c|c|c|c|c|c|c|c|c|c|c|}
\hline \multirow[b]{2}{*}{ Exercise Component } & \multicolumn{3}{|c|}{1} & \multicolumn{2}{|c|}{2} & \multicolumn{2}{|c|}{3} & \multicolumn{2}{|c|}{4} & \multicolumn{2}{|c|}{5} & \multicolumn{2}{|c|}{ Mean } \\
\hline & Round & $\mathrm{R} 1$ & $\mathrm{R} 2$ & $\mathrm{R} 1$ & $\mathrm{R} 2$ & $\mathrm{R} 1$ & $\mathrm{R} 2$ & $\mathrm{R} 1$ & $\mathrm{R} 2$ & R1 & $\mathrm{R} 2$ & $\mathrm{R} 1$ & $\mathrm{R} 2$ \\
\hline With MB throw-in* & & 10.0 & 0.0 & 0.0 & 0.0 & 40.0 & 12.5 & 10.0 & 75.0 & 40.0 & 12.5 & 3.70 & 4.00 \\
\hline SL with MB throw-in* & & 12.5 & 0.0 & 0.0 & 0.0 & 25.0 & 12.5 & 25.0 & 62.5 & 37.5 & 25.0 & 3.75 & 4.13 \\
\hline SL on unstable surface with MB throw-in & & 11.1 & 0.0 & 0.0 & 0.0 & 33.3 & 40.0 & 44.4 & 40.0 & 11.1 & 20.0 & 3.44 & 3.80 \\
\hline With header & & 0.0 & 0.0 & 22.2 & 0.0 & 22.2 & 42.9 & 33.3 & 57.1 & 22.2 & 0.0 & 3.56 & 3.57 \\
\hline SL with header & & 0.0 & 0.0 & 25.0 & 0.0 & 12.5 & 42.9 & 50.0 & 57.1 & 12.5 & 0.0 & 3.50 & 3.57 \\
\hline Progression with mastery of current exercise & & 0.0 & 0.0 & 0.0 & 0.0 & 0.0 & 0.0 & 55.6 & 66.7 & 44.4 & 33.3 & 4.44 & 4.33 \\
\hline Progression with mastery of stable surface & & 11.1 & 0.0 & 0.0 & 0.0 & 11.1 & 12.5 & 33.3 & 62.5 & 44.4 & 25.0 & 4.00 & 4.13 \\
\hline
\end{tabular}

Key: R= Round; MB= Medicine Ball; SL= Single Leg; *= change between rounds, meeting consensus in R2; highlight= included in program

Table D13. Percentage Distribution and Mean Scores for First and Second Round - Lunge Sequencing

\begin{tabular}{|c|c|c|c|c|c|c|c|c|c|c|c|c|}
\hline \multirow[b]{2}{*}{ Exercise Component } & \multicolumn{2}{|c|}{1} & \multicolumn{2}{|c|}{2} & \multicolumn{2}{|c|}{3} & \multicolumn{2}{|c|}{4} & \multicolumn{2}{|c|}{5} & \multicolumn{2}{|c|}{ Mean } \\
\hline & $\mathrm{R} 1$ & $\mathrm{R} 2$ & $\mathrm{R} 1$ & $\mathrm{R} 2$ & $\mathrm{R} 1$ & $\mathrm{R} 2$ & $\mathrm{R} 1$ & $\mathrm{R} 2$ & $\mathrm{R} 1$ & $\mathrm{R} 2$ & $\mathrm{R} 1$ & $\mathrm{R} 2$ \\
\hline Forward with MB throw-in* & 11.1 & 0.0 & 0.0 & 0.0 & 22.2 & 12.5 & 22.2 & 75.0 & 44.4 & 12.5 & 3.89 & 4.00 \\
\hline $\begin{array}{l}\text { Forward onto unstable surface with MB throw- } \\
\text { in* }\end{array}$ & 11.1 & 0.0 & 11.1 & 0.0 & 33.3 & 0.0 & 11.1 & 80.0 & 33.3 & 20.0 & 3.44 & 4.20 \\
\hline Lateral with MB throw-in* & 10.0 & 0.0 & 0.0 & 0.0 & 20.0 & 22.2 & 50.0 & 55.6 & 20.0 & 22.2 & 3.70 & 4.00 \\
\hline Lateral onto unstable surface with MB throw-in & 0.0 & 0.0 & 0.0 & 0.0 & 22.2 & 20.0 & 55.6 & 60.0 & 22.2 & 20.0 & 4.00 & 4.00 \\
\hline Resisted forward with MB throw-in & 11.1 & 0.0 & 11.1 & 16.7 & 22.2 & 33.3 & 33.3 & 16.7 & 22.2 & 33.3 & 3.44 & 3.67 \\
\hline Forward onto SB & 9.1 & 0.0 & 0.0 & 0.0 & 18.2 & 0.0 & 27.3 & 71.4 & 45.5 & 28.6 & 4.00 & 4.29 \\
\hline Forward onto SB with MB toss* & 20.0 & 0.0 & 10.0 & 0.0 & 10.0 & 0.0 & 30.0 & 71.4 & 30.0 & 28.6 & 3.40 & 4.20 \\
\hline Lateral onto SB* & 11.1 & 0.0 & 0.0 & 0.0 & 11.1 & 14.3 & 44.4 & 57.1 & 33.3 & 28.6 & 3.89 & 4.14 \\
\hline Progression with mastery of current exercise & 0.0 & 0.0 & 0.0 & 0.0 & 10.0 & 0.0 & 40.0 & 55.6 & 50.0 & 44.4 & 4.40 & 4.44 \\
\hline Progression with mastery of stable surface & 0.0 & 0.0 & 0.0 & 0.0 & 11.1 & 0.0 & 44.4 & 71.4 & 44.4 & 28.6 & 4.33 & 4.29 \\
\hline Progression with mastery of unstable surface* & 10.0 & 0.0 & 0.0 & 0.0 & 10.0 & 25.0 & 50.0 & 37.5 & 30.0 & 37.5 & 3.90 & 4.13 \\
\hline
\end{tabular}

Key: R= Round; MB= Medicine Ball; SB= Swiss Ball; *= change between rounds, meeting consensus in R2; highlight= included in program 
Table D14. Percentage Distribution and Mean Scores for First and Second Round -Core Stabilization

\begin{tabular}{|c|c|c|c|c|c|c|c|c|c|c|c|c|}
\hline \multirow[b]{2}{*}{ Exercise Component } & \multicolumn{2}{|c|}{1} & \multicolumn{2}{|c|}{2} & \multicolumn{2}{|c|}{3} & \multicolumn{2}{|c|}{4} & \multicolumn{2}{|c|}{5} & \multicolumn{2}{|c|}{ Mean } \\
\hline & $\mathrm{R} 1$ & $\mathrm{R} 2$ & R1 & $\mathrm{R} 2$ & $\mathrm{R} 1$ & $\mathrm{R} 2$ & $\mathrm{R} 1$ & $\mathrm{R} 2$ & $\mathrm{R} 1$ & $\mathrm{R} 2$ & $\mathrm{R} 1$ & $\mathrm{R} 2$ \\
\hline Diagonal Chops with MB & 9.1 & 0.0 & 0.0 & 0.0 & 9.1 & 0.0 & 36.4 & 75.0 & 45.5 & 25.0 & 4.09 & 4.25 \\
\hline Diagonal Chops with MB on unstable surface & 0.0 & 0.0 & 10.0 & 0.0 & 20.0 & 28.6 & 40.0 & 42.9 & 30.0 & 28.6 & 3.90 & 4.00 \\
\hline Marching on SB with foot traps & 0.0 & 0.0 & 22.2 & 0.0 & 22.2 & 57.1 & 33.3 & 42.9 & 22.2 & 0.0 & 3.56 & 3.43 \\
\hline $\begin{array}{l}\text { Marching on SB with MB throw-in plus } \\
\text { resisted leg extension }\end{array}$ & 11.1 & 0.0 & 22.2 & 14.3 & 22.2 & 57.1 & 22.2 & 28.6 & 22.2 & 0.0 & 3.22 & 3.14 \\
\hline Marching on SB with MB throw-in & 10.0 & 0.0 & 30.0 & 0.0 & 20.0 & 28.6 & 30.0 & 57.1 & 10.0 & 14.3 & 3.00 & 3.29 \\
\hline Side-plank & 0.0 & 0.0 & 9.1 & 0.0 & 9.1 & 12.5 & 27.3 & 62.5 & 54.5 & 25.0 & 4.27 & 4.13 \\
\hline Side-plank with resisted hip flexion & 0.0 & 0.0 & 11.1 & 16.7 & 11.1 & 33.3 & 55.6 & 33.3 & 22.2 & 16.7 & 3.89 & 3.50 \\
\hline Side-plank on SB & 0.0 & 0.0 & 0.0 & 0.0 & 0.0 & 14.3 & 66.7 & 71.4 & 33.3 & 14.3 & 4.00 & 4.00 \\
\hline Side-plank on SB with resisted hip flexion & 0.0 & 0.0 & 11.1 & 14.3 & 11.1 & 28.6 & 55.6 & 57.1 & 22.2 & 0.0 & 3.89 & 3.43 \\
\hline Plank with forearms on SB & 0.0 & 0.0 & 0.0 & 0.0 & 11.1 & 0.0 & 33.3 & 71.4 & 55.6 & 28.6 & 4.44 & 4.29 \\
\hline SL plank with forearms on SB & 0.0 & 0.0 & 0.0 & 0.0 & 11.1 & 0.0 & 33.3 & 85.7 & 55.6 & 14.3 & 4.44 & 4.14 \\
\hline $\begin{array}{l}\text { SL plank with forearms on SB with ankle } \\
\text { weight* }\end{array}$ & 0.0 & 0.0 & 12.5 & 0.0 & 25.0 & 0.0 & 37.5 & 85.7 & 25.0 & 14.3 & 3.75 & 4.14 \\
\hline Plank roll-outs on SB & 0.0 & 0.0 & 0.0 & 0.0 & 0.0 & 14.3 & 62.5 & 71.4 & 37.5 & 14.3 & 4.38 & 4.00 \\
\hline Plank with feet on SB & 0.0 & 0.0 & 0.0 & 0.0 & 10.0 & 14.3 & 40.0 & 71.4 & 50.0 & 14.3 & 4.40 & 4.00 \\
\hline Plank with feet on SB with abdominal rolls & 0.0 & 0.0 & 0.0 & 0.0 & 0.0 & 25.0 & 44.4 & 50.0 & 55.6 & 25.0 & 4.56 & 4.00 \\
\hline $\begin{array}{l}\text { Plank with feet on SB with roll, push-up, } \\
\text { pike* }\end{array}$ & 0.0 & 0.0 & 22.2 & 0.0 & 22.2 & 0.0 & 22.2 & 100 & 33.3 & 0.0 & 3.67 & 4.00 \\
\hline Supine SB rear overhead throw with MB & 12.5 & 0.0 & 50.0 & 14.3 & 12.5 & 28.6 & 12.5 & 57.1 & 12.5 & 0.0 & 2.63 & 3.43 \\
\hline Russian twist with MB & 0.0 & 0.0 & 11.1 & 0.0 & 0.0 & 12.5 & 66.7 & 75.0 & 22.2 & 12.5 & 4.00 & 4.00 \\
\hline Six inch hold & 22.2 & 0.0 & 0.0 & 14.3 & 22.2 & 14.3 & 33.3 & 71.4 & 22.2 & 0.0 & 3.33 & 3.57 \\
\hline V sit-ups & 0.0 & 0.0 & 12.5 & 0.0 & 12.5 & 28.6 & 50.0 & 57.1 & 25.0 & 14.3 & 3.88 & 3.86 \\
\hline Jack knife sit-ups & 0.0 & 0.0 & 12.5 & 0.0 & 37.5 & 28.6 & 37.5 & 57.1 & 12.5 & 14.3 & 3.50 & 3.86 \\
\hline Crunch on SB with MB toss* & 0.0 & 0.0 & 0.0 & 0.0 & 37.5 & 14.3 & 37.5 & 71.4 & 25.0 & 14.3 & 3.88 & 4.00 \\
\hline Kneeling balance on SB with MB throw-in & 11.1 & 0.0 & 22.2 & 0.0 & 44.4 & 14.3 & 11.1 & 85.7 & 11.1 & 0.0 & 2.89 & 3.86 \\
\hline Standing on SB & 22.2 & 0.0 & 22.2 & 14.3 & 44.4 & 57.1 & 11.1 & 28.6 & 0.0 & 0.0 & 2.44 & 3.14 \\
\hline Russian eccentric hamstrings & 0.0 & 0.0 & 0.0 & 0.0 & 0.0 & 14.3 & 33.3 & 71.4 & 66.7 & 14.3 & 4.67 & 4.00 \\
\hline Progression with mastery of current exercise & 0.0 & 0.0 & 0.0 & 0.0 & 10.0 & 0.0 & 40.0 & 85.7 & 50.0 & 14.3 & 4.40 & 4.14 \\
\hline Progression with mastery of neutral spine* & 11.1 & 0.0 & 0.0 & 0.0 & 22.2 & 0.0 & 33.3 & 85.7 & 33.3 & 14.3 & 3.78 & 4.14 \\
\hline
\end{tabular}

Key: R= Round; MB= Medicine Ball; SB= Swiss Ball; SL= Single Leg; *= change between rounds, meeting consensus in R2; highlight= included in program 
Table D15. Percentage Distribution and Mean Scores for First and Second Round - Plyometric Exercises

\begin{tabular}{|c|c|c|c|c|c|c|c|c|c|c|c|c|}
\hline \multirow[b]{2}{*}{ Exercise Component } & \multicolumn{2}{|c|}{1} & \multicolumn{2}{|c|}{2} & \multicolumn{2}{|c|}{3} & \multicolumn{2}{|c|}{4} & \multicolumn{2}{|c|}{5} & \multicolumn{2}{|c|}{ Mean } \\
\hline & R1 & $\mathrm{R} 2$ & R1 & R2 & R1 & $\mathrm{R} 2$ & R1 & R2 & R1 & R2 & R1 & $\mathrm{R} 2$ \\
\hline SL step-up with MB throw-in & 11.1 & 0.0 & 11.1 & 0.0 & 22.2 & 14.3 & 33.3 & 85.7 & 22.2 & 0.0 & 3.44 & 3.86 \\
\hline Resisted SL step-up with MB throw-in & 10.0 & 0.0 & 30.0 & 14.3 & 20.0 & 14.3 & 20.0 & 71.4 & 20.0 & 0.0 & 3.10 & 3.57 \\
\hline $\begin{array}{l}\text { SL step-up onto unstable surface with MB } \\
\text { throw-in }\end{array}$ & 11.1 & 0.0 & 22.2 & 0.0 & 22.2 & 14.3 & 33.3 & 85.7 & 11.1 & 0.0 & 3.11 & 3.86 \\
\hline $\begin{array}{l}\text { SL resisted step-up onto unstable surface } \\
\text { with MB throw-in }\end{array}$ & 11.1 & 0.0 & 22.2 & 14.3 & 44.4 & 14.3 & 22.2 & 71.4 & 0.0 & 0.0 & 2.78 & 3.57 \\
\hline Depth box jumps with MB throw-in & 10.0 & 0.0 & 20.0 & 0.0 & 40.0 & 42.9 & 20.0 & 57.1 & 10.0 & 0.0 & 3.00 & 3.57 \\
\hline Depth box jumps with header & 0.0 & 0.0 & 0.0 & 0.0 & 10.0 & 0.0 & 60.0 & 100 & 30.0 & 0.0 & 4.20 & 4.00 \\
\hline Squat jump to header & 0.0 & 0.0 & 0.0 & 0.0 & 0.0 & 14.3 & 25.0 & 71.4 & 75.0 & 14.3 & 4.75 & 4.0 \\
\hline Lunge jump to header & 0.0 & 0.0 & 0.0 & 0.0 & 0.0 & 0.0 & 77.8 & 100 & 22.2 & 0.0 & 4.22 & 4.00 \\
\hline Lateral lunge with explosive ball save^ & 0.0 & 0.0 & 0.0 & 0.0 & 0.0 & 14.3 & 77.8 & 85.7 & 22.2 & 0.0 & 4.22 & 3.86 \\
\hline Pullover with MB & 10.0 & 0.0 & 20.0 & 0.0 & 20.0 & 28.6 & 20.0 & 57.1 & 30.0 & 14.3 & 3.40 & 3.86 \\
\hline Pullover pass with MB & 11.1 & 0.0 & 22.2 & 0.0 & 11.1 & 14.3 & 33.3 & 85.7 & 22.2 & 0.0 & 3.33 & 3.86 \\
\hline Pullover with sit-up* & 0.0 & 0.0 & 33.3 & 0.0 & 0.0 & 0.0 & 55.6 & 100 & 11.1 & 0.0 & 3.44 & 4.00 \\
\hline Overhead to feet with MB & 0.0 & 0.0 & 11.1 & 0.0 & 11.1 & 28.6 & 66.7 & 71.4 & 11.1 & 0.0 & 3.78 & 3.71 \\
\hline Knee throw & 0.0 & 0.0 & 25.0 & 14.3 & 37.5 & 42.9 & 37.5 & 42.9 & 0.0 & 0.0 & 3.13 & 3.29 \\
\hline Kick toss & 0.0 & 0.0 & 22.2 & 0.0 & 11.1 & 28.6 & 44.4 & 71.4 & 22.2 & 0.0 & 3.67 & 3.71 \\
\hline Sit-up toss & 0.0 & 0.0 & 0.0 & 0.0 & 33.3 & 14.3 & 55.6 & 85.7 & 11.1 & 0.0 & 3.78 & 3.86 \\
\hline Backward MB throw & 0.0 & 0.0 & 11.1 & 0.0 & 22.2 & 28.6 & 44.4 & 71.4 & 22.2 & 0.0 & 3.78 & 3.71 \\
\hline Kneeling throw & 0.0 & 0.0 & 11.1 & 14.3 & 33.3 & 14.3 & 33.3 & 71.4 & 22.2 & 0.0 & 3.67 & 3.56 \\
\hline Over and through the legs with MB & 11.1 & 0.0 & 33.3 & 0.0 & 11.1 & 28.6 & 22.2 & 71.4 & 0.0 & 0.0 & 3.11 & 3.71 \\
\hline Hurdler extension with MB & 0.0 & 0.0 & 11.1 & 0.0 & 33.3 & 57.1 & 33.3 & 42.9 & 22.2 & 0.0 & 3.56 & 3.43 \\
\hline Front toss & 0.0 & 0.0 & 11.1 & 14.3 & 44.4 & 28.6 & 22.2 & 57.1 & 22.2 & 0.0 & 3.56 & 3.43 \\
\hline Leg toss & 0.0 & 0.0 & 11.1 & 14.3 & 22.2 & 42.9 & 55.6 & 42.9 & 11.1 & 0.0 & 3.67 & 3.29 \\
\hline Heel toss with MB & 0.0 & 0.0 & 22.2 & 0.0 & 22.2 & 57.1 & 44.4 & 42.9 & 11.1 & 0.0 & 3.44 & 3.43 \\
\hline Lateral hops over cone & 0.0 & 0.0 & 0.0 & 0.0 & 0.0 & 14.3 & 40.0 & 57.1 & 60.0 & 28.6 & 4.60 & 4.14 \\
\hline Forward/backward hops over cone & 0.0 & 0.0 & 0.0 & 0.0 & 0.0 & 0.0 & 44.4 & 75.0 & 55.6 & 25.0 & 4.56 & 4.25 \\
\hline SL hops over cone & 0.0 & 0.0 & 0.0 & 0.0 & 10.0 & 0.0 & 30.0 & 71.4 & 60.0 & 28.6 & 4.50 & 4.29 \\
\hline Vertical jumps with header & 0.0 & 0.0 & 0.0 & 0.0 & 0.0 & 0.0 & 33.3 & 71.4 & 66.7 & 28.6 & 4.67 & 4.29 \\
\hline Scissor jumps & 0.0 & 0.0 & 0.0 & 0.0 & 0.0 & 14.3 & 66.7 & 71.4 & 33.3 & 14.3 & 4.33 & 4.00 \\
\hline Resisted slide board and catch* & 0.0 & 0.0 & 11.1 & 0.0 & 33.3 & 0.0 & 22.2 & 85.7 & 33.3 & 14.3 & 3.78 & 4.14 \\
\hline
\end{tabular}

Key: R= Round; SL= Single Leg; MB= Medicine Ball; *= change between rounds, meeting consensus in R2; $\wedge=$ change between rounds, not meeting consensus in R2; highlight= included in program 
Table D16. Percentage Distribution and Mean Scores for First and Second Round - Functional Activity Progression

\begin{tabular}{|c|c|c|c|c|c|c|c|c|c|c|c|c|}
\hline \multirow[b]{2}{*}{ Exercise Component } & \multicolumn{2}{|c|}{1} & \multicolumn{2}{|c|}{2} & \multicolumn{2}{|c|}{3} & \multicolumn{2}{|c|}{4} & \multicolumn{2}{|c|}{5} & \multicolumn{2}{|c|}{ Mean } \\
\hline & $\mathrm{R} 1$ & $\mathrm{R} 2$ & $\mathrm{R} 1$ & $\mathrm{R} 2$ & $\mathrm{R} 1$ & $\mathrm{R} 2$ & $\mathrm{R} 1$ & $\mathrm{R} 2$ & $\mathrm{R} 1$ & $\mathrm{R} 2$ & $\mathrm{R} 1$ & $\mathrm{R} 2$ \\
\hline \multicolumn{13}{|l|}{ KICKING PROGRESSION } \\
\hline Dry kick with weight shift & 0.0 & 0.0 & 0.0 & 0.0 & 0.0 & 0.0 & 3.75 & 85.7 & 62.5 & 14.3 & 4.63 & 4.14 \\
\hline Dry kick with resistance* & 11.1 & 0.0 & 0.0 & 0.0 & 11.1 & 0.0 & 44.4 & 85.7 & 33.3 & 14.3 & 3.89 & 4.14 \\
\hline Kick stationary ball: short distance & 0.0 & 0.0 & 0.0 & 0.0 & 10.0 & 0.0 & 30.0 & 75.0 & 60.0 & 25.0 & 4.50 & 4.25 \\
\hline Kick stationary ball: long distance & 0.0 & 0.0 & 10.0 & 0.0 & 0.0 & 0.0 & 30.0 & 62.5 & 60.0 & 37.5 & 4.50 & 4.38 \\
\hline Kick moving ball: short distance & 10.0 & 0.0 & 0.0 & 0.0 & 0.0 & 0.0 & 30.0 & 62.5 & 60.0 & 37.5 & 4.30 & 4.38 \\
\hline Kick moving ball: long distance & 0.0 & 0.0 & 0.0 & 0.0 & 0.0 & 0.0 & 33.3 & 62.5 & 66.7 & 37.5 & 4.67 & 4.38 \\
\hline Knee traps to kicks & 0.0 & 0.0 & 22.2 & 0.0 & 0.0 & 14.3 & 33.3 & 71.4 & 44.4 & 14.3 & 4.00 & 4.00 \\
\hline Kick to juggling & 0.0 & 0.0 & 0.0 & 0.0 & 0.0 & 28.6 & 66.7 & 57.1 & 33.3 & 14.3 & 4.33 & 3.86 \\
\hline Chest pass to kick to header & 0.0 & 0.0 & 11.1 & 0.0 & 0.0 & 14.3 & 55.6 & 85.7 & 33.3 & 0.0 & 4.11 & 3.86 \\
\hline Dry kick with plant onto unstable surface & 0.0 & 0.0 & 12.5 & 0.0 & 0.0 & 0.0 & 50.0 & 100 & 37.5 & 0.0 & 4.13 & 4.00 \\
\hline $\begin{array}{l}\text { Resisted kick with plant onto unstable } \\
\text { surface }\end{array}$ & 0.0 & 0.0 & 12.5 & 14.3 & 12.5 & 14.3 & 37.5 & 71.4 & 37.5 & 0.0 & 4.00 & 3.57 \\
\hline $\begin{array}{l}\text { Stationary ball kick with plant onto unstable } \\
\text { surface }\end{array}$ & 0.0 & 0.0 & 11.1 & 0.0 & 0.0 & 0.0 & 44.4 & 100 & 44.4 & 0.0 & 4.22 & 4.00 \\
\hline $\begin{array}{l}\text { Moving ball kick with plant onto unstable } \\
\text { surface }\end{array}$ & 0.0 & 0.0 & 22.2 & 0.0 & 11.1 & 20.0 & 22.2 & 80.0 & 44.4 & 0.0 & 3.89 & 3.80 \\
\hline $\begin{array}{l}\text { Progression with mastery of current exercise } \\
\text { ANAEROBIC and AEROBIC } \\
\text { PROGRESSION }\end{array}$ & 0.0 & 0.0 & 0.0 & 0.0 & 10.0 & 0.0 & 50.0 & 50.0 & 40.0 & 50.0 & 4.30 & 4.50 \\
\hline Fartleks & 0.0 & 0.0 & 0.0 & 0.0 & 0.0 & 12.5 & 44.4 & 75.0 & 55.6 & 12.5 & 4.56 & 4.00 \\
\hline $50 / 50$ interval training & 0.0 & 0.0 & 0.0 & 0.0 & 0.0 & 14.3 & 66.7 & 71.4 & 33.3 & 14.3 & 4.33 & 4.00 \\
\hline Bike & 0.0 & 0.0 & 0.0 & 12.5 & 33.3 & 12.5 & 44.4 & 75.0 & 22.2 & 0.0 & 3.89 & 3.63 \\
\hline Elliptical & 0.0 & 0.0 & 11.1 & 14.3 & 22.2 & 0.0 & 44.4 & 71.4 & 22.2 & 14.3 & 3.78 & 3.86 \\
\hline Stair Climber & 0.0 & 0.0 & 11.1 & 14.3 & 33.3 & 57.1 & 33.3 & 28.6 & 22.2 & 0.0 & 3.67 & 3.14 \\
\hline Treadmill* & 11.1 & 0.0 & 0.0 & 0.0 & 11.1 & 0.0 & 44.4 & 100 & 33.3 & 0.0 & 3.89 & 4.00 \\
\hline 1-mile endurance & 0.0 & 0.0 & 11.1 & 0.0 & 0.0 & 14.3 & 66.7 & 85.7 & 22.2 & 0.0 & 4.00 & 3.86 \\
\hline 2-mile endurance & 0.0 & 0.0 & 11.1 & 0.0 & 11.1 & 28.6 & 55.6 & 71.4 & 22.2 & 0.0 & 3.89 & 3.71 \\
\hline $\begin{array}{l}\text { Progression with } 50 \% \text { MHR for specified } \\
\text { time }\end{array}$ & 11.1 & 0.0 & 22.2 & 0.0 & 11.1 & 28.6 & 33.3 & 71.4 & 22.2 & 0.0 & 3.33 & 3.71 \\
\hline $\begin{array}{l}\text { Progression with } 60 \% \text { MHR for specified } \\
\text { time }\end{array}$ & 12.5 & 0.0 & 25.0 & 0.0 & 25.0 & 14.3 & 12.5 & 85.7 & 25.0 & 0.0 & 3.13 & 3.86 \\
\hline $\begin{array}{l}\text { Progression with } 70 \% \text { MHR for specified } \\
\text { time }\end{array}$ & 11.1 & 0.0 & 0.0 & 0.0 & 11.1 & 0.0 & 33.3 & 100 & 44.4 & 0.0 & 4.00 & 4.00 \\
\hline
\end{tabular}




\begin{tabular}{|c|c|c|c|c|c|c|c|c|c|c|c|c|}
\hline $\begin{array}{l}\text { Progression with } 80 \% \text { MHR for specified } \\
\text { time }\end{array}$ & 14.3 & 0.0 & 0.0 & 0.0 & 28.6 & 25.0 & 14.3 & 62.5 & 42.9 & 12.5 & 3.71 & 3.88 \\
\hline $\begin{array}{l}\text { Completion of } 15 \text { ' of specified aerobic } \\
\text { training* }\end{array}$ & 12.5 & 0.0 & 0.0 & 0.0 & 37.5 & 0.0 & 37.5 & 100 & 12.5 & 0.0 & 3.38 & 4.00 \\
\hline $\begin{array}{l}\text { Completion of } 20^{\prime} \text { of specified aerobic } \\
\text { training* }\end{array}$ & 12.5 & 0.0 & 0.0 & 0.0 & 25.0 & 0.0 & 50.0 & 100 & 12.5 & 0.0 & 3.50 & 4.00 \\
\hline $\begin{array}{l}\text { Completion on 30' of specified aerobic } \\
\text { training* }\end{array}$ & 11.1 & 0.0 & 0.0 & 0.0 & 11.1 & 0.0 & 55.6 & 100 & 22.2 & 0.0 & 3.78 & 4.00 \\
\hline \multicolumn{13}{|l|}{ AGILITY PROGRESSION } \\
\hline Figure eight runs & 0.0 & 0.0 & 0.0 & 0.0 & 0.0 & 0.0 & 33.3 & 62.5 & 66.7 & 37.5 & 4.67 & 4.38 \\
\hline Zig-zag runs & 0.0 & 0.0 & 0.0 & 0.0 & 0.0 & 0.0 & 33.3 & 50.0 & 66.7 & 50.0 & 4.67 & 4.50 \\
\hline T-run & 0.0 & 0.0 & 22.2 & 0.0 & 0.0 & 14.3 & 33.3 & 71.4 & 44.4 & 14.3 & 4.00 & 4.00 \\
\hline SL dot hop bounding & 0.0 & 0.0 & 0.0 & 0.0 & 0.0 & 28.6 & 66.7 & 42.9 & 33.3 & 28.6 & 4.33 & 4.00 \\
\hline Dot hop & 0.0 & 0.0 & 0.0 & 0.0 & 0.0 & 14.3 & 66.7 & 71.4 & 33.3 & 14.3 & 4.33 & 4.00 \\
\hline Ladder line run & 0.0 & 0.0 & 0.0 & 0.0 & 0.0 & 0.0 & 55.6 & 75.0 & 44.4 & 25.0 & 4.44 & 4.24 \\
\hline Ladder line spring and backpedal & 0.0 & 0.0 & 0.0 & 0.0 & 0.0 & 0.0 & 55.6 & 100 & 44.4 & 0.0 & 4.44 & 4.00 \\
\hline Ladder line shuffles & 0.0 & 0.0 & 0.0 & 0.0 & 11.1 & 0.0 & 44.4 & 100 & 44.4 & 0.0 & 4.33 & 4.00 \\
\hline Pro-Agility run & 0.0 & 0.0 & 0.0 & 0.0 & 11.1 & 0.0 & 55.6 & 100 & 33.3 & 0.0 & 4.22 & 4.00 \\
\hline Box runs & 0.0 & 0.0 & 0.0 & 0.0 & 33.3 & 14.3 & 33.3 & 85.7 & 33.3 & 0.0 & 4.00 & 3.86 \\
\hline Carioca runs & 0.0 & 0.0 & 0.0 & 0.0 & 22.2 & 0.0 & 33.3 & 100 & 44.4 & 0.0 & 4.22 & 4.00 \\
\hline 20' run with dribbling & 11.1 & 0.0 & 33.3 & 14.3 & 11.1 & 14.3 & 11.1 & 57.1 & 33.3 & 14.3 & 3.22 & 3.71 \\
\hline Zigzag runs with dribbling & 0.0 & 0.0 & 0.0 & 0.0 & 0.0 & 0.0 & 44.4 & 75.0 & 55.6 & 25.0 & 4.56 & 4.25 \\
\hline T-run with dribbling & 0.0 & 0.0 & 22.2 & 0.0 & 11.1 & 14.3 & 33.3 & 85.7 & 33.3 & 0.0 & 3.78 & 3.86 \\
\hline Up and back dot run with dribbling & 0.0 & 0.0 & 0.0 & 0.0 & 11.1 & 0.0 & 55.6 & 75.0 & 33.3 & 25.0 & 4.22 & 4.25 \\
\hline Ladder line run with dribbling & 12.5 & 0.0 & 0.0 & 0.0 & 12.5 & 28.6 & 37.5 & 71.4 & 37.5 & 0.0 & 3.88 & 3.71 \\
\hline Box runs with dribbling^ & 0.0 & 0.0 & 0.0 & 0.0 & 25.0 & 14.3 & 37.5 & 85.7 & 37.5 & 0.0 & 4.13 & 3.86 \\
\hline Figure eight runs with dribbling & 0.0 & 0.0 & 12.5 & 0.0 & 12.5 & 0.0 & 37.5 & 85.7 & 37.5 & 14.3 & 4.00 & 4.14 \\
\hline Fartlecks with dribbling^ & 0.0 & 0.0 & 22.5 & 0.0 & 0.0 & 14.3 & 33.3 & 85.7 & 44.4 & 0.0 & 4.00 & 3.86 \\
\hline
\end{tabular}

Key: R= Round; MHR= Maximum Heart Rate; *= change between rounds, meeting consensus in R2; $\wedge=$ change between rounds, not meeting consensus in R2; highlight= included in program 


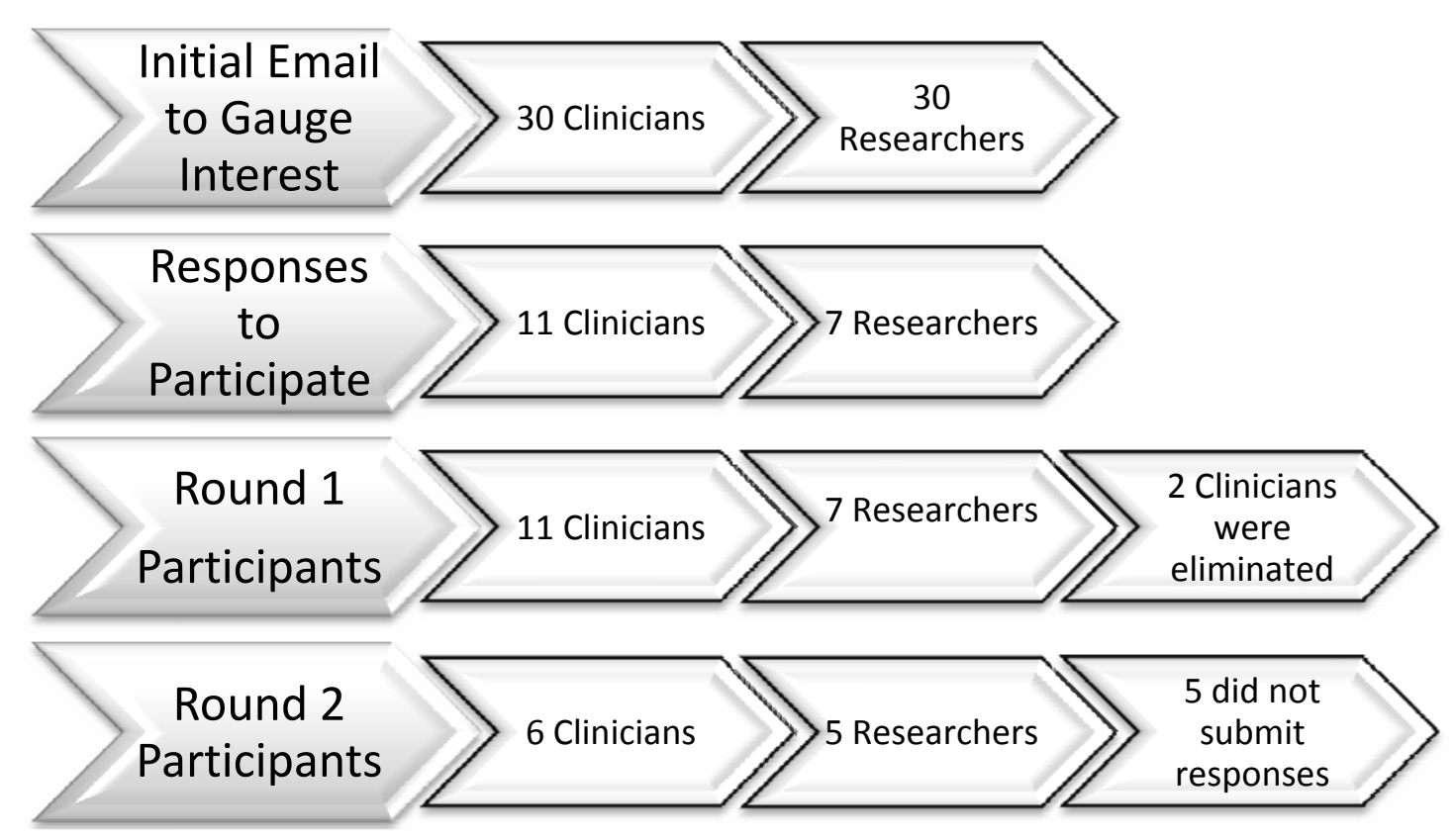


Figure D2. Example Use of the Soccer Specific Functional Rehabilitation Program

Patient: Attacking Midfielder

Injury: Second Degree Hamstring Strain, day 5-10 of rehabilitation

\begin{tabular}{|c|c|c|c|c|c|c|c|c|c|c|c|c|c|c|c|c|c|c|c|c|c|c|}
\hline \multirow{2}{*}{$\begin{array}{l}\text { DATE: } \\
\text { EXERCISE: }\end{array}$} & & \multicolumn{3}{|c|}{ Monday } & \multicolumn{3}{|c|}{ Tuesday } & \multicolumn{3}{|c|}{ Wednesday } & \multicolumn{3}{|c|}{ Thursday } & \multicolumn{3}{|c|}{ Friday } & \multicolumn{3}{|c|}{ Saturday } & \multicolumn{3}{|c|}{ Sunday } \\
\hline & & Set & Reps & WT & Set & Rep & WT & Set & Rep & WT & Set & Rep & WT & Set & Rep & WT & Set & Rep & WT & Set & Rep & WT \\
\hline \multicolumn{23}{|l|}{ Dynamic Flexibility } \\
\hline $\begin{array}{l}\text { Walking Lunge with } \\
\text { Torso Rotation }\end{array}$ & 1 & 1 & 20yd & - & 1 & 20yd & & 1 & 20yd & & 1 & $20 y d$ & & 1 & $20 y d$ & & & & & & & \\
\hline Walking Side-Lunge & 1 & 1 & 20yd & - & 1 & 20yd & & 1 & 20yd & & 1 & 20yd & & 1 & 20yd & & & & & & & \\
\hline Walking Hurdler & 1 & 1 & 20yd & - & 1 & 20yd & & 1 & 20yd & & 1 & $20 y d$ & & 1 & $20 \mathrm{yd}$ & & & & & & & \\
\hline Forward Leg Swings & 1 & 1 & 20yd & - & 1 & 20yd & & 1 & 20yd & & 1 & 20yd & & 1 & 20yd & & & & & & & \\
\hline Lateral Leg Swings & 1 & 1 & 20yd & - & 1 & 20yd & & 1 & 20yd & & 1 & 20yd & & 1 & $20 \mathrm{yd}$ & & & & & & & \\
\hline \multicolumn{23}{|l|}{ Single Leg Balance } \\
\hline $\begin{array}{l}\text { with ball kick on } \\
\text { unstable surface }\end{array}$ & 1 & 3 & 15 & - & & & & 3 & 15 & & & & & 3 & 15 & & & & & & & \\
\hline with header & 2 & & & & & & & & & & & & & & & & & & & & & \\
\hline \multicolumn{23}{|l|}{ Squat } \\
\hline $\begin{array}{l}\text { With soccer ball } \\
\text { throw-in }\end{array}$ & 1 & 3 & 15 & - & & & & 3 & 15 & - & & & & 3 & 15 & - & & & & & & \\
\hline With MB throw-in & 2 & & & & & & & & & & & & & & & & & & & & & \\
\hline $\begin{array}{l}\text { Squat to forward } \\
\text { lunge }\end{array}$ & 2 & & & & & & & & & & & & & & & & & & & & & \\
\hline SL with throw-in & 3 & & & & & & & & & & & & & & & & & & & & & \\
\hline Squat to lateral lunge & 3 & & & & & & & & & & & & & & & & & & & & & \\
\hline $\begin{array}{l}\text { SL with MB throw- } \\
\text { in }\end{array}$ & 4 & & & & & & & & & & & & & & & & & & & & & \\
\hline $\begin{array}{l}\text { On unstable surface } \\
\text { with MB throw-in }\end{array}$ & 5 & & & & & & & & & & & & & & & & & & & & & \\
\hline \multicolumn{23}{|l|}{ Heel Raise } \\
\hline With MB throw-in & 1 & & & & 2 & 15 & $6 \#$ & & & & 2 & 15 & $6 \#$ & & & & & & & & & \\
\hline
\end{tabular}




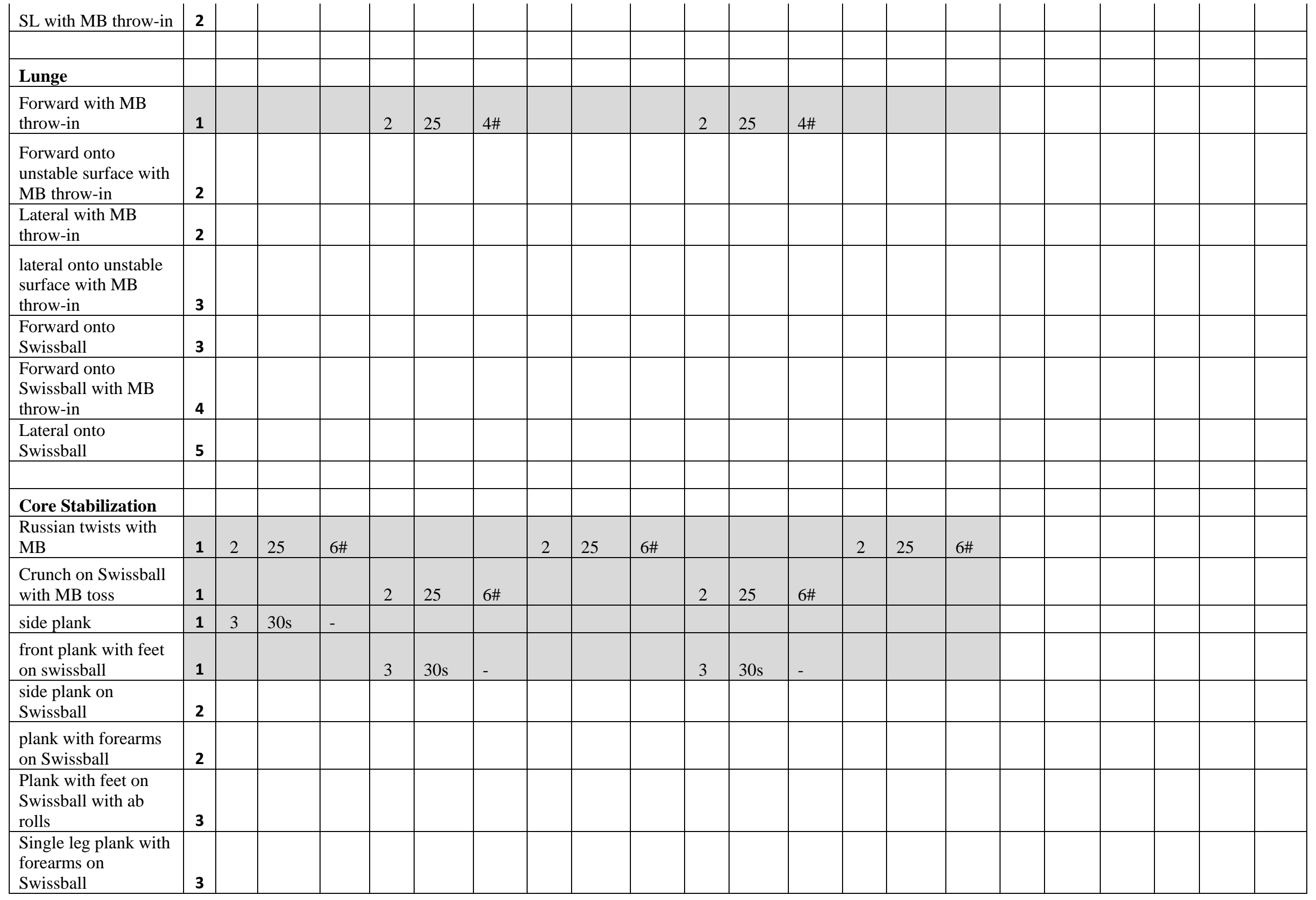




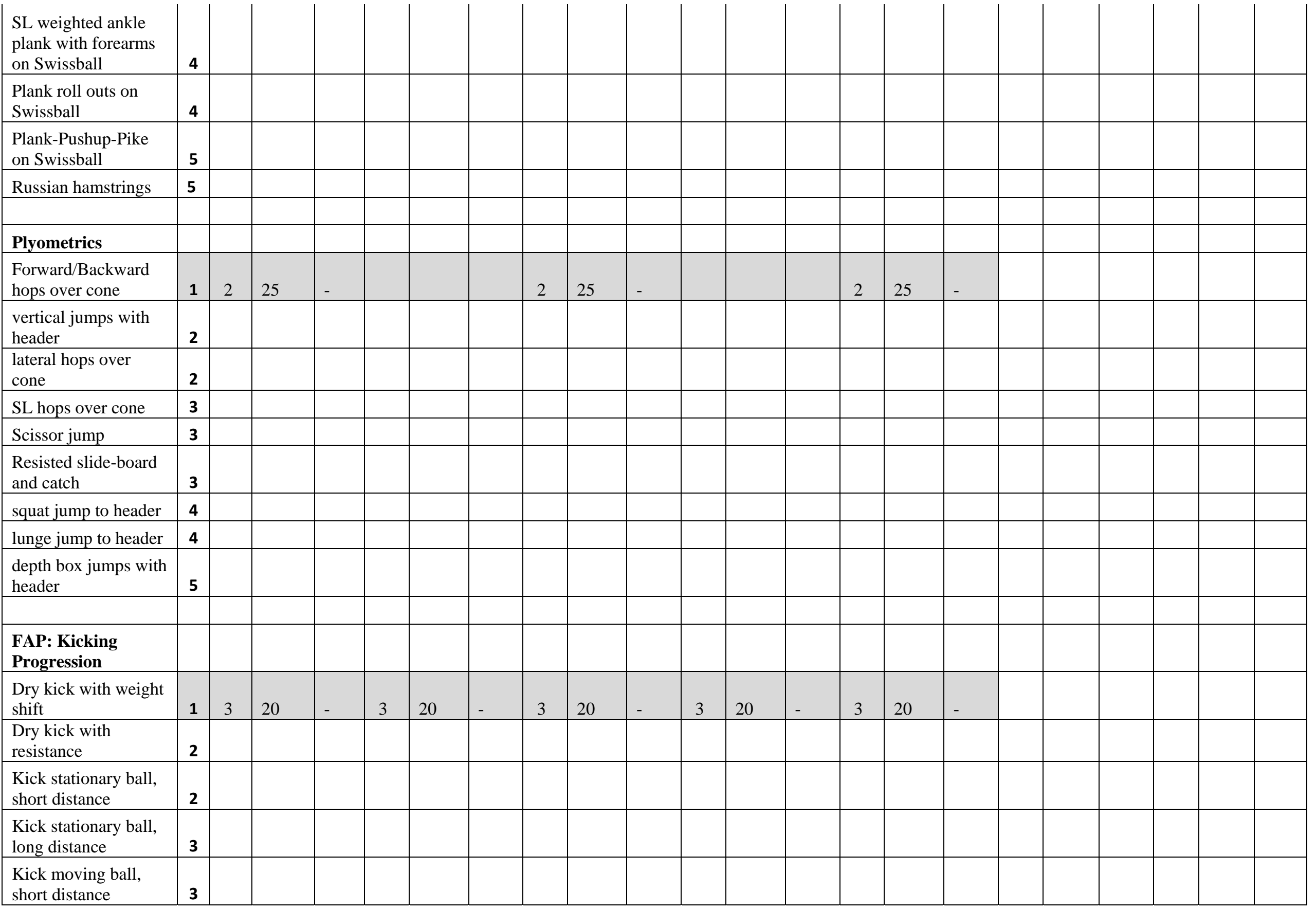




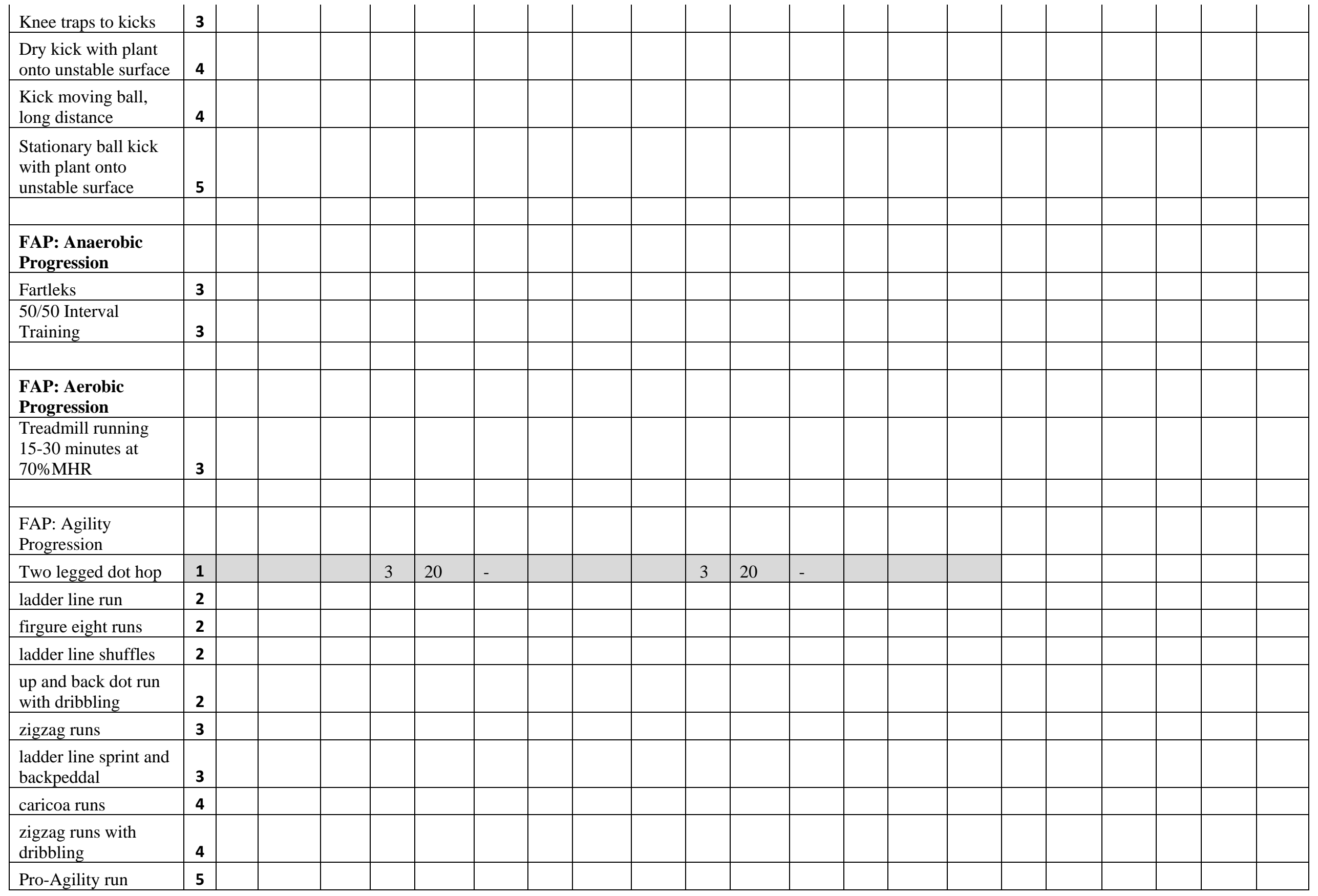


Figure D3. Soccer Specific Functional Rehabilitation Program Outline

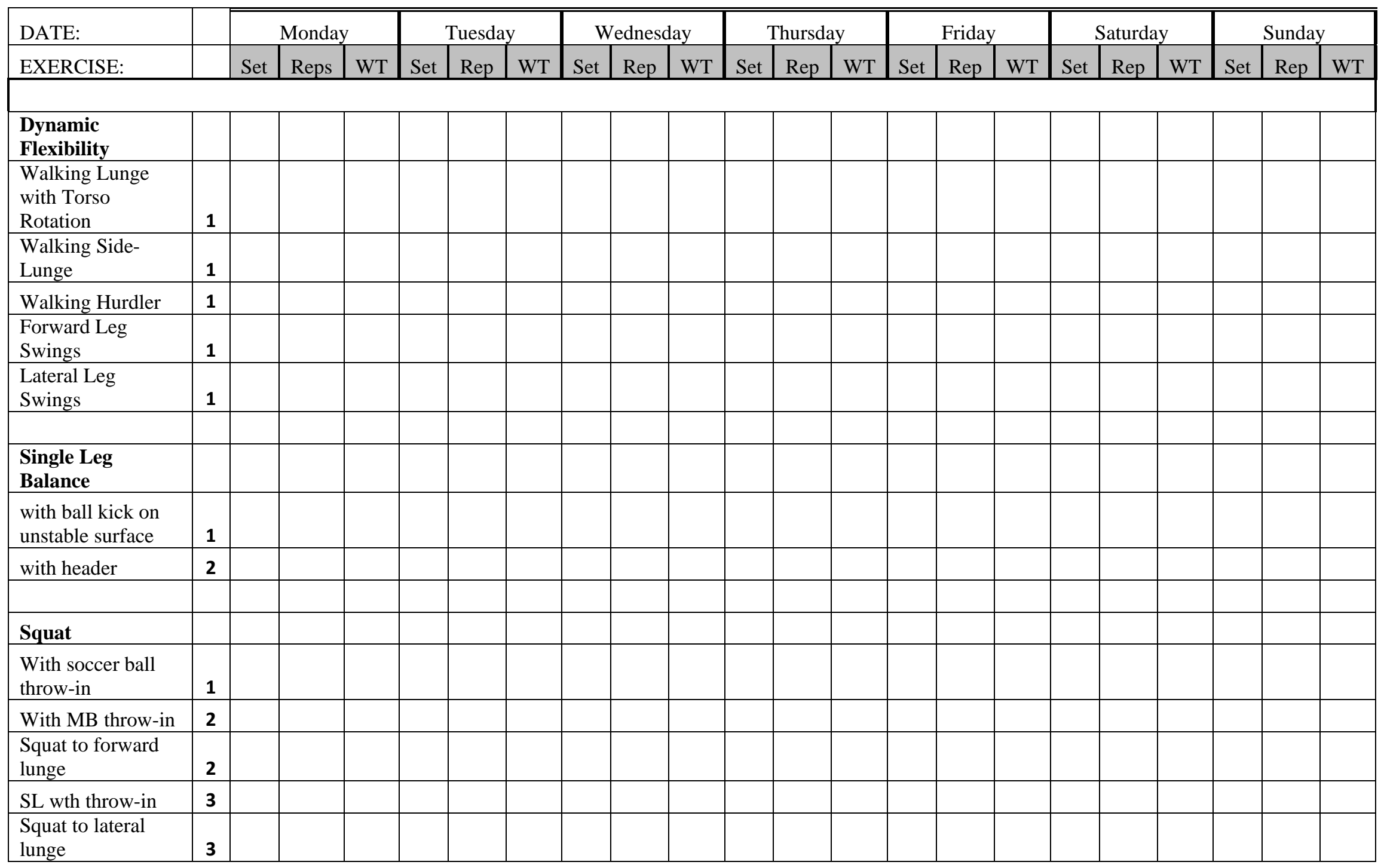




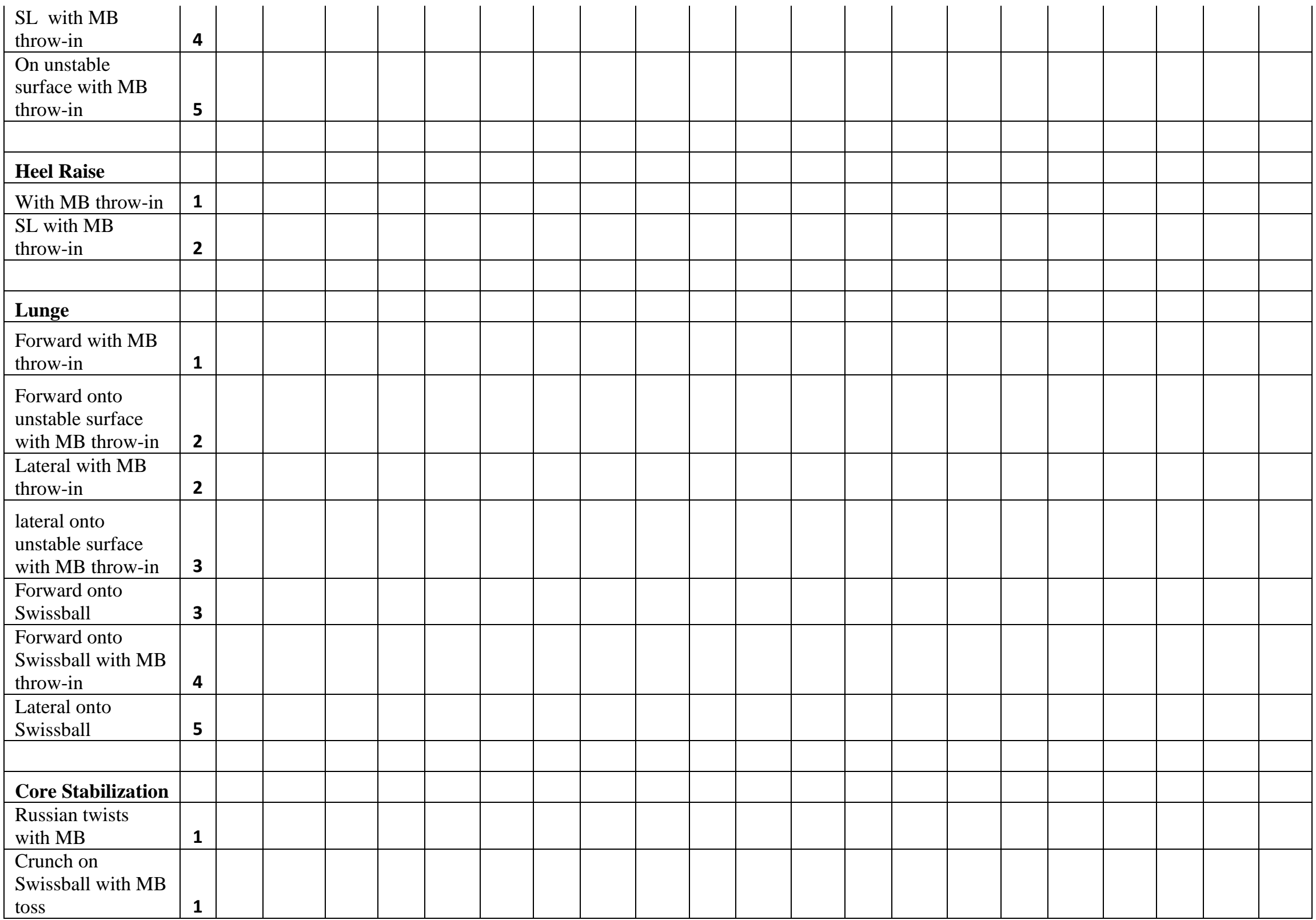




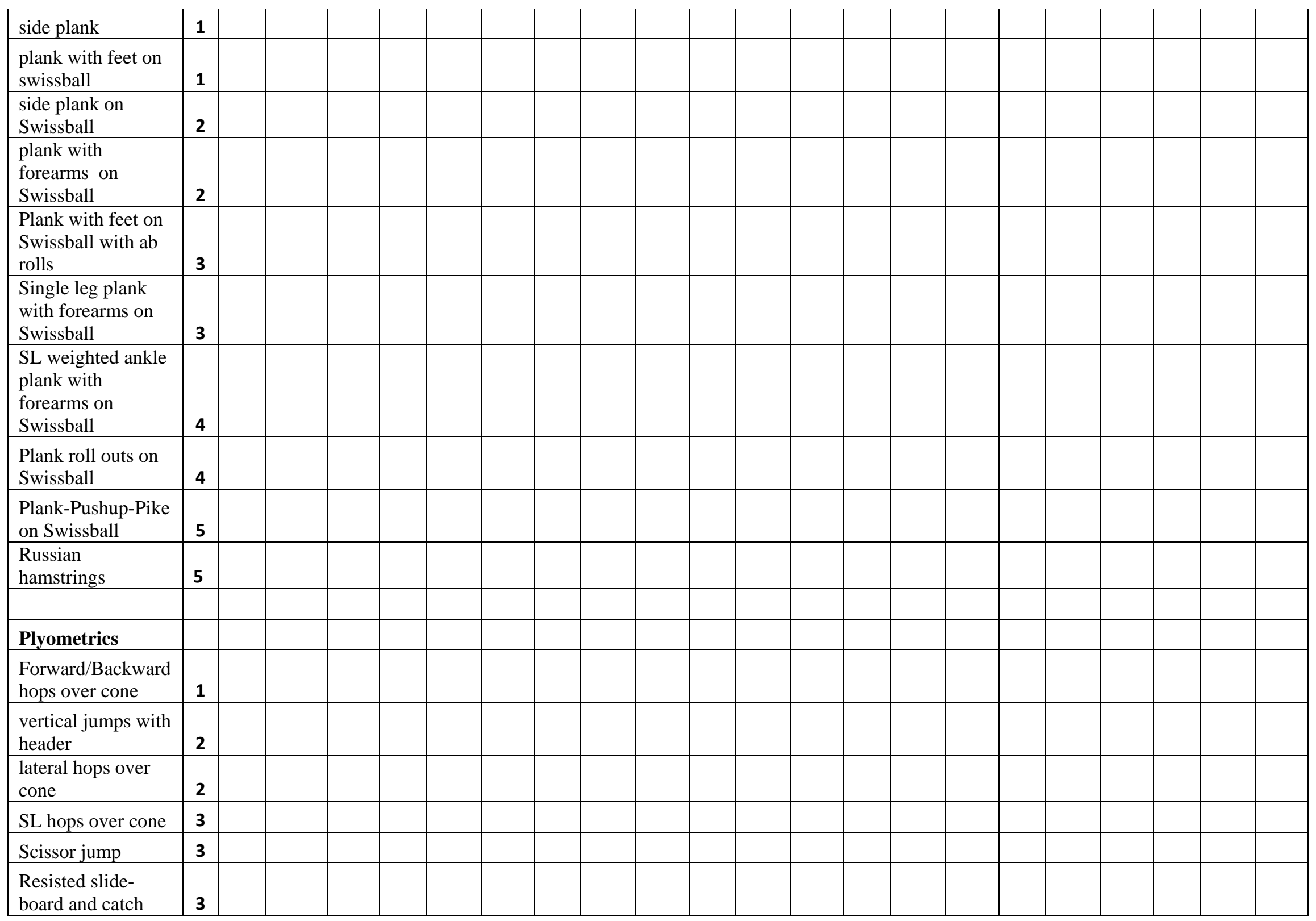




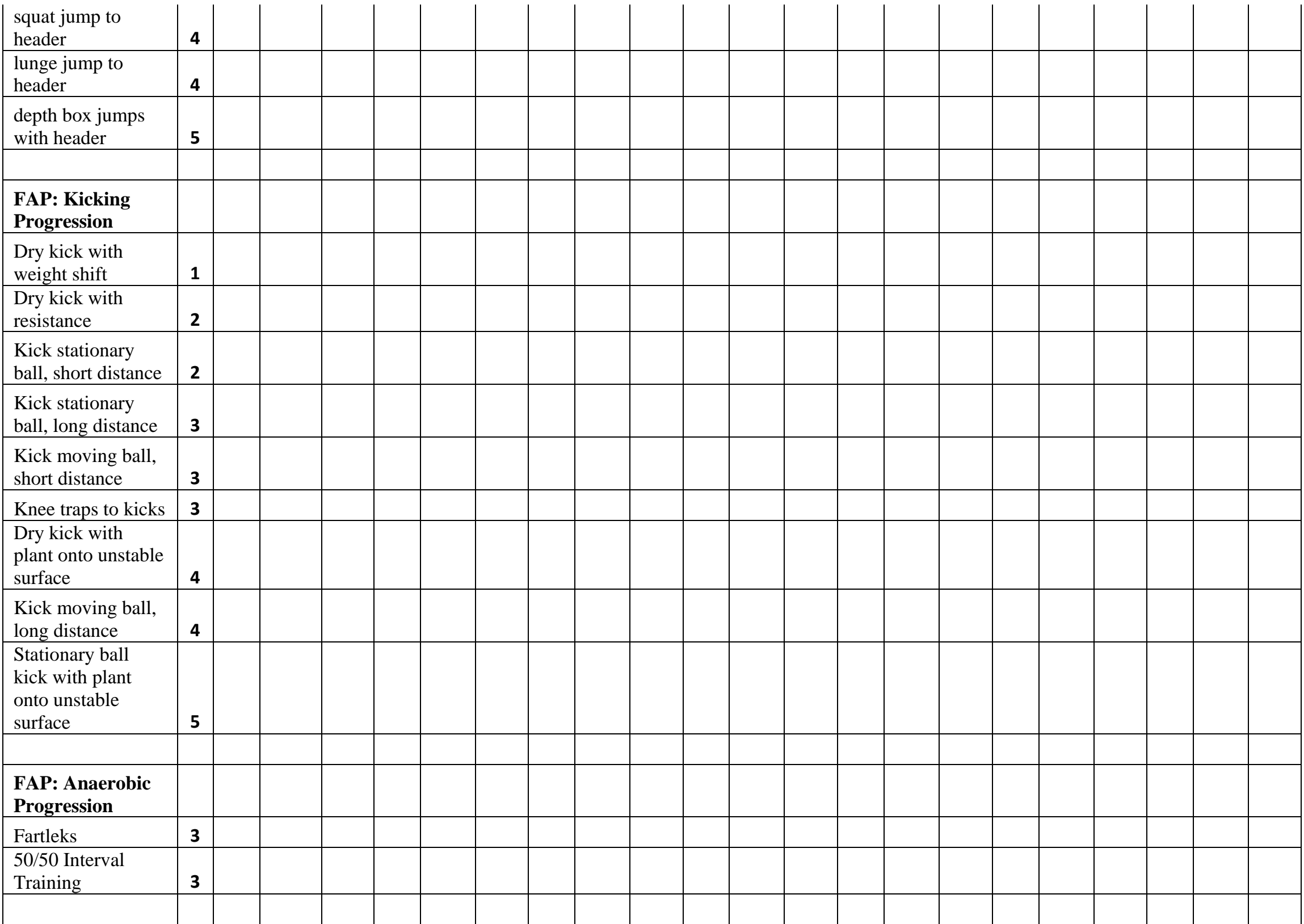




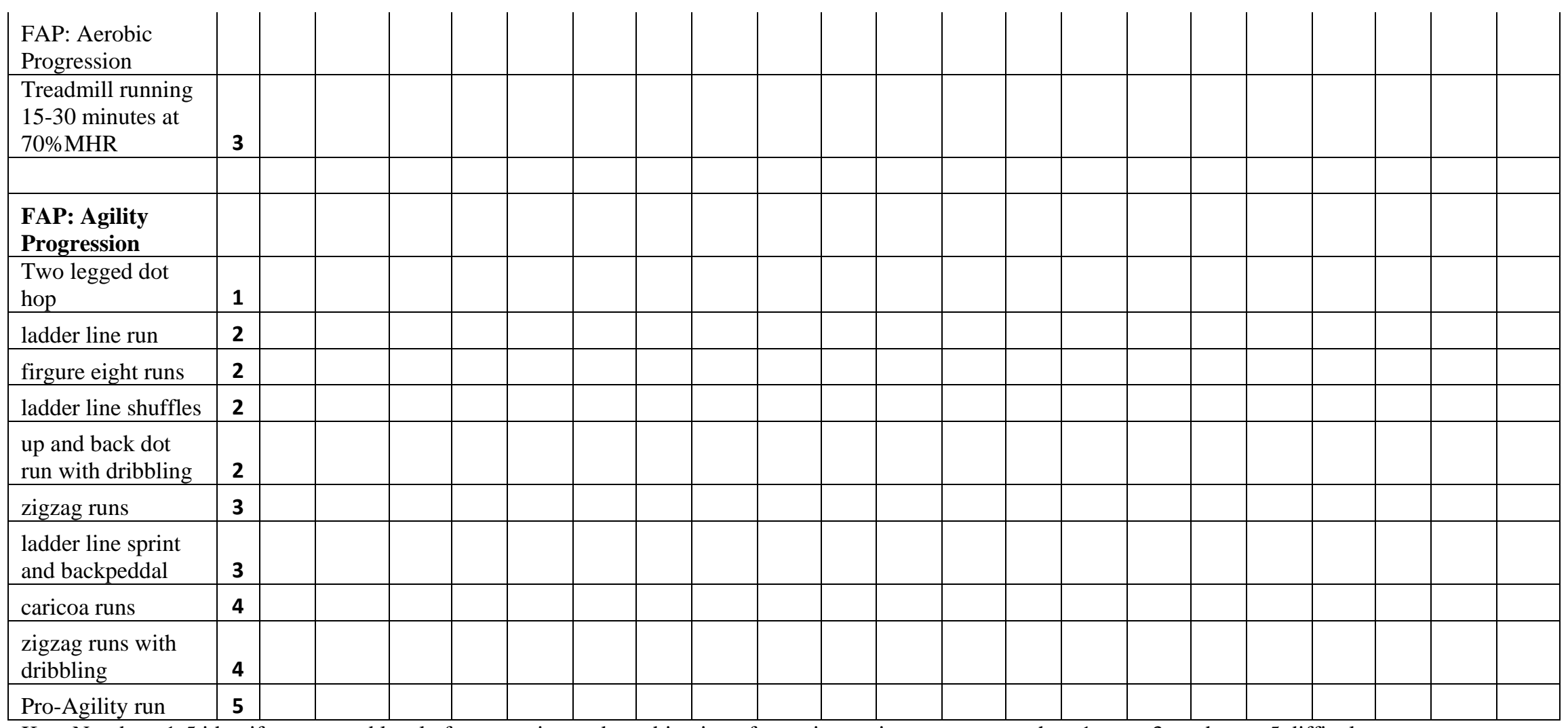

Pro-Agility run

Key: Numbers 1-5 identify suggested level of progression and combination of exercises to incorporate together. 1 easy, 3 moderate, 5 difficult. 


\section{APPENDIX E \\ RECOMMENDATIONS FOR FUTURE RESEARCH}

1. It would benefit the researcher to do all of the data collection during the end of the sport season. The number of participants might have been higher if the questionnaires were not sent during off season into the beginning of pre-season. During this time frame, most of the professional were on personal vacation and then traveling outside of the country with their respective teams. This would also avoid any turnover in staff which often occurs during the off-season.

2. It would benefit the researcher to either conduct the study during professional conferences/conventions or network with the experts to gauge interest. This study could have benefited if conducted or presented during the Soccer Industry Medical Symposium held in January.

3. It would benefit the researcher and participants to provide photographs and/or detailed descriptions of each exercise during both rounds of the questionnaire. This would avoid any confusion and misinterpretation of the exercises.

4. It would be beneficial to the outcome of the rehabilitation program to outline a specific joint or injury. It would also be beneficial to outline the exercise components in phases of the specified rehabilitation to further develop the final program.

It would be beneficial to perform such research as a Delphi study compared to using the modified Delphi technique. This would allow for the panel of experts to determine the original components of the questionnaire. 


\section{ADDITONAL REFERENCES}

50. Wong P, Hong Y. Soccer injury in the lower extremities. Br J Sports Med. 2005 Aug;39(8):473-82.

51. Richardson CA, Jull G, Toppenberg R, Comerford M. Techniques for Active Lumbar Stabilization for Spinal Protection. Austr J Physio. 1992;38:105-112.

52. Hodges PW, Richardson CA. Inefficient Muscular Stabilization of the Lumbar Spine Associated with Low Back Pain. Spine. 1996;21:2640-2650.

53. Aspden RM. Review of the Functional Anatomy of the Spinal Ligaments and the Lumbar Erector Spinae Muscles. Clin Anat.1992;5:372-387.

54. Moore KL, Dalley AF. $\left(5^{\text {th }}\right)$. (2006) Clinically Oriented Anatomy. Baltimore, MD: Lippincott Williams \& Wilkins.

55. Netter FH. $\left(2^{\text {nd }}\right)$. (1997). Atlas of Human Anatomy. Teterboro, NJ: ICON Learning Systems.

56. Magee DJ. $\left(4^{\text {th }}\right)$. (2006). Orthopedic Physical Assessment. St. Louis, MO: Elsevier Sciences.

57. Konin JG, Peterson CL. Strengthening the core from the inside out. Athl Ther Today. 2003;8:41-43.

58. Levanon J, Dapena J. Comparison of the Kinematics of the Full-Instep and Pass Kicks in Soccer. Med Sci Sports Exerc. 1998; 30(6):917-927.

59. Prentice WE. $\left(11^{\text {th }}\right)$ (2003) Arnheim's Principles of Atheltic Training: a competencybased approach. New York, NY: Mc-Graw Hill.

60. Levangie PK, Norkin CC. $\left(4^{\text {th }}\right)$ (2005) Joint Structure and Function: a comprehensive analysis. Philadelphia, PA: F.A. Davis Company

61. Beiser T, Llyod D, Ackland T, Cochrane J. Anticipatory Effects on Knee Joint Loading During Running and Cutting Maneuvers. Med Sci Sports Exerc. 2001; 33(7):1176-1181.

62. Beiser T, Llyod D, Ackland T. Muscle Activation Strategies at the Knee during Running and Cutting Maneuvers. Med Sci Sports Exerc. 2003; 35(1):119-127.

63. Besier T, Llyod D, Cochrane J, Ackland T. External Loading of the Knee Joint During Running and Cutting Maneuvers. Med Sci Sports Exerc. 2001; 33(7):1168. 
64. Kellis E, Katis A, Gissis I. Knee Biomechanics of the Support Leg in Soccer Kicks from Three Angles of Approach. Med Sci Sports Exerc. 2004; 36(6):1017-1028.

65. Kellis E, Katis A, Vrabas S. Effects of an Intermittent Exercise Fatigue Protocol on Biomechanics of Soccer Kick Performance. Scan J Med Sci Sports. 2006; 16:334-344.

66. Brophy BH, Backus SI, Pansy BS, Lyman S, Williams RJ. Lower Extremity Muscle Activation and Alignment During the Soccer Instep and Side-Foot Kicks. Orthop Sports Phys Ther. 2007;37(5):260-8.

67. Barfield W. The Biomechanics of Kicking in Soccer. Clinc Sports Med. 1998; 17(4):712728.

68. Nielsen AB, Yde J. Epidemiology and traumatology of injuries in soccer. Am J Sports Med. 1989;17:803-807.

69. Waldén M, Hägglund M, Ekstrand J. UEFA Champions League study: a prospective study of injuries in professional football during the 2001-2002 season. Br J Sports Med. 2005;39(8):542-6.

70. Woods C, Hawkins, R, Maltby S, Hulse M, Thomas A, Hodson A. The Football Association Medical Research Programme: an audit of injuries in professional footballanalysis of hamstring injuries. Br J Sports Med. 2004;38(1):36-41.

71. Hawkins RD, Fuller CW. An examination of the frequency and severity of injuries and incidents at three levels of professional football. Br J Sports Med. 1998;32(4):326-32.

72. Ekstrand J, Timpka T, Hägglund M. Risk of injury in elite football played on artificial turf versus natural grass: a prospective two-cohort study. $\mathrm{Br} J$ Sports Med. 2006;40(12):975-80.

73. Taylor DC, Dalton JD, Seaber AV, et al. Experimental muscle strain injury. Early functional and structural deficits and the increased risk for reinjury. Am J Sports Med. 1993;21:190-4.

74. Hawkins RD, Fuller CW. Risk Assessment in Professional Football: An Examination of Accidents and Incidents in the 1994 World Cup Finals. Br J Sports Med. 1999; 30:165170.

75. Davis S, Ashby P, McCale K, McQuain J, Wine J. The Effectiveness of 3 Stretching Techniques on Hamstring Flexibility Using Consistent Stretching Parameters. J Strength Cond Res. 2005; 19(1):27-32. 
76. Chan S, Hong Y, Robinson D. Flexibility and Passive Resistance of the Hamstrings of Young Adults Using Two Different Static Stretching Protocols. Scand J Med Sci Sports. 2001; 11:81-86.

77. Ferreria G, Teixiera-Salmela L. Gains in Flexibility Related to Measures of Muscular Performance: Impact of Flexibility on Muscular Performance. Clin J Sport Med. 2007; 17(4):277.

78. LaRoche D, Connolly D. Effects of Stretching on Passive Muscle Tension and Response to Eccentric Exercise. Am J Sports Med. 2006; 34:1000.

79. Fletcher I, Jones B. The Effect of Different Warm-Up Stretch Protocols on 20 Meter Sprint Performance in trained Rugby Union Players. J Strength Cond Res.2004; 18(4), 885-888.

80. Kokkonen J, Nelson A, Elderedge C, Winchester J. Chronic Static Stretching Improves Exercise Performance. Med Sci Sports Exerc. 2007; 39(10):1825-1831.

81. Nelson A, Kokkonen J, Arnall D. Acute Muscle Stretching Inhibits Muscle Strength Endurance Performance. J Strength Cond Res. 2005; 19(20):338-343.

82. Pope R, Herbert R, Kirwan J, Graham B. A Randomized Trial of Preexercise Stretching for Prevention of Lower-Limb Injury. Med Sci Sports Exerc. 2000; 32(2):271-277.

83. Cross K, Worrell T. Effects of a Static Stretching Program on the Incidence of Lower Extremity Musculotendinous Strains. J Ath Train. 1999; 34(1):11-14.

84. Gribble P, Hertel J, Denegar C, Buckley W. The Effects of Fatigue and Chronic Ankle Instability on Dynamic Postural Control. J Ath Train. 2004; 39(4):321-329.

85. Cressy E, West C, Tiberio D, Kraemer W, Maresh C. The Effects of Ten Weeks of Lower-Body Unstable Surface Training on Markers of Athletic Performance. J Strength Cond Res. 2007; 21(2):561-567.

86. Yaggie J, Campbell B. Effects of Balance Training on Selected Skills. J Strength Cond Res.2006; 20(2):422-428.

87. Leetun DT. Core Stability Measures as Risk Factors for Lower Extremity Injury in Athletes. Med Sci Sports Exerc. 2004;36:926-34.

88. F-Marc: The 11. http://www.fifa.com/aboutfifa/developing/medical/the11/index.html. 2008. 